\title{
AVALIACAOO DO DESEMPENHO DO TENSIOMETRO \\ DE BOLHA DE AR NA MEDIDA DO POTENCIAL MATRICIAL \\ DA ÁGUA NO SOLO
}

MARCOS SCHI AYON VILLA NOVA

Engenheiro-Agrónomo

Orientador: ANTONIO SANCHEZ DE OLIYEIRA

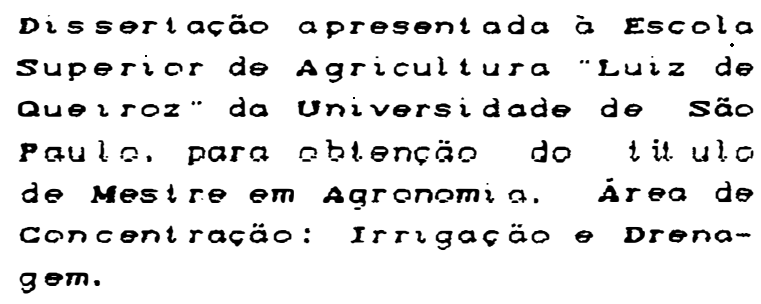

$P I R A C I C$ A B A

Estado de São Paulo - Brasil

Agosto - 1991 


\section{Ficha catalográfica preparada pela Seção de Livros da Divisão de Biblioteca e Documentação - PCAP/USP}

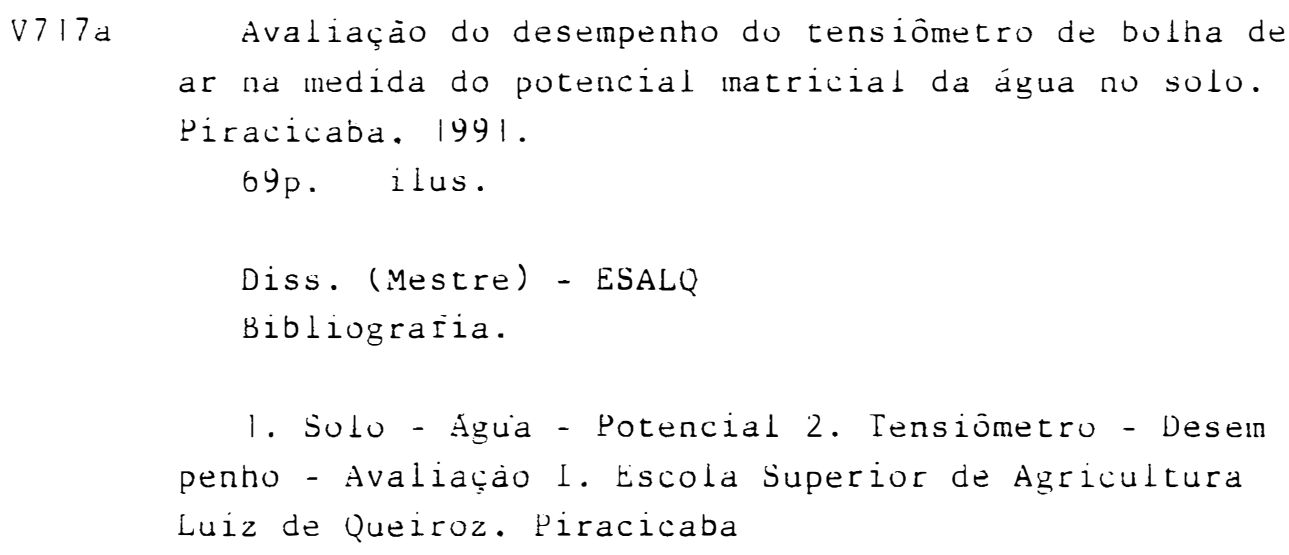




\section{AVALIACAOO DO DESEMPENHO DO TENSIOMETRO \\ DE BOLHA DE AR NA MEDIDA DO POTENCIAL MATRICIAL \\ DA ÁGUA NO SOLO}

MARCOS SCHI AVON VILLA NOVA

Aprovado em 19.11 .1991

Comissấo julgadora:

Prof: Dr: Artonio Sanches de Oliveira

ESALQ

Prof. Ir. Klaus Reichardt

Prof. [r. Angelo Paes de Camargo

I AC

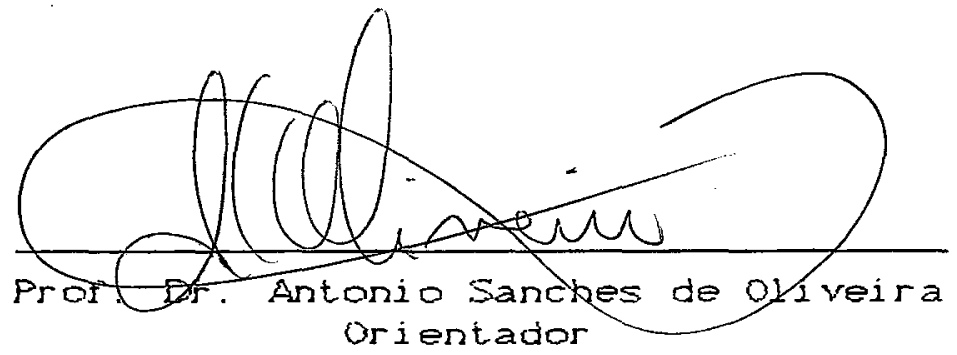


A ti, 0 Deus, confiança $=1$ ouvor

em Si ̃o.

Os que habitam nos confins da terra

temem os teus sinais;

os que vêm do Oriente e do Ocidente

tu os fazes exultar de júbilo.

Tu visitas a terra e a regas;

tu a enriqueces copiosamente;

os ribeiros de Deus săo abundantes de água:

preparas o cereal,

porque para isso a dispöes;

regando-Ihe os sulcos, aplanando-l he as leivas.

Tu a amoleces com chuviscos;

e I he abençoas a produção.

Coroas o ano da tua bondade,

as tuas pegadas destilam fartura;

destilam sobre as pastagens do deserto,

e de júbilo se revestem os outeiros.

Os campos cobrem-se de rebanho,

e os vales vestem-se de espigas;

exultam de alegria; e cantam. 
Aos meus queridos pais,

Nilson e Roselis,

$D E D I C D$

Ao Prof. Dr. Ângelo Paes de camargo ro primeiro pesquisador a estudar o tensiometro de bolha de ars,

$O F E R E G O$ 
A Deus pela permissão.

A USP, QNPq $=$ aos meus orientadores, Prof. Dr. Antonio Sanches de oliveira e Nilson A. Villa Nova, pela opor tuni dade.

Aos Professores Klaus Reichardt, Sergio O. Moraes, Tarley A. Botrel e Sergio Duarte, pelas enormes contribuicões e pela amizade.

Aos técnicos I van, Gilmar e Robinson Iuon, por * suas inestimáveis ajudas. 


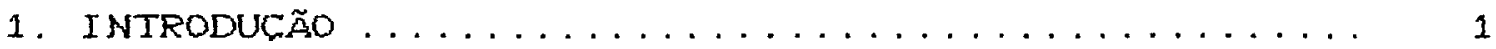

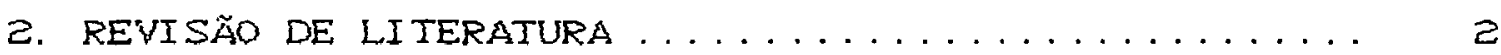

2.1. Conceitos Teóricos ................. z

2. 2. Tensiómetria .................. 8

3. MATERIAL E MÉTODOS .................... 14

3.1. Área Experimental ................ 14

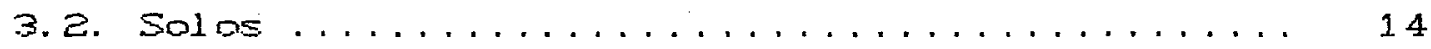

3.2.1. Solo Argiloso ................. 14

3. 2. 2. Salo Arenoso .................... 14

3. 3. Montagem ...................... 16

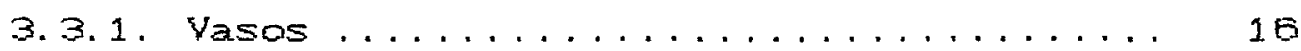

3. 3. 2. Tensibmetros .................. 1 B

3. 3.2.1. Căpsulas ............. 16

3. 3.2.2. Tensi ômetros convencionais ... 18

3. 3.2. 3. Tensiômetros de holha de ar.. 18

3. 3.2. 4. Montagem .............. 20

3. 4. Avaliação dos Potenciais da Água no Solo .... 21

3. 4.1. Tensiómetro convencional .......... 21

3. 4.2. Tensiómetro de bolha de ar ........ 22

3.5. Avaliaçäo da Umidade do Solo ............ 25 
Página

3. 6. Condurão do Experimento .............. 26

3. 6. 1. Ajuste iniciais ............. 26

3.6. 2. Inicio das leituras ........... 27

3. 6. 3. Análises estatisticas .......... 27

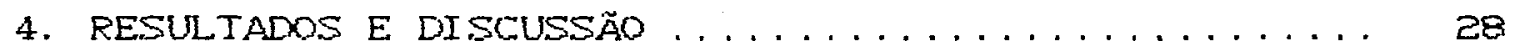

4.1. Dimensionamento e Curvas de Resposta dos Tensiômetro de Bolha de Ar ............ 28

4.2. Dados obtidos de $\psi \times \Leftrightarrow \ldots \ldots \ldots \ldots \ldots$

4.2.1. Solo Argiloso ................ 31

4. 2. 2. Solo Arenoso ................... 31

4. 3. Reláões de Dependéncia Entre $\psi \times \theta$ CSolo Ar-

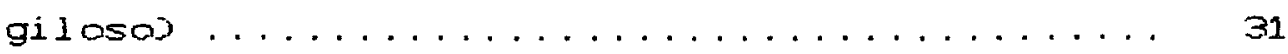

4. 3.1. Leituras das $9: 00 \ldots \ldots 30$

4.3.2. Leituras das 16:00 ........... 36

4. 4. Comparacöes $\psi_{\text {TaA }} \times \psi_{\text {Tr }}$ CSolo Argiloso $\ldots . . .37$

4.5. Erro Estimado do Tensiómetro de Bolha de Ar Devido a Diferencas de Temperatura ......... 43

4. 6. Relacóes de Dependência Entre $\psi$ e e csolo are-

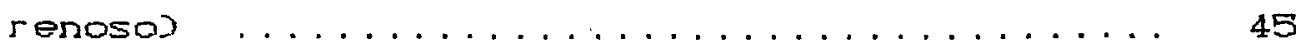

4. 6.1. Leituras das $9: 00 \ldots \ldots \ldots 47$

4. 6. 2. Leituras das $16: 00 \ldots \ldots \ldots \ldots \ldots$

4.7. Comparacốes $\psi_{\mathbf{T B A}} \times \psi_{\mathbf{T C}}$ CSOlo Arenoso) ...... 50

4.8. Tempo de Resposta ................... 50

4.9. Generalidades ................... 56 
vii.

Păgina

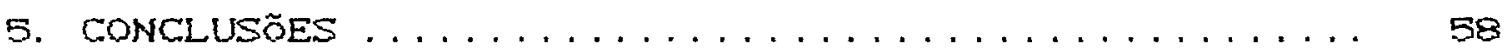

6. REFERENCI AS BI BLIOGRAFICAS .............. GO

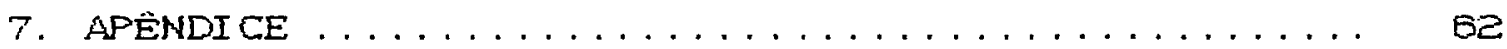




\title{
AVALIACÃO DO DESEMPENHO DO TENSIÓMETRO \\ DE BOLHA DE AR NA MEDIDA DO POTENCIAL MATRICIAL \\ DA ÁGUA NO SOLO
}

\author{
Autor: MARCOS SCHIAYON VILLA NOVA \\ Orientador: ANTONIO SANCHEZ DE OLIVEIRA
}

RESUMO

\begin{abstract}
o tensiômetro de leitura direta (TBA) foi desenvolvido para substituir o tensiómetro convencional (TC) em medidas de potencial da água no solo. Para testar a performance do instrumento um experimento fai conduzido em condi côes de laboratório. Seis vasos foram preenchidos com cerca de $15 \mathrm{~kg}$ de solo arenoso e seis com cerca de $13 \mathrm{~kg}$ sola argiloso Csolo seco ao ar). No centro dos vasos foram instalados seis tensiómetros de leitura direta e seis tensiómetros convencionais. Os vasos com tensiômetros foram saturados, cobertos com plástico e conduzidos a drenar por vários dias, após os quais, o plástico foi retirado iniciando-se um ciclo de secagem do solo. Cada vaso foi pesado diariamente para determinar-se a umidade do solo (o). Os tensiometros foram lidos duas vezes ao dia las 9:00 hs e 16:00 hsj. Em funcão disto foi possível estabelecer-se rela-
\end{abstract}


cöes de dependéncia entre $\psi$ e $\theta$ para os dois tensiómetros, para cada tipo de solo. Estudou-se também o efeito da pressão atmosférica e temperatura, na resposta dada pelo TBA. Verificou-se que o TBA tem um tempo de resposta mais baixo do que o TC sendo que os resul tados obtidos indicaram que o TBA pode substituir o IC sem perda de precisão. As seguintes regressóes lineares entre IBA e TC foram determinadas:

\section{Solo Argilaso}

Leituras das 9:00 AM

$$
\begin{gathered}
\psi_{\text {TBA }}=-24,35+1,20 \psi_{\mathrm{TC}} \\
r^{2}=0,990 .
\end{gathered}
$$

Leituras das 16:00 PM

$$
\begin{gathered}
\psi_{\text {TBA }}=20,46+1,11 \psi_{\mathbf{T C}} \\
r^{2}=0,999
\end{gathered}
$$

\section{Solo Arenoso}

Leituras das 9:00 AM

$$
\begin{gathered}
\psi_{(\mathbf{T B A})}=-9,82+0,87 \psi_{\mathrm{TC}} \\
r^{2}=0,999
\end{gathered}
$$

Leituras das 16:00 PM

$$
\begin{gathered}
\psi_{(\mathbf{T B A})}=8,95+0,88 \psi_{T C} \\
r^{2}=0,999
\end{gathered}
$$




\title{
EVALUATION OF THE SIMPLIFIED DIRECT READING \\ "AIR POCKET" TENSIOMETER \\ FOR MATRIC WATER POTENCIAL MEASUREMENTS
}

\author{
Author: MARCOS SCHI AVON VILLA NOVA \\ Adviser: ANTONIO SANCHEZ DE OLIVEIRA
}

\section{SUMMARY}

The direct reading "air pocket" tensiometer CAPT was developed to substitute the conventional tensiometer (CT) in field measurements of soil water status cmatric water potential $\psi_{m}$. In order to test the performance of such instrument an experiment was conducted under laboratory conditions, where $\theta$ containers were filled with about $22 \mathrm{~kg}$ of a dry sandy soil and other six with abont $13 \mathrm{~kg}$ of a dry clayey soil. Each container received either a CT or a APT in the center of the soil volume. The containers were then saturated, covered with plastic and left to drain the excess water for several days. Plastic covers were removed to begin a drying cycle, being each container weighted daily in order to estimate its soil water content $(\theta)$. The tensiometers were read twice a day cat 9 a.m. and at 4:0 p.m. J. Therefore, it was possible to 
$x i$

establish the relationship $\psi$ versus $\theta$ for both, the GI and the APT for each soil type. It was possible to determine the effect of both, air pressure and temperature, upon the results given by the APT. The APT had a lower time response than the CI. Therefore, the results obtained here indicate that the DRT can replace the CI without precision loss. Ihe following linear regressions between $\psi_{\text {apt }}$ and $\psi_{\text {GT }}$ were found:

\section{Clay Soil}

$9: 00$ A. M. Readings

$$
\begin{gathered}
\psi_{\text {APT: }}=-24,35+1,20 \psi_{\text {LT }} \\
r^{2}=0,550
\end{gathered}
$$

4:00 P.M. Readings

$$
\begin{gathered}
\psi_{\text {(APT) }}=20,40+1,11 \psi_{\text {CT }} \\
r^{2}=0,999
\end{gathered}
$$

\section{Sandy Soil}

9:00 A. M. Readings

$$
\begin{gathered}
\psi_{\text {(APT) }}=-9,82+0,87 \psi_{\mathrm{CT}} \\
r^{2}=0,999
\end{gathered}
$$

4:00 P.M. Readings

$$
\begin{gathered}
\psi_{\text {APT })}=8,95+0,88 \psi_{\text {CT }} \\
r^{2}=0,999
\end{gathered}
$$




\section{I NTRODUC̆ÃO}

Com a possibilidade da irrigacão, podemos obter um aumento da produtividade não só pelas condicỗes de um melhor manejo hídrico das culturas, como pela diminuicão do processo degradativo do solo, pois a irrigacão possibilitaria rotacóes com culturas anuais de interesse económico, cujas li mi tacóes poderiam ser suas necessidades hídricas.

Um manejo correto da irrigação para obtenção de uma produtividade viável economicamente, seria aquele em que aplica-se água no solo no momento oportuno e em quantidade suficiente para suprir às necessidades hidricas das culturas, sem falta ou desperdicio de água e energia. Para que isto ocorra, há necessidade do uso de métodos de campo que determinem direta ou indiretamente a disponibilidade de água no solo para uma determinada cultura.

Entre os instrumentos disponiveis para avaliacão da umi dade do salo a baixas tensões Caproximadamente 0,8 at. o tensiómetro convencional de mercúrio, situa-se praticamente en primeiro plano, sendo largamente utilizado para monitoramento de irrigacăo, determinacóes de condutividade hidráulica do solo e outras finalidades. O tensiómetro convencional é um instrumento de fácil construro desde que 
2.

se utilize material adequado, mas não prescinde da utilizacão de mercúrio que além de ser caro, necessita de cuidados no seu manuseio (limpeza e lavagem periódica) sob pena de sofrer o fracionamento da coluna, que ocasiona erros de leitura bastante inconvenientes.

CAMARCO et ali (1982) procurando uma solucão mais simples idealizou o tensiómetro de leitura direta, calibrando-o com comparacốes de leituras simultaneas com tensiámetros aneróides, todavia sem realizar um estudo físico detal hado do seu comportamento.

VILLA NOVA et ali $i$ (1989) estudando as condicões de equilibrio do tensiômetro de leitura direta propáa uma equação de calibracão e em função disto uma geometria de construcão padrão, sem contudo testar as formulacões propostas.

No presente trabalho readaptando as equacóes a geometria proposta por VILLA NOVA et ali $i$ (1989), conduziram-se calibrações do método contra medidas simultâneas do tensiómetro convencional, sob condicốes de laboratório, en dois tipos de salo (argiloso $\theta$ arenoso), propondo-se um modêlo de construcão mais rústica. Simultaneamente uma análise de prováveis erros de determinacão do potencial foi realizada, para melhor adequar a sua utilização.

Os resultados obtidos para os dois tipos de solo ensaiados demonstraram ser viável a utilizacão do tensiômetro de leitura direta. 


\section{REYISÃO DE LITERATURA}

\subsection{Conceitos Teóricos}

Tanto a água como gualquer partícula na natureza tem como característica um estado de energia. A física clássica reconhece como formas principais de energia a cinética e potencial. Como o movimento de água no sistema solo-pianta-atmosfera é muito lento, a energia cinética é desprezível. A energia potencial por ser uma funcão da posicão física em relacão ao ponto de referencia, e da condição interna da água em um ponto considerado, é importante para caracterizar seu estado de energia total.

A tendência espontânea de toda matéria na

natureza é assumir um estado de energia minima, procurando equilibrio com o meio ambiente.

A ăgua é a mesma em qualquer posicão e tempo dentro do solo. Ela não difere na forma, mas sim em seu estado de energia, pois no solo, está sujeita a uma variedade de forcas, cada uma relacionada com o seu potencial parcial, as quais, causam a variacão do potencial total daquela da água, livre e pura. As forcas que resultam da atracăo da água pela matriz do solo causam a existência de um potencial ma- 
4.

tricial (um). A presenca de sais dissolvidos resulta em um estado de energia chamado de potencial osmótico (wos). A ação da pressão local na fase gasosa do solo, ou o fato do solo estar sujeito a uma carga hidráulica ou a uma tensão, resulta em um estado de energia causador do potencial de pressão cypl. Finalmente, a acão do campo gravitacional terrestre indica que todo corpo nele presente tem um potencial gravitacional $(\psi g)$. O potencial total da água no solo ( $\psi$ t) pode ser considerado como a somatória das contribuicóes destes componentes, mas a adicăo de outros componentes é em muitos casos necessário.

A componente matricial ( $\psi \mathrm{m})$ da água no sistema solo-planta, ao contrário do potencial gravitacional e de pressão, não pode ser calculada deterministicamente, devido à complexi dade e heterogeneidade dos fatores envol vidos, mas pode ser medida experimentalmente por meio de tensiometros ou instrumentos de succão ou pressão. Esta componente é resultado de forcas capilares Cadvém da tensão superficial da água e do ângulo de contato com as particulas sólidas e da adsor cão Cobservada em formas de capa de hidratacão sobre a superficie das partículas’. A adsorcão é mais importante em solos argilosos, porque também sofre influência da dupla camada elétrica e dos cătions trocáveis presentes e capilaridade tem maior importância em solos arenosos, devido a poros e partículas relativamente grandes. Para um solo mais úmido as forcas capilares são mais importantes e a medida que a umidade decresce as forcas adsortivas vão tomando seu 1 ugar. 
Numa amostra homogênea de terra, cada valor do potencial mátrico corresponde a uma certa umidade volumétrica $(\theta)$. A representacão gráfica do potencial mátrico $[y m$ em funcão da umidade volumétrica $(\theta)$ é uma característica da amostra de terra e é chamada de "curva caracteristica da umi dade" ou "curva de retencão". Esta curva passa a depender do arranjo, do tamanho e da forma das partículas do solo que por sua vez, determinam as dimensões dos poros. Em situacões de altos teores de água, onde os fenömenos capilares são de maior importância, o potencial mátrico ( $\psi \mathrm{m}$ ) passa a ser basicamente uma funcăo da distribuicão da porosidade do solo e da densidade global. Na Figura 2.1 podemos observar as curvas características da umidade do solo para solos tipicamente argiloso e arenoso e também um solo qualquer em estrutura natural e compactado.
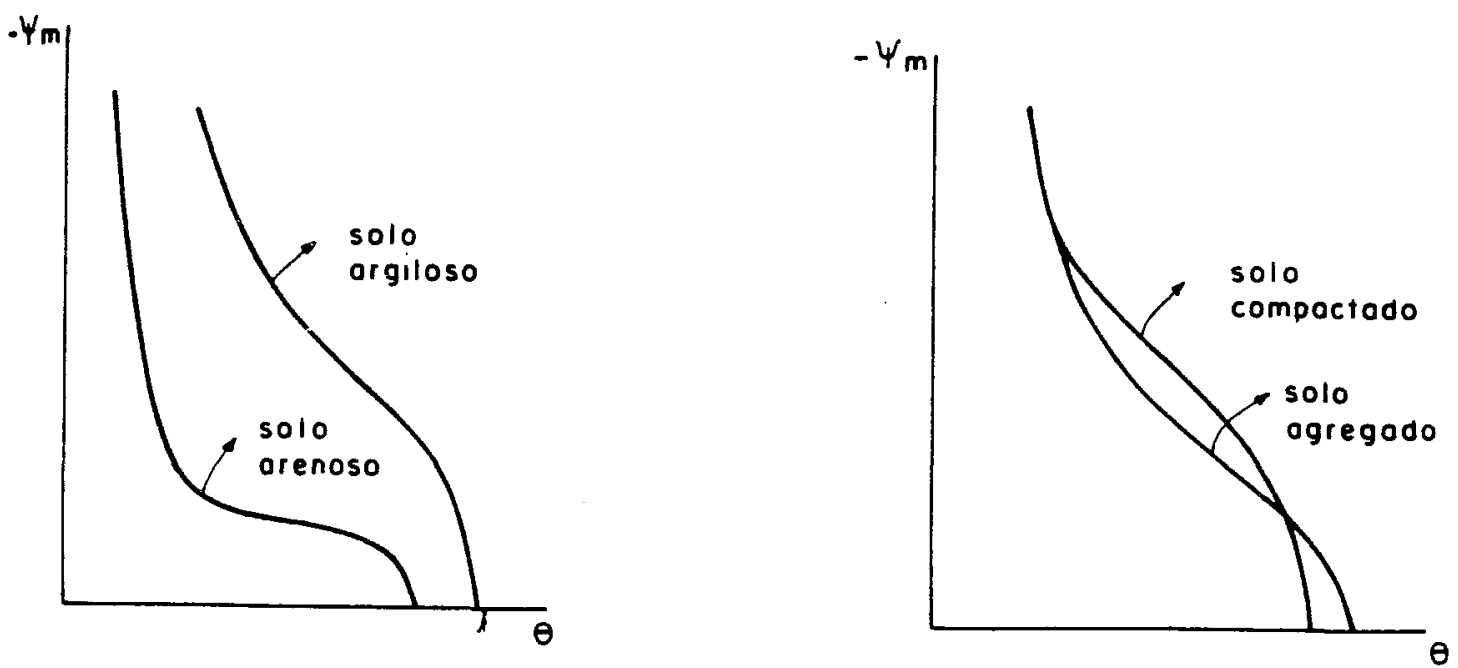

Figura 2.1 - Curvas características da umidade do solo CREICHARDT, 1985 . 
A umi dade de saturacão ces Figura 2.1 é igual à sua porosidade total e maior no solo argiloso em relacão ao solo arenoso. Ao compactarmos um solo es diminue, pois a compactacão di minue sua porosidade. Na situacão de potencial mátrico nulo $6 \psi m=0$ o solo está saturado e en equilibrio com a água pura à mesma elevacăo.

Com a obtencão do valor de umidade em volume (e) de um solo e fazendo uso de sua curva caracteristica podemos estimar o potencial mátrico e vice-versa. Se mantivermos a geometria da amostra do solo, durante o tempo, a curva caracteristica é considerada única para o procedimento experimental na qual foi gerada, pois ainda não existe uma teoria satisfatória para sua obtencão que pode ser por "secamento" ou "mol hamento". No secamento cmétodo usado neste trabalho toma-se uma amostra de terra inicialmente saturada de água e aplica-se à mesma tensões cada vez maiores, fazendo medidas sucessivas de umidade $(e)$ em funcão da tensão ( $\psi \mathrm{m})$. No molhamento toma-se uma amostra inicialmente seca ao ar e permitimos seu gradual molhamento por reducão da tensão. Os dois métodos originam curvas contínuas que são diferentes para uma mesma amostra. Esta diferenca chamamos de histerese CFigura 2.2). 


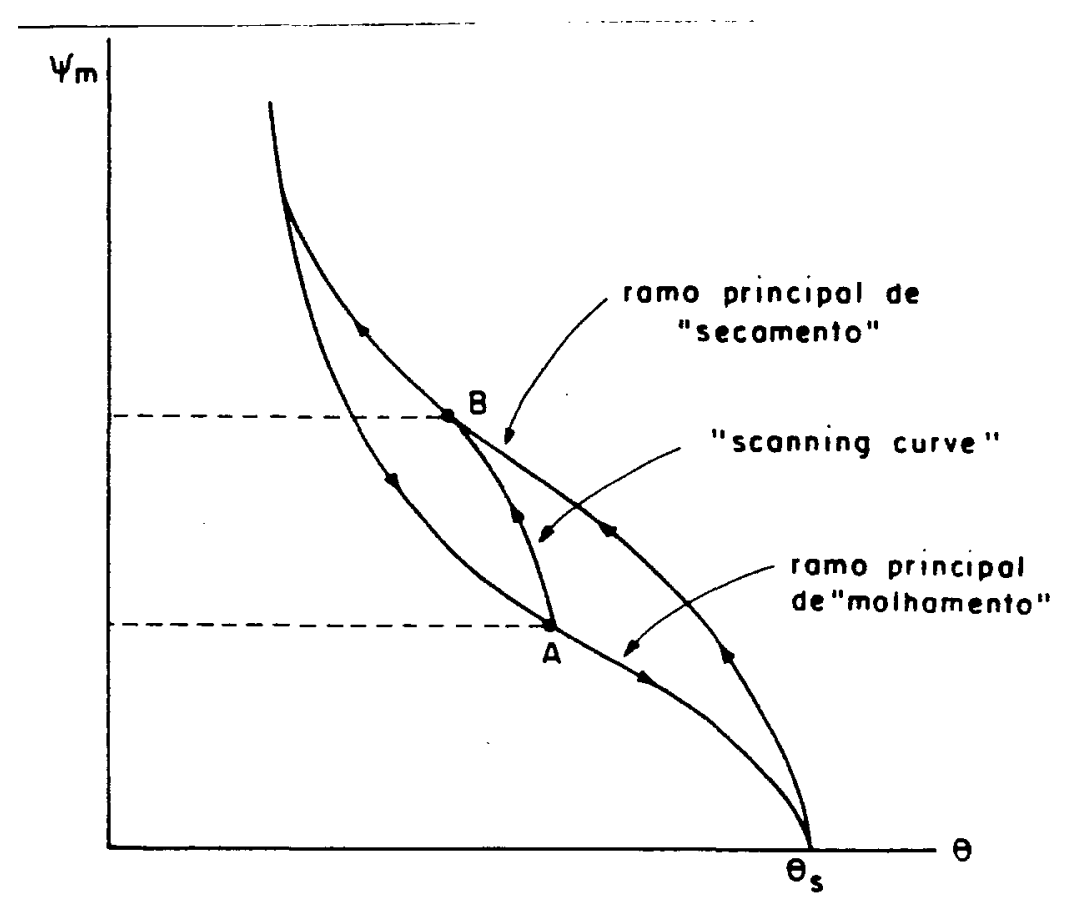

Figura 2.2 - Curvas de retencão (histerese) (REICHARDT, 1985$).$

Na Figura Z. 2 podemos observar que a umidade de equilíbrio a uma dada tensão é maior na drenagem (secamento) do que na infiltração (molhamentos e ainda, se a determinacão da curva característica for gerada de um regime di nâmico os resultados seriam diferentes de um processo desenval vido em equilíbrio. Para aceitarmos a curva de potencial mátrico em função da umidade volumétrica $(\psi(\theta))$ como única devemos considerar separadamente a drenagem csecamentos e a infiltracão (molhamento) e rão ambos em conjunto, tomando para cada caso a curva correspondente. 
A curva de retencão é de fundamental importância para a física de solos porque expressa a influência da estrutura, porosidade, textura e drenagem. A sua variacão em um perfil determina a direcão e a influência da taxa de movimento de água no solo e a retirada de água pelas raizes.

\section{2. Tensiômetria}

Desde 1922 os tensiômetros foram utilizados para estimar a tensão da água em solos não saturados CGARDNER et alii, 1922). Segundo citado por RICHARDS \& GARDNER em 1936, o tensiómetro era a combinacão de uma membrana porosa e um medidor de pressão, para medida da tensão capilar ou a energia que a água está retida no solo e o termo energia era expresso como pF, definido como logaritmo da altura da coluna de água (em centimetros equi valente a tensäo da água no solo ou de um potencial cenergia por unidade de massa em volumes. Por facilidade de medida e cálculo, a unidade de energia por unidade de peso é a de maior emprego en cálculos de balanco hídrico, irrigacão, etc, pois representa uma coluna de água CLIBARDI, 1984; ROSE; $1986 ;$ RICHARDT, 1975$).$

O tensiómetro convensional consiste numa cápsula porosa conectada a um manômetro atrayés de um tubo que possui em seu interior uma coluna continua de água unindo a cápsula de cerâmica ao dispositivo de medida que pode ser simples tubo em "u" de água e mercúrio (Figura 2.3 ). 
9.

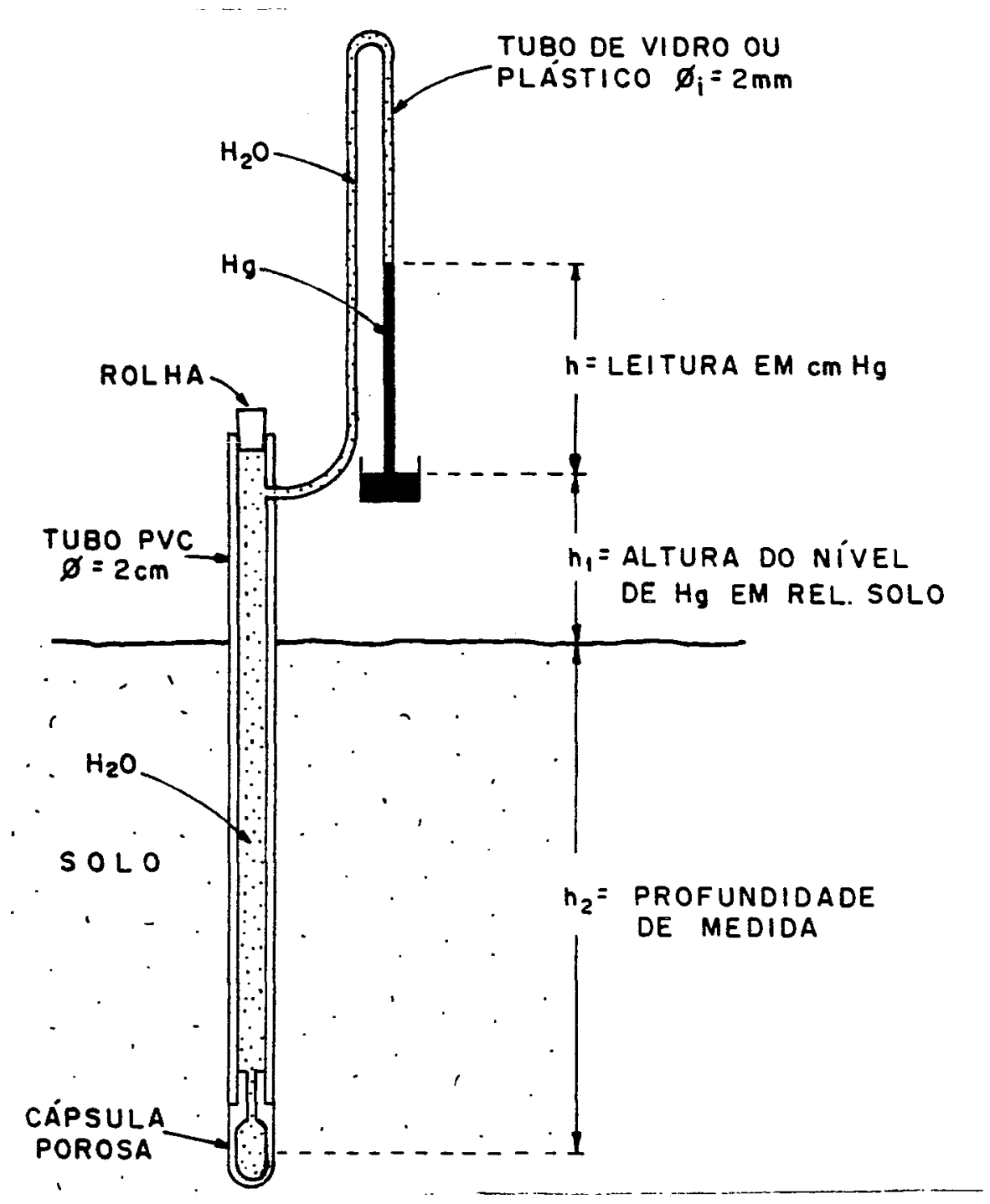

Figura 2. 3 - Tensiómetro convencional com manômetro de mercúrio (REI CHARDT, 1985 ). 
Quando a cápsula entra em contato com o solo, a água do tensiômetro cque é herméticamente fechado entra em contato com a água do solo e o equilibrio tende a estabelecer-se. Antes de colocar-mos o instrumento em contato com - solo, sua água está a pressão atmosférica, o potencial matrico é nulo $(\psi m=0)$. A água do solo, estando sob tensão, exerce uma succão sobre o instrumento e dele retira certa quantidade de água causando a queda de sua pressão interna. Como o instrumento é vedado, a coluna de mercúrio h do manômetro cresce, indicando a tensão interna da água. Estabelecido o equilibrio, o potencial da água dentro do tensiometro é igual ao potencial da água do solo e assim h é uma medida direta do potencial mátrico $c \psi m$ (REICHARDT, 19753.

A cápsula do tensiómetro geralmente é de cerâmica, mas pode ser constituída de materiais como por exemplo filtros plásticos e fibra de vidro, desde que resista a pressão submetida e permita que água e solutos passem livremente, mas impedindo a passagem de particulas de solo e ar. Ela funcionará como uma membrana permeável, permitindo que a água dentro do tensiómetro fique com a mesma composicão e concentracão da água do soloe, isso implica que o tensiómetro não mede potencial osmótico, a menos que seja equipado com algum sensor especial para sais (OLITIA, 1974 ).

o intervalo de acão do tensiómetro para estimativa do potencial mátrico é limitado, porque a uma tensão de aproximadamente 0,8 atm, ocorrerá uma ruptura da coluna 
de água ou a entrada de ar no sistema, igual ando a pressão interna a atmosférica (HILLEL, 1971). Para solos arenosos o intervalo de ação do tensiómetro pode cobrir até $90 \%$ da água disponível o que não ocorre em solos argilosos e por exemplo um solo com $42 \%$ de montmorilonita, a tensão pode variar de 200 a $800 \mathrm{~cm}$ de água para apenas $1 \%$ de variacão de umidade CABELE et alii, 19790.

- tensiómetro presta-se principalmente para contrale de irrigacão intensiva sendo colocado em uma ou mais profundidades dentro das raizes CRICHARDS et alii, 19513 .

Para efeito de pesquisa KLUTE \& GARDNER (1961) dividiram o estudo do tempo de resposta do tensiómetro em duas consideracóes distintas onde, em um delas, consideraram apenas as caracteristicas do instrumento control ando o tempo de resposta e a condutividade hidráulica como limitaste. Para este estudo definiram trés fatores que podem atuar no tempo de resposta. O primeiro deles foi a condutância hidráulica (k) da cápsula, que é definida como o volume de líquido que atravessa a membrana porosa na umidade de tempo - pela diferenca de tensão entre o interior o exterior da cápsula,

$$
\begin{aligned}
& \quad K=\frac{\Delta V}{\Delta t . \Delta h}=5 m^{2} / s e g \\
& 0 \text { segundo fator, já tinha sido definido por }
\end{aligned}
$$
RICHARDS \& NEAL em 1937 como sensibilidade do dispositivo de medida CSD. Diz respeito a variação de pressão registrada no 
dispositivo de medida pelo volume de água transferido para o solo ou vice-versa.

$$
S=\frac{\Delta h}{\Delta V}\left(\mathrm{~cm}^{-2}\right)
$$

Quando o tensiómetro perde água, passa a ter queda na sua pressão hidrostática que é registrada pelo dispositivo de medida e, quanto menor for a perda de água para registrar uma mesma diferença de pressão, menor o tempo de resposta e mais sensivel será o dispositivo de medida.

o terceiro fator estudado que atua so tempo de resposta, é a condutividade hidráulica do solo porque, quando o tensiômetro está instalado e funcionando, modifica o sistema água-solo uma vez que libera água para o solo. 0 tempo de resposta será tâo curto quanto o tempo que o solo gastaria para armazenar e redistribuir a água liberada e por isso quanto maior a condutividade hidráulica de um solo menor será o tempo de resposta.

TOHER (1980) estabeleceu um critério adequado para analisar o caso geral em que tanto o tensiómetro como o solo controlam o tempo de resposta.

Os tensiómetros possuem inúmeras vantagens no seu uso para estimativa do potencial mátrico do solo CSCHMUGGE et alii, 1980), mas se seu uso não é tão intenso é porque são facilmente danificáveis, às vezes caros e requerem uma masutencăo cuidadosa. Os tensiômetros equipados com tensiômetro de mercúrio não são caros, são sensíveis, mas requerem cuidado no manuseio do mercúrio, além de manutencão 
constante a nivel de campo. Com o objetivo de minimizar os custos e eliminar o uso de mercúrio. PAES DE CAMARGO et ali (1982) desenval veu e testou um tensiômetro em um tubo transparente Cchamando-o de tensibimetro simples de leitura direta), baseado na expansăo de uma câmara de ar, deixada propositalmente dentro do tensiometro e cuja variacão foi correlacionada com a tensăo matricial no solo estimada por um tensiómetro aneróide adjacente. VILLA NOVA et alii (1989) propuseram un modelo matemático teórico para este mesmo tensiômet.ro Cchamando-o de tensiômetro de bolha de ars, onde estudaram as variáveis climáticas que interagem sobre o mesmo. Neste trabalho, além de verificarmos o emprego deste modelo matemático, estaremos mudando a geometria da construcão a fim de obter uma melhor performance de seu desempenho. 
14.

\section{MATERI AL E MÉTODOS}

\section{1. Área Experimental}

O presente trabal ho foi conduzido no laboratório de solos do Departamento de Engenharia Rural da Escola Superior de Agricultura "Luiz de Queiroz" USP, Piracicaba SP, Clatitude $22^{\circ} 43^{\circ} S 47^{\circ} 38^{\circ}$ Langitude $\%$ e Altitude de $540 \mathrm{~m}$.

\subsection{Solos}

Foram utilizados dois solos extremos em termos de capacidade de contencão de água, sendo um muito argiloso - outro arenoso, caracterizados a seguir:

3.2.1. Solo argiloso - classificado como Latossolo Vermel ho Escuro (UDOX)

3.2. 2. Solo arenoso - classificado como Areia QuartzOSa (TROPEPT)

As amostras de solo foram conduzidas ao laboratório, e após 1 iberadas de corpos estrashos, foram homoge- 
nizadas e postas a secar ao ar livre para posterior utilizaธão. Uma fracão das amostras foi enviada para o Departamento de solos da Escola Superior de Agricultura "luiz de Queiroz" USP onde foram realizadas as análises mecänicas e quimicas que são demonstradas nos Quadros 3.1 ?. 2.

Quadro 3.1 - Análise mecânica $(\mathrm{mm})(\%$, Pipeta, dos solos utilizados CDepartamento de Solos ESALQMUPP.

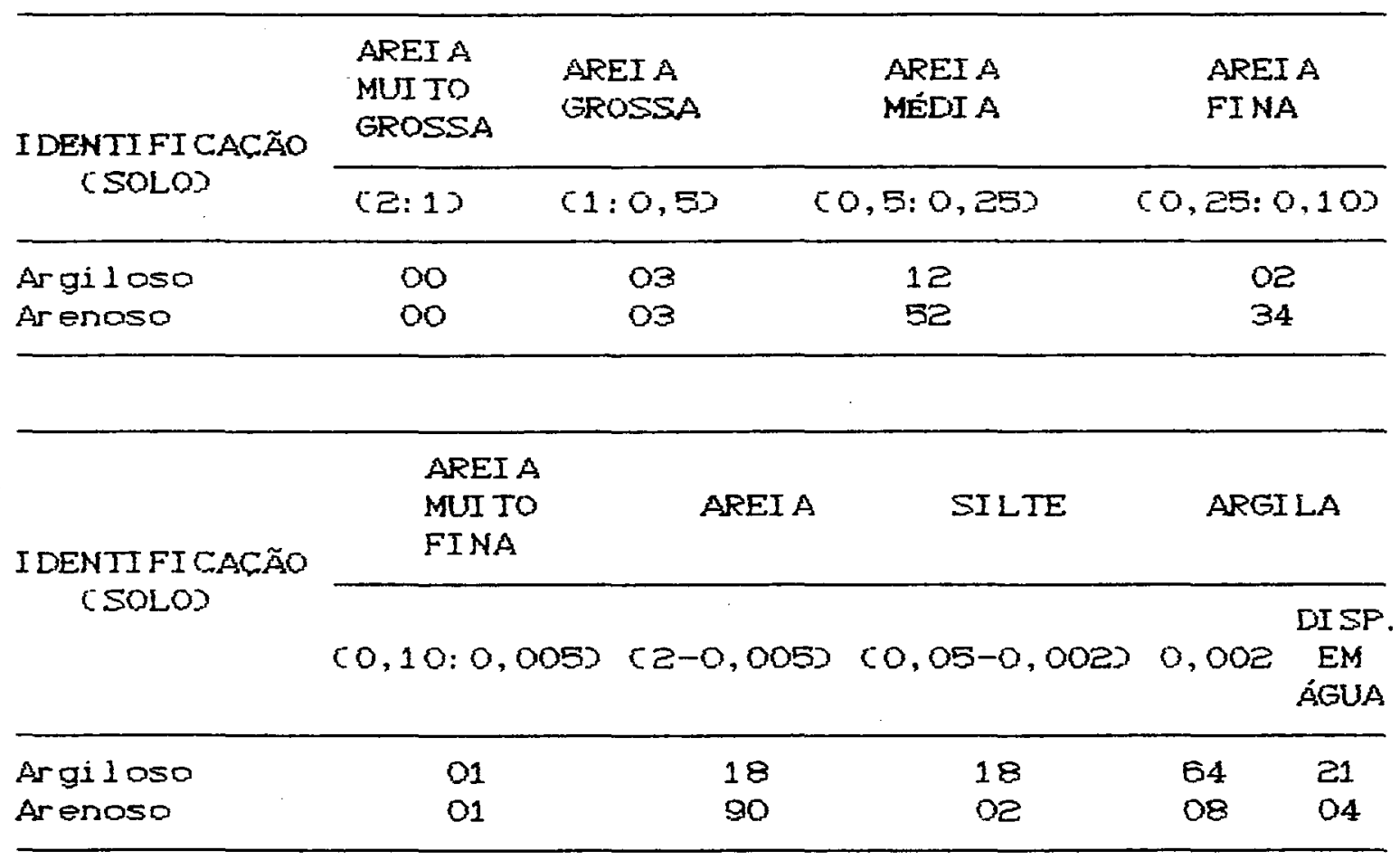

Quadro 3.2 - Análise química dos solos utilizados CDepartamento de Solos ESALQ USPP.

\begin{tabular}{|c|c|c|c|c|c|c|c|c|c|c|c|}
\hline \multirow{2}{*}{$\begin{array}{c}\text { IDENTIF. } \\
\text { (SOLO) }\end{array}$} & \multirow{2}{*}{$\mathrm{CaCl}_{2}$} & \multirow{2}{*}{$\begin{array}{r}\text { MO } \\
\%\end{array}$} & \multirow{2}{*}{\multicolumn{2}{|c|}{$\frac{P^{*} S-S O}{m g / c m^{3}}$}} & \multirow{2}{*}{4} & \multirow[t]{2}{*}{$\mathrm{Ca}$} & $\mathrm{Mg} \mathrm{Al}$ & $H+A I$ & $S B$ & \multirow[t]{2}{*}{$T$} & \multirow[t]{2}{*}{$V \mathrm{Al}$} \\
\hline & & & & & & & meq & $100=$ & $m^{3}$ & & \\
\hline Argil oso & 5,7 & 2,2 & 6 & - & 0,12 & 6,17 & 1,46 & $-2,5$ & 7,75 & 10,25 & 76 \\
\hline Arenoso & 4,1 & 1,0 & 3 & - & 0,14 & 0,10 & 0,08 & $-2,2$ & 0,22 & 2,42 & 9 \\
\hline
\end{tabular}


10.

\section{3. Montagem}

\subsubsection{Vasos}

Para acondicionamento dos solos foram utilizados vasos de plástico de forma tronco cônica $C \phi$ superior de $28 \mathrm{~cm} e \phi$ inferior de $20 \times 30 \mathrm{~cm}$ de altural, volume de 13 litros. A drenagen foi feita por 5 furos $6 \phi 1 \mathrm{~cm}$ no fundo do vaso. Para impedir-se a perda de solo foi colado um pedaco de bidin no fundo do vaso e para facilitar a drenagem foi colncado $5 \mathrm{~cm}$ de pedrisco pequeno em cima do bidin. Em seguida, o solo seco ao ar com massa seca conbecida foi colocado sobre o pedrisco em arrimo natural.

\section{3.2. Tensiômetros}

\subsubsection{Cápsulas}

Na determinação da condutância hidráulica foram testadas por volta de 100 cápsulas de fabricacão nacional. A metodologia utilizada foi a de carga decrescente que consiste na determinacão do tempo que uma coluna de água, que atua em carga sobre a cápsula, leva para cair alturas previamente determinadas em um tuho transparente.

A fórmula utilizada para seu cálculo foi a seguinte: 


$$
K=\frac{a \operatorname{tn}\left(\mathrm{H}_{1} / \mathrm{H}_{2}\right)}{t_{2}-t_{1}}
$$

ande:

$$
\begin{aligned}
& K=\text { conduti vidade hidráulica }\left(\mathrm{cm}^{2} / s\right) ; \\
& a=\text { seccão do tubo transparente; } \\
& H_{1} \text { - } H_{2}=\text { potenciais hidráulicos nos tempos } t_{1} \text { e } t_{2}(\mathrm{~cm} ; \\
& t_{2}-t_{1}=\text { intervalo de tempo que o nivel de água leva pa- } \\
& \text { ra variar de } \mathrm{H}_{1} \text { para } H_{2} .
\end{aligned}
$$

No Quadro 3.3 são relatados os resultados da determinação da condutividade hidráulica do conjunto de cápsulas utilizadas no experimento. o teste foi realizado com a finalidade de verificar algum defeito de fabricarão e condicóes de homogenei dade para a experimentacáo.

Quadro 3.3 - Condutividade hidráulica $\left(\mathrm{cm}^{2} / s\right)$ das cápsulas tensiomét.ricas.

\begin{tabular}{ccc}
\hline $\begin{array}{c}\text { NÚMERO DE CONTROLE } \\
\text { DA CÁPSULA }\end{array}$ & $\begin{array}{c}\text { NÚMERO DO } \\
\text { TENSI OMETRO }\end{array}$ & $\begin{array}{c}\text { CONDUTI VI DADE HI DRÁULICA } \\
\left(\mathrm{cm}^{2}, \mathrm{~S}^{\prime}\right.\end{array}$ \\
\hline 150 & 1 & $1,8119 \times 10^{-4}$ \\
175 & 2 & $1,9744 \times 10^{-4}$ \\
361 & 3 & $1,6500 \times 10^{-4}$ \\
354 & 4 & $1,6129 \times 10^{-4}$ \\
333 & 5 & $1,5475 \times 10^{-4}$ \\
242 & 6 & $1,8074 \times 10^{-4}$ \\
323 & 7 & $1,8331 \times 10^{-4}$ \\
170 & 8 & $1,9744 \times 10^{-4}$ \\
383 & 9 & $1,3193 \times 10^{-4}$ \\
230 & 10 & $1,7720 \times 10^{-4}$ \\
343 & 11 & $1,7617 \times 10^{-4}$ \\
393 & 12 & $1,8293 \times 10^{-4}$ \\
\hline
\end{tabular}




\title{
* 3.3.3.2. Tensiómetros convencionais
}

\begin{abstract}
Denomi namos de tensiômetro convencional aquele que se utiliza de mercúrio para medir as depressóes resultantes da sucião do solo. As cápsulas foram coladas com araldite em tubo de PVC $\left[\phi{ }^{3,4}, 41,905 \mathrm{~cm} \times 60 \mathrm{~cm}\right]$. Da maneira usual conectou-se um pedaco de baguete do tubo a um depósito de mercúrio de vidro (vide Figura 3.1).
\end{abstract}

\section{* 3.3.3.3. Tensiómetro de bolha de ar}

Construidos com tubo de PVC $\left[\phi^{3 / 4} *(1,905 \mathrm{~cm})\right.$ $\times 60 \mathrm{~cm} J$ na porção inferior. A porcão superior constituiu-se de tubo de PVC transparente $\left[\phi{ }^{3} / 8 \cdot 60,952 \mathrm{~cm} \times 64 \mathrm{~cm}\right\}$ colado com araldite no tubo $\phi^{3 / 4}$ " $61,905 \mathrm{~cm}$ e fechado por tampa removível com rosca e junta de borrachal na parte superior. A cápsula foi conectado de maneira identica a realizada no tensiômetro convencional. A construção aqui descrita é uma modificacão daquela propósta por VILLA NOVA et alii (1989) com a finalidade de tornar o equipamento economicamente mais viável, e de mais fácil operacionalidade. 

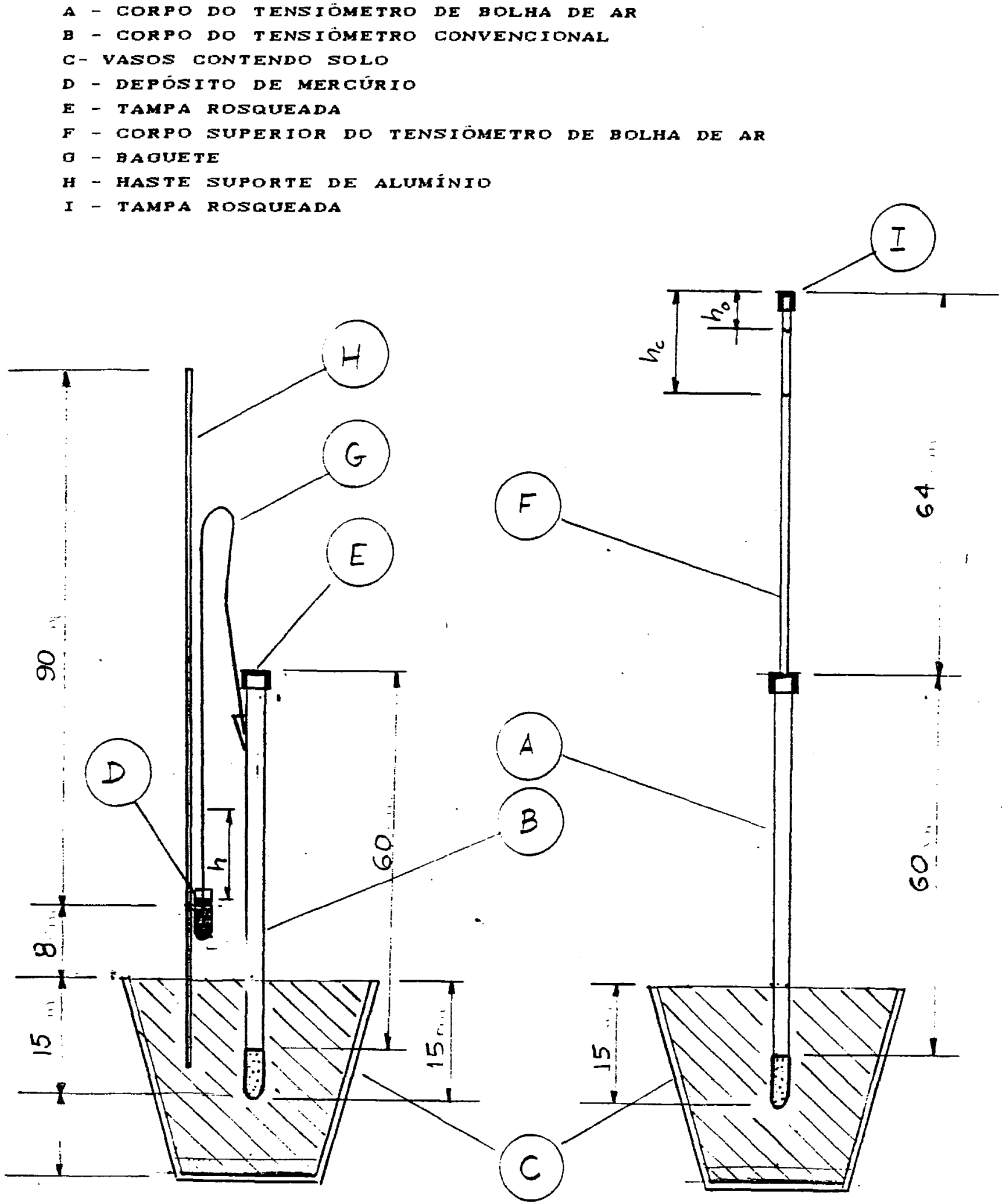

Figura 3.1 - Crôqui da montagem e detalhes dos tensiômetros convencional e de bol ha de ar. 
20.

\section{3. 3. 4. Montagem}

A montagem dos tensiómetros convencionais é de leitura direta nos vasas contendo solo mostrada no cróquis da Figura 3.1. Dentro de cada vaso as cápsulas foram colocadas a profundidade de $15 \mathrm{~cm}$. De acordo com a especificacão descrita for am montados e numerados, 12 conjuntos tensiômetro/vaso sendo:

3 conjuntos tensiometro convencional em salo argiloso (Tensiômetros $\left.n^{2} 2,4 \in 6\right)$

3 conjuntos tensiometro bolha de ar em solo argiloso CTensiômetros ne $7,9011 \mathrm{~J}$

3 conjuntos tensiometro convencional en solo arenoso CTensiómetros $n^{2} 8,10$ e 122

3 conjuntos tensiometro bolha de ar em solo arenoso CTensiómetros $n^{2} 1,3 e 5$

os vasos montados foram colocados sobre uma mesa no laboratório de física de solos do Departamento de Engenharia Rural/ESALQ. Na Figura (3.2) (fotografias) trada uma vista da montagem dos conjuntos. 


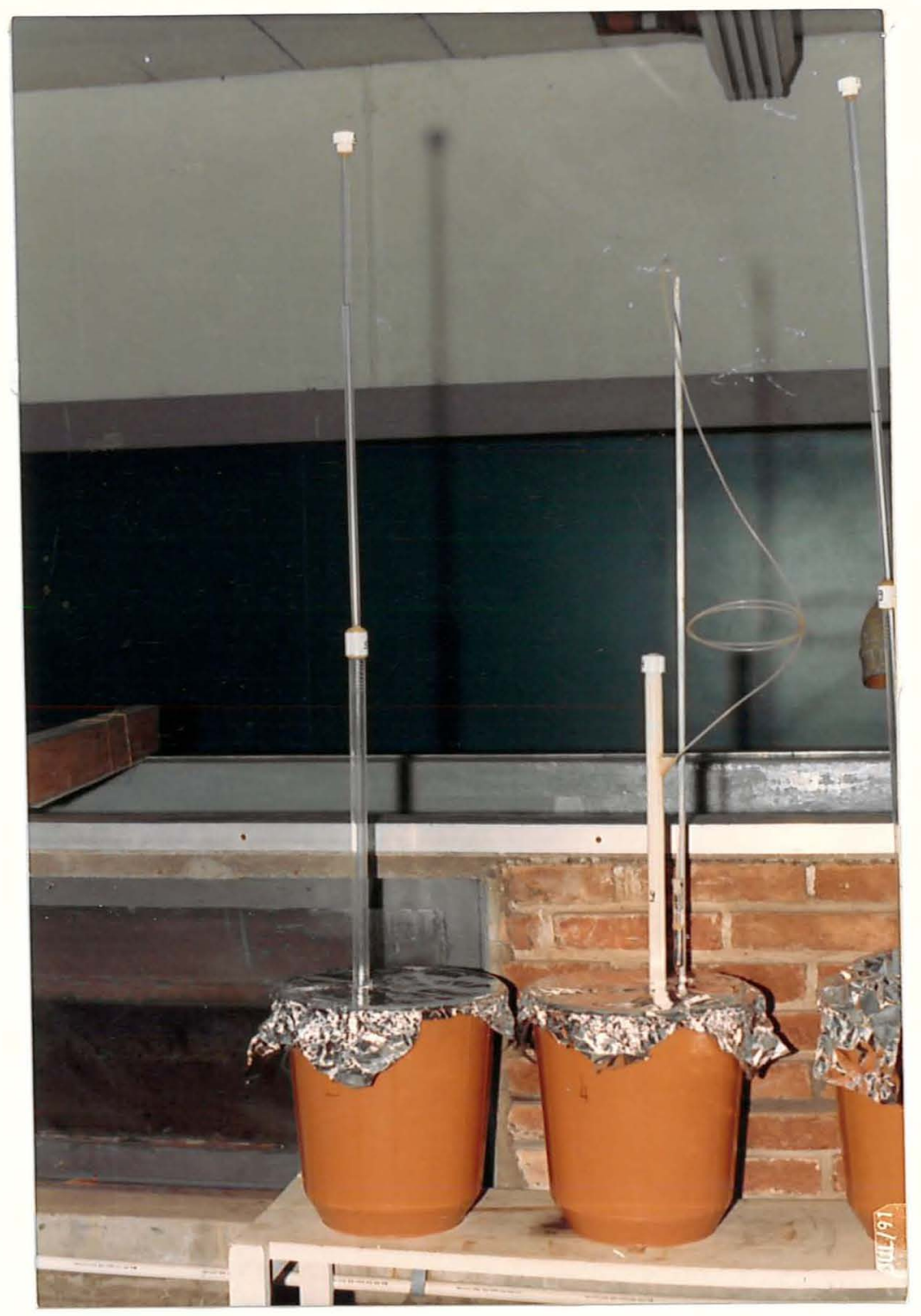

Figura 3.2 - Vista da montagem dos tensiómetros.

\section{4. Avaliação dos Potenciais da Água do Solo}

\subsubsection{Tensiómetro convencional}

A avaliação do potencial da água no solo pelo tensiómetro convencional foi realizada através da equacão usual : 


$$
\psi_{c}=12,6 h+c h_{1}+h_{2}
$$

onde:

$$
\begin{aligned}
& \psi_{c}=\text { potencial mátrico }\left(\mathrm{cm} H_{z} O\right) \text {, medido pelo tensibmetro } \\
& \text { convencional; } \\
& \text { h = altura de equilíbrio da coluna de mercúrio }(\mathrm{cm} \text {; } \\
& h_{1}=\text { distância do nivel de mercúrio na cuba ao nível do } \\
& \text { sola ( } 8 \mathrm{~cm} \text { na montagem descrita ?; } \\
& h_{2}=\text { distância do nivel do solo ao meio da cápsula de } \\
& \text { cerâmica } \mathrm{C} 15 \mathrm{~cm} \text { na montagem descrita } \text {. }
\end{aligned}
$$

De acordo com a montagem (vide Figura 3.2$)$ os valores de $h_{1} e h_{2}$ foram respectivamente 8 e $15 \mathrm{~cm}$. Assim sendo a equacão (3.1) tornou-se

$$
\psi_{c}=-12,6 h+23,0
$$

\title{
3. 4.2. Tensiómetro de leitura direta
}

\begin{abstract}
De acordo com as modificacóes introduzidas na geometria de construção, a condicão de equilibrio que nos permite avaliar o potencial da água no solo através do tensiômetro de bolha de ar $\left[\psi_{\mathbf{T B A}}\right)$ modificado é a seguinte: 0 Tensiómetra (Figura 3.3$)$ é de cheio d'água pela parte superior deixando-se uma camara vazia inicial de altura $h_{0}$ que irá estabilizar-se na altura $h$, com o solo saturado.
\end{abstract}


23.

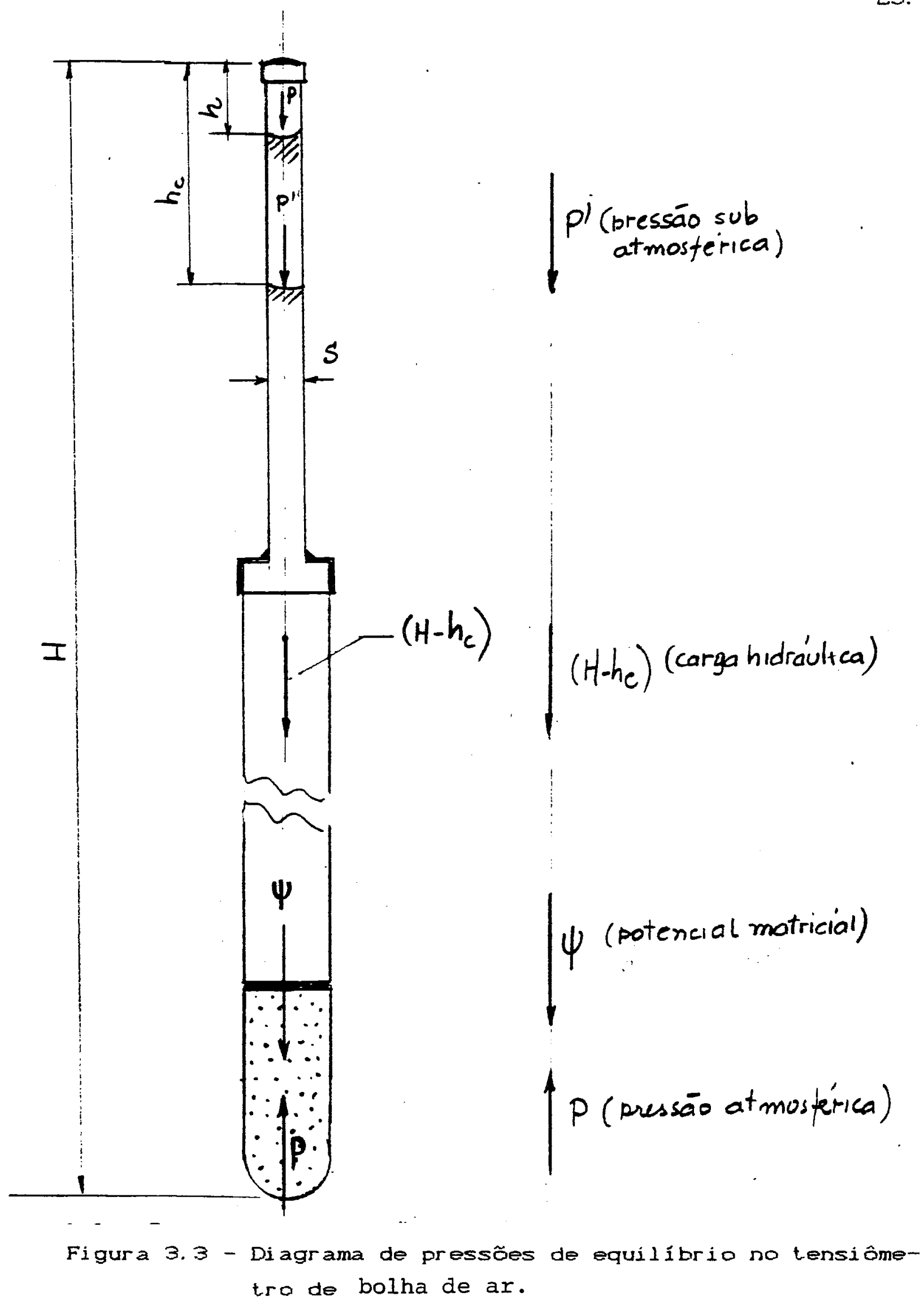


De acordo com a sucção $\psi$ exercida pelo solo, a medida que o mesmo seca parte da água escoa pela cápsula e num estado de equilíbrio qualquer a camara vazia atinge a altura $h_{c}$. As pressônes forcas por unidade de áreal que mantém este equilíbrio são:

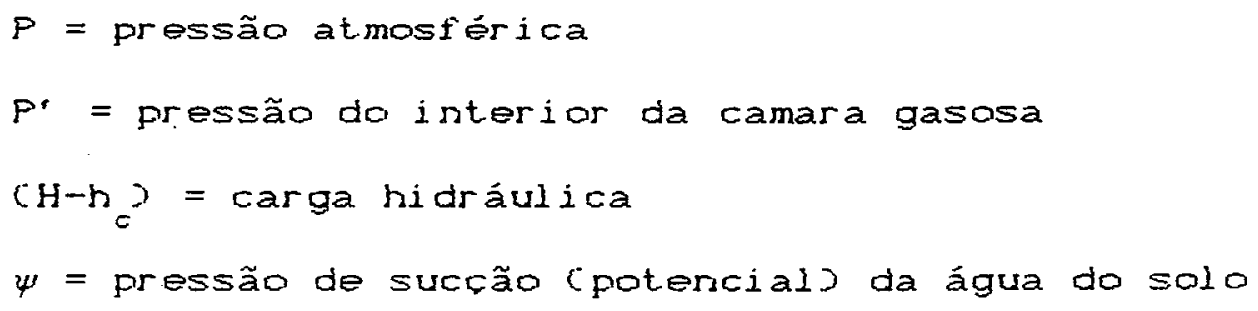

Sendo a seccão de tubo $S$, a relacão entre as pressões P Cpressão atmosf́érica local e a pressão P' Cpressão no interior da camara estabilizada de altura h j de acordo com a equacão geral de estado dos gases, será,

$$
\frac{P^{\prime} V^{*}}{T^{*}}=\frac{P V}{T}
$$

onde $I^{\prime}$ e I são as temperaturas $\left.C^{\circ} \mathrm{S}\right)$, respectivamente na hora da lejtura da camara e na hora do fechamento.

Consideranda-se também que,

$$
V^{\prime}=\operatorname{Sh}_{c} \quad \theta \quad V=\operatorname{Sh}
$$

Substituindo-se (3.5) em (3.3) e rearranjando teremos,

$$
\psi=P\left[1-\frac{h}{h_{e}} \frac{T^{*}}{T}\right]-\left[H-h_{e}\right]
$$

Para efeitos práticos considerando-se que as temperaturas $T^{*}$ e $I$ não sejam muito diferentes cprocesso aproximadamente isotérmico) a equacão (3.6) tornar-se: 
25.

$$
\psi=P\left(1-\frac{h}{h_{c}}\right)-\left(H-h_{c}\right)
$$

De acordo com a convencão Cminimo potencial da água no solo igual a zero) a equacão (3.7) tornar-se:

$$
\psi_{\text {LD }}=-P\left[1-\frac{h}{h_{C}}\right]+\left[H-h_{C}\right]
$$

Ajustando as unidades, para expressar $\psi$ agora denominado $\psi_{\text {LD }}$ (potencial da água do solo lido pelo tensiómetro de leitura diretas, sendo a pressão local em média Ccom pequenas variacóos) igual a $71 \mathrm{~cm}$ de $\mathrm{Hg}$ c965 cm de coluna d’água) teremos para a equacão (3.8)

$$
\psi_{L D}=-955\left[1-\frac{h}{h_{C}}\right]+\left[H-h_{C}\right]
$$

Sendo também nas condicões específicas do experimento, $H=130 \mathrm{~cm}$, $=$ a altura da camara inicial depois do fechamento, $h=3 \mathrm{~cm}$, a equacão $(3.9)$ torna-se:

$$
\psi_{L D}=-835+\frac{2895}{h_{c}}-h_{e}\left(0 m h_{2} 0\right.
$$

A equacão (3.10) nos fornece a medida do potencial matricial estimado pelo tensiómetro de leitura direta, nas dimensōes construtivas, em $\mathrm{cm}$ de água, em funcão da altura de equilibrio $h_{c}$ em $c m$, Iida num instante qual quer.

\subsection{Aval iação da Umidade do Solo}

A umidade dos sol os arenosos e argiloso dentro dos vasos $(\theta \%$, foi avaliada em um instante qualquer pela equação: 


$$
\theta \%=\left[\frac{M_{\text {su }}-M_{s s}}{M_{\text {ss }}} \times d \mathrm{dg}\right] \times 100
$$

sendo:

$$
\begin{aligned}
& M_{\text {SU }}=\text { massa do solo umi do }(g) ; \\
& M_{S S}=\text { massa do solo seco }(g) ; \\
& d g=\text { densidade global do solo }\left(g / \mathrm{cm}^{3}\right)
\end{aligned}
$$

\begin{abstract}
A densidade global foi avaliada dividindo-se a massa de salo seco em estufa pelo vol ume ocupado pelo mesmo. A medida das massas foi realizada em balanca eletrónica modelo Marte com fundo de escala $0-40 \mathrm{~kg}$, com aproximacöes permissiveis de 1, o grama.
\end{abstract}

\title{
3. 6. Condução do Experimento
}

\subsubsection{Ajustes iniciais}

\begin{abstract}
Pesaram-se cada um dos doze vasos, primeiro vazios e depois cheios de solo. A seguir os vasos foram irrigados com cerca de 10 litros de $\mathrm{H}_{2} \mathrm{O}$ as que continham solos argilosos e 51 itros os arenosos, sendo cobertos com papel aluminio postos a drenar durante 10 dias. Antes de irrigar, instalaram-se os tensiómetros, que haviam sido previamente colocados em água para completa saturacăo das cápsulas, abrirdo-se um furo de $15 \mathrm{~cm}$ de profundidade no solo inserindo os tensiometros. os tensiómetros convencionais foram escorvados de maneira usual ajustando-se o nivel da
\end{abstract}


cuba de mercúrí na altura de 8,0 cm. Os tensiómetros de bolna de ar foram enchidos com água até $3 \mathrm{~cm}$ abaixo da borda da tampa, sendo fiechados rapidamente a partir deste instante.

\subsubsection{Inicio das leituras}

Após permanecerem em equilibrio durante dois dias deu-se inicio a leitura dos sistemas, duas vezes por dia co:00 16:00). Liam-se as leituras h, calculando-se o potencial medido pelo tensiómetro convencional pela equacăo (3.2) 1 iam-se as leituras, denominadas h no tensiometro de bolha de ar estimando-se os potenciais pela equacão (3.10). Após as leituras cada vaso era pesado calculando-se $0 \%$ pela equação $(3.11)$

\subsubsection{Análises estatísticas}

As análises estatísticas pertinentes foram conduzidas usando computador e basicamente se constituiram na determinacão das funcŏes de ajuste entre $\psi x \Leftrightarrow, e \psi x t$, - na verificacão das correlacóes entre os $\psi$ ajustados. 
28.

\title{
4. RESULTADOS E DISCUSSÃO
}

\subsection{Dimensionamento e Curvas de Resposta do Tensiómetro de Bolha de Ar}

\begin{abstract}
o tubo superior do tensiômetro de bolha de ar tem que obedecer as condicóes operacionais, sob pena de tornar-se inviável a sua utilização. Deve ter um diâmetro que permita sua recarga e condicóes de campo, sendo a menor possivel para não afetar o tempo de resposta. Em funcão desta elegeu-se o tubo $\phi^{3} / 8^{*}$ co,95e $\mathrm{cm}$ de PVC como ideal.

Com relação a al tura vê-se pela equacão (3. 9 )

que nas condicões locais de pressão atmosférica (96s cm $\mathrm{H}_{2}$ ) - para altura do tubo inferior eleita $600 \mathrm{~cm}$ e do tubo superior $(64 \mathrm{~cm}$, obteve-se para $H$; valor de $130 \mathrm{~cm}$. Assumi u-se que potencial máximo como sendo $\psi_{\mathbf{T B A}}=0,8$ at $6826,4 \mathrm{~cm}$ $\mathrm{H}_{2}$ OJ. Nestas condicões para que o valor de $h_{c}$ máximo fosse cerca de $50 \mathrm{~cm}$, teve-se que assumir para o valor da altura da camara inicial ho valor de $3 \mathrm{~cm}$, sujeito as condicäes da equaçäo (3.9).
\end{abstract}

$$
\begin{array}{r}
\text { Na Figura } 4.1 \text { são demonstradas as curvas de } \\
\text { resposta } \psi_{\text {TBA }} \times h_{\text {C }} \text { para as condi cóos relatadas } C H=130 \mathrm{~cm} \text {, }
\end{array}
$$


29.

$P=96 s \mathrm{~cm} H_{z}$ os para diferentes valores de $h$, de acordo com a equacăo (3.9). Para as condicóes do experimento vale a curva $h_{1}=3 \mathrm{~cm}$. Nota-se pela Figura 4.1 que se perderia precisão nas leituras baixas de $h_{c}$ se adotassemos o valor $h=1 \mathrm{~cm}$. De outro modo por exemplo para valores de $\mathrm{h}$ maiores que 6 cm para que pudessemos realizar a leitura de $\psi=826,4 \mathrm{~cm}$ de $\mathrm{H}_{2} \mathrm{O}$ precisariamos de ler um valor he, muito elevado, a que seria pouco prático Cdeformacão e possível quebra do tubo plástico). A equacäo (3.9) nos mostra também que a curva de resposta $\left(\psi \times h_{e}\right)$ do tensiómetro de bol ha de ar dependem da pressão local. Para local de pressão atmosférica $750 \mathrm{mmHg}(1019,4 \mathrm{~cm} \mathrm{H}$ O) a equacão (3.9) torna-se:

$$
\psi=-1019,4\left[1-\frac{h}{h_{c}}\right]+C H-h_{g}
$$

De acordo com esta nova forma da equacão (3.9) para $H=130 \mathrm{~cm}, h=3 \mathrm{~cm} e \psi=-0,8$ at $\mathrm{c824} \mathrm{cm} \mathrm{H}_{2} \mathrm{O} 0$ valor de $h_{\text {e }}$ no equilibrio seria de $31,5 \mathrm{~cm}$, bem menor que os $50 \mathrm{~cm}$ já determinados na condicão de pressão atmostérica $710 \mathrm{mmHg}(965 \mathrm{~cm} \mathrm{H} O)$ 


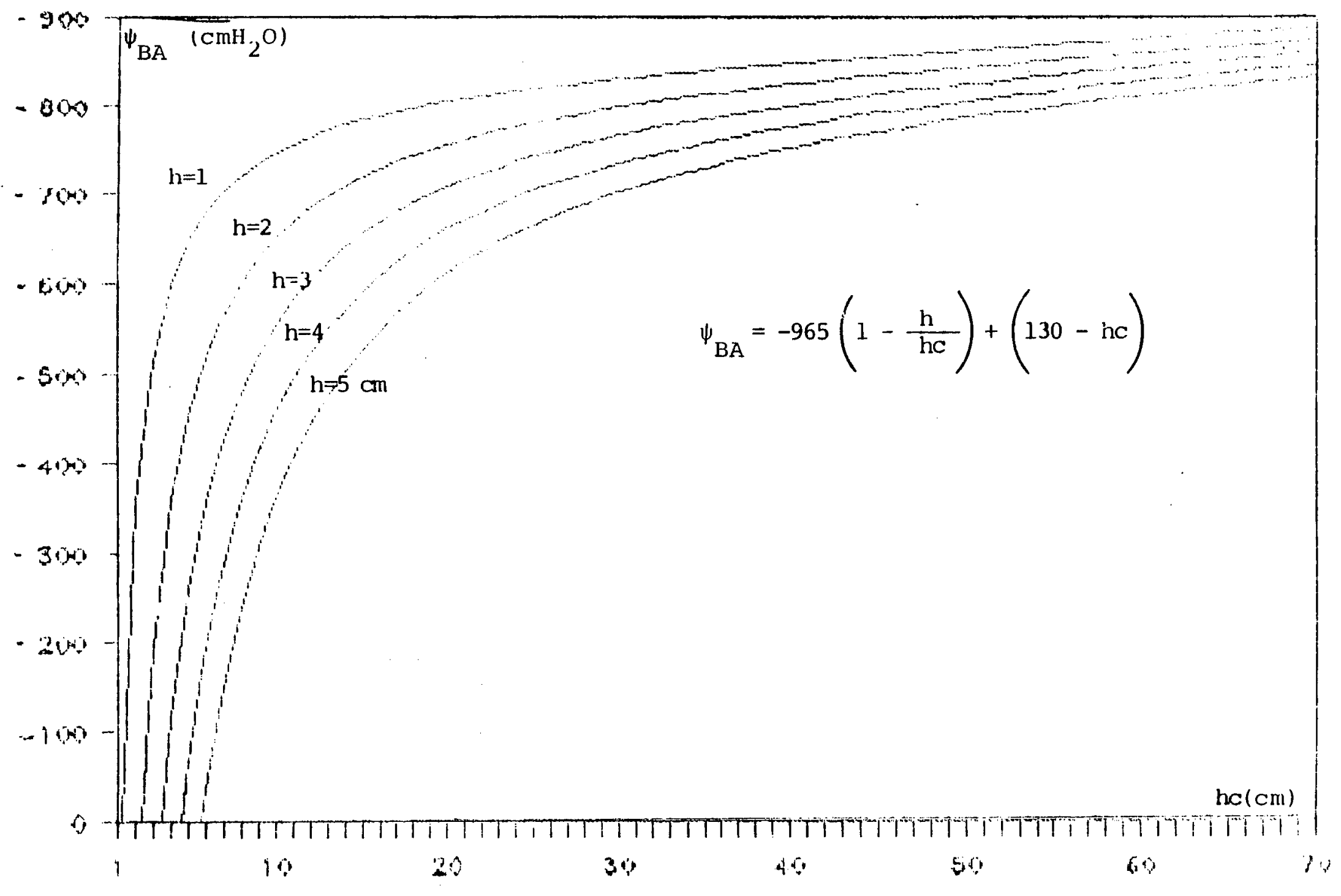

Fig. 4.1. Curvas de resposta do Tensiômetro de bolha de ar $\left(\psi_{\mathrm{BA}} \mathbf{x} \mathrm{hc}\right)$ para diferentes valores de $\mathrm{h}$. 
4.2. Dados obtidos de $\psi \times \Leftrightarrow$

\title{
4.2.1. Solo argiloso
}

\begin{abstract}
Nos Quadros $4.1,4.2,4.3$ e 4.4 , são relatados os valores de $\psi$ estimados pelas equacöes (3.1), (tensiometro convencional) e(3.10) tensiometro de bol ha de ar e as medidas de $\theta$ correspondentes estimados pela equaçäo (3.11), para cada conjunto tensiométrico. Nos dois horários de leitura 69:00 e 16:00). Para as diferentes datas o horários de leitura foi estabelecida a média aritmética dos três valores de $\psi^{\prime}$ e observados, denominados de $\bar{\psi}_{\text {c }}$ Ctensiometro convencionals $=\bar{\psi}_{\text {Lp }}$ ctensiometro de bolha de ar’.
\end{abstract}

\subsubsection{Solo arenoso}

Nos Quadros $4.5,4.6,4.7$ e 4.8 identico procedimento do item 4.2.1 foi adotado para o solo arenoso.

\section{3. Relações de Dependência Entre $\psi e \theta$ (Solo Argiloso)}

Através de análise estatística c vide Quadros A-1, A-Z, A-3 e A-4 do Apêndice) determinou-se a funcão que melhor se ajustou aos valores médios simultâneos $\bar{\psi}_{\text {Tc }} \times \bar{\theta} \theta$ $\bar{\psi}_{\text {TBA }} \times \bar{\ominus}$. 


\begin{tabular}{|c|c|c|c|c|c|c|c|c|c|c|c|}
\hline data & $\mathrm{h}_{2}$ & $\psi_{2}$ & $h_{4}$ & $\psi_{4}$ & $h_{6}$ & $\psi_{6}$ & $\bar{\psi}_{\mathrm{C}}$ & $\theta_{2}$ & $\dot{\theta}_{4}$ & $\theta_{6}$ & $\bar{\theta}$ \\
\hline $30-140 v$ & 3.9 & 26.14 & 4.1 & 28.66 & 4.0 & 27.40 & 27.40 & 51.76 & 48.73 & 51.65 & 50.71 \\
\hline & & 33.7 & 4.9 & 38.74 & & 41.26 & 37.90 & 47.10 & 45.35 & & 46.47 \\
\hline ec & 5. & 40.00 & 5. & 43.78 & .7 & .82 & 44.20 & 44.23 & 42.65 & & .63 \\
\hline 18 & 5.9 & 51.34 & 5.9 & 31.34 & 6.5 & .90 & 53.86 & 41.20 & 39.86 & 91 & 0.66 \\
\hline ec & 8.0 & 66.46 & 8.1 & 72.76 & 9.2 & 84.10 & 74.44 & .95 & 35.82 & 54 & 6.44 \\
\hline lec & 10.0 & 103.00 & 9.9 & 101.74 & 11.7 & 124.42 & 109.79 & 1.22 & 33.30 & 33.74 & 33.75 \\
\hline$\approx 0$ & 12.4 & 133.24 & 12.1 & 129.46 & 14.3 & 157.13 & 139.96 & 32.68 & 31.83 & 32.16 & 32.22 \\
\hline Tan & 17.2 & 193.72 & 15.8 & 176.08 & 19.6 & $223.96^{\circ}$ & 197.92 & 30.49 & 29.72 & 30.01 & 30.07 \\
\hline $\operatorname{lan}$ & 26.4 & 309.64 & 24.2 & 231.92 & 30.5 & 361.30 & 317.62 & 28.94 & 28.27 & $\div 3.52$ & 28.58 \\
\hline an & 34.2 & 407.92 & 31.4 & 372.64 & 41.7 & 502.42 & 427.66 & 27.81 & 27.15 & 27.40 & 37.45 \\
\hline & 39.6 & 475.96 & 37.5 & 449.50 & 47.8 & 579.28 & 501.58 & 27.19 & 26.55 & 26.91 & 6.88 \\
\hline & 51.7 & 628.42 & 52.0 & 632.20 & 57.5 & 701.50 & 654.04 & 26.25 & 5.65 & 26.01 & 5.97 \\
\hline & 60.9 & 744.34 & 62.5 & 764.50 & 62.9 & 769.54 & 759.46 & 25.22 & 24.64 & 25.00 & 4.95 \\
\hline $16-\mathrm{Jan}$ & 63.6 & 778.36 & 63.7 & 779.62 & 63.7 & 779.62 & 779.20 & 24.85 & 24.19 & 23.78 & 24.26 \\
\hline
\end{tabular}

Quadro4.1.Valores de $\mathrm{h}(\mathrm{cmHg}), \psi\left(\mathrm{cm} \mathrm{H}_{2} \mathrm{O}\right)$ e $\theta(\%)$ observados. Solo argiloso. Tensiómetro Convencional, horário 9:00 hs.

\begin{tabular}{|c|c|c|c|c|c|c|c|c|}
\hline data & $h_{7}$ & $\psi 7$ & $n_{11}$ & $\psi_{11}$ & $\bar{\psi}_{\mathrm{BA}}$ & $\theta_{7}$ & $\theta_{11}$ & $\bar{\Theta}$ \\
\hline jec & 3.60 & 34.43 & 3.60 & 34.43 & 34.43 & 50.06 & 51.44 & 5011.75 \\
\hline & & & & & 3 & & & \\
\hline & 3.65 & 45.50 & 3.70 & 56.27 & 50.8 & & & \\
\hline ec & 3.90 & 96.59 & 3.90 & 96.59 & 96.5 & 02 & 99 & \\
\hline$\Theta C$ & 4.10 & 133.00 & 4.00 & 115.25 & 124.1 & 87 & & \\
\hline$e$ & 4.40 & 181.45 & 4.20 & 149.91 & 5. & .57 & 31.59 & . \\
\hline an & 5.30 & 294.07 & 4.60 & 210.25 & 252. & .22 & 30.14 & ) \\
\hline ari & 6.30 & 381.78 & 4.60 & 210.25 & 296. & .55 & 29.42 & \\
\hline & 7.60 & 461.68 & 5.50 & 314.14 & 387.9 & .12 & 28.97 & . \\
\hline & 9.20 & 529.53 & 6.10 & 366.51 & 448.0 & 80 & 27.81 & 7 \\
\hline & 4.70 & 652.76 & 8.20 & 490.15 & 571. & & 27.48 & \\
\hline & 18.50 & 697.01 & 0.20 & 561.38 & 629. & & 26.93 & \\
\hline & 6.30 & 751.22 & 3.30 & 630.63 & 690. & & 6. & \\
\hline & & 817.35 & 5.40 & 746.42 & & & 25 & \\
\hline & 6.50 & 857.97 & 4.20 & 813.70 & 835. & 24. & 25.09 & \\
\hline
\end{tabular}

Quadro4.2.Valores de $\mathrm{h}\left(\mathrm{cm} \mathrm{H}_{2} \mathrm{O}\right), \psi\left(\mathrm{crn} \mathrm{H}_{2} \mathrm{O}\right)$ e $\theta(\%)$ observadas. Solor argiloso.

Tensiômetro de bolha de ar, horáriu das 9:00 hs. 


\begin{tabular}{|c|c|c|c|c|c|c|c|c|c|c|c|}
\hline data & $h_{2}$ & $\psi_{2}$ & $h_{4}$ & $\psi_{4}$ & $h_{6}$ & $\psi_{6}$ & $\bar{\psi}_{\mathrm{TC}}$ & $\Theta_{2}$ & $\theta_{4}$ & $\Theta_{6}$ & $\bar{\theta}$ \\
\hline 27 & 40 & 19.8 & 3.50 & 21.10 & 3.60 & 22.36 & 21.10 & 52,98 & 51.78 & 5.3 .77 & 52,84 \\
\hline & & & & & & & & 49.21 & & $4 \bar{y} .112$ & 48.51 \\
\hline & 3. & 38 & 5. & & & & 41.26 & 4. & & 45.40 & \\
\hline & 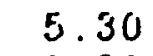 & & 0 & & & & 50.50 & $4 \angle .2 \angle$ & 20 & 42.03 & \\
\hline & t & & 0 & & & & 58.90 & .71 & & 39.41 & 22 \\
\hline & 0 & & 0 & 77 & 9. & 92. & 83.68 & 0.23 & & 35.76 & 72 \\
\hline & & 1 & 20 & 130 & 14 & 15 & 140.8 & 49 & & 31.98 & 04 \\
\hline & & & & 220. & & & 246.2 & 63 & & .15 & .2 \\
\hline & & 30 & 24. & 279. & & & 317.20 & 28.80 & & .41 & .46 \\
\hline & & 409 & & 378 & & 50 & 432.28 & .68 & & .32 & 35 \\
\hline & & 477 & & 455. & & 58 & 504.9 & .06 & & .79 & \\
\hline & & 562. & & & & & 590.6 & & & & \\
\hline & & & & & & & & & & & \\
\hline & $\begin{array}{l}61.00 \\
63.00\end{array}$ & $\begin{array}{l}745.60 \\
770.80\end{array}$ & $\begin{array}{l}62.10 \\
63.40\end{array}$ & $\begin{array}{l}759.46 \\
775.84\end{array}$ & $\begin{array}{l}62.70 \\
63.80\end{array}$ & $\begin{array}{l}767.02 \\
780.88\end{array}$ & $\begin{array}{l}757.36 \\
775.84\end{array}$ & $\begin{array}{l}25.18 \\
25.12\end{array}$ & & & \\
\hline & & & & & & & & & & & \\
\hline
\end{tabular}

Quadro 4.3. Valores de $\mathrm{h}(\mathrm{cmHg}), \psi_{\mathrm{c}}\left(\mathrm{cm} \mathrm{H} \mathrm{CH}_{2}\right.$ e $\theta(\%)$ observados. Solo argiloso. Tensiómetro Convencional, horärio 16:00 hš.

\begin{tabular}{|c|c|c|c|c|c|c|c|c|}
\hline & h 7 & $\psi 7$ & & $\psi 11$ & $\Psi_{\mathrm{TE}}$ & $\theta_{7}$ & $\theta_{11}$ & $\theta$ \\
\hline $17-$ & 3.60 & 34.43 & 3.80 & 76.96 & 55.70 & 40.63 & 41.86 & 41.25 \\
\hline ec & 4.00 & 115.25 & 4.00 & 115.25 & 115.25 & 34. & 35.15 & 60 \\
\hline & 4.30 & 166.04 & 4.20 & 149.91 & 157.98 & 32.63 & 33.69 & .16 \\
\hline & 4.40 & 181.45 & 4.20 & 149.91 & 165.68 & 31.11 & 32.10 & .61 \\
\hline & 4.60 & 210.25 & 4.40 & 181.45 & 195.85 & 30.35 & 31.34 & 30.85 \\
\hline an & 5.40 & 304.29 & 4.80 & 236.68 & 270.49 & 29.10 & 29.98 & 29.54 \\
\hline $\operatorname{Ian}$ & 6.50 & 396.12 & 5.20 & 283.47 & 339.80 & 28.39 & 29.26 & 28.83 \\
\hline Ian & 9.50 & 539.76 & 6.20 & 374.26 & 457.01 & 27.66 & 28.49 & 28.08 \\
\hline an & 15.80 & 667.57 & 8.50 & 502.91 & 585.24 & 26.60 & 27.34 & 26.97 \\
\hline & & .64 & 10.80 & 577.74 & 6 & .97 & 26.8 & 40 \\
\hline & 28.30 & $.0(1$ & 14.30 & 646.85 & 7 & 25.66 & 26.44 & .05 \\
\hline & & 795.30 & 19.70 & 707.75 & & 25.29 & 25.96 & .65 \\
\hline & & 823 & 27.30 & 756 & & 24.99 & 5.67 & \\
\hline
\end{tabular}

Quadro 4.4.Valores de $\mathrm{h}\left(\mathrm{cm} \mathrm{H} \mathrm{H}_{2} \mathrm{O}\right), \psi\left(\mathrm{cm} \mathrm{H} \mathrm{H}_{2} \mathrm{O}\right.$ \& $8(\because)$ observados. Tensiómetro bolha de ar. Solo argilloso, horärio 16:00 hs. 


\begin{tabular}{|c|c|c|c|c|c|c|c|c|c|c|c|}
\hline aata & $n_{0}$ & $\psi_{\theta}$ & $h \perp 0$ & $\psi 10$ & $h: 2$ & $\psi 12$ & $\Psi_{\mathrm{T} C}$ & $\theta_{8}$ & $\theta_{10}$ & $\theta_{12}$ & $\bar{\theta}$ \\
\hline (1)-Dez & 4.7 & 36.22 & 5.1 & 41.26 & 4.9 & 38.74 & 38.71 & 34.08 & 33.23 & 33.84 & 33.72 \\
\hline $\begin{array}{l}06-\text { Dez } \\
10 \text {-Dez }\end{array}$ & $\begin{array}{l}4.9 \\
5.1\end{array}$ & $\begin{array}{l}38.74 \\
41.26\end{array}$ & $\begin{array}{l}5.4 \\
5.5\end{array}$ & $\begin{array}{l}45.04 \\
46.30\end{array}$ & 5.3 & 43.78 & 42.52 & 31.77 & 30.92 & 31.55 & 31.41 \\
\hline 17-Iez & 5.4 & 45.04 & 5.6 & 47.56 & 5.6 & $\begin{array}{l}46.30 \\
47.56\end{array}$ & $\begin{array}{l}94.62 \\
46.72\end{array}$ & $\begin{array}{l}29.18 \\
26.30\end{array}$ & $\begin{array}{l}28.47 \\
25.69\end{array}$ & $\begin{array}{l}28.97 \\
26.24\end{array}$ & $\begin{array}{l}28.87 \\
26.08\end{array}$ \\
\hline $\begin{array}{l}24 \text {-Dez } \\
28-\text { Dez }\end{array}$ & 5.8 & 50.018 & 6.3 & 56.38 & 6. & 53.86 & 53.44 & 21.35 & 20.73 & 21.57 & $21.22^{\circ}$ \\
\hline $02-J a n$ & $\begin{array}{l}6.2 \\
7.1\end{array}$ & $\begin{array}{l}55.12 \\
66.46\end{array}$ & $\begin{array}{l}6.7 \\
7.8\end{array}$ & $\begin{array}{l}61.42 \\
75.28\end{array}$ & $\begin{array}{l}6.5 \\
6.9\end{array}$ & $\begin{array}{l}58.90 \\
63.94\end{array}$ & $\begin{array}{l}58.48 \\
68.56\end{array}$ & 18.56 & 17.98 & 18.94 & 18.49 \\
\hline $07-J$ an & 8.3 & 81.58 & 9.4 & 95.44 & 8.2 & 80.32 & 85.78 & 11.80 & 11.30 & 12.47 & $\begin{array}{l}14.7 .3 \\
11.86\end{array}$ \\
\hline $\begin{array}{l}10-\mathrm{Jan} \\
16-\mathrm{Jan}\end{array}$ & 10.5 & 109.30 & 12.1 & 129.46 & 9.3 & 94.18 & 110.98 & 10.01 & 9.69 & 10.79 & 10.16 \\
\hline $\begin{array}{l}\text { Jan } \\
\text { Jan }\end{array}$ & 13.6 & 148.36 & 14.7 & 162.22 & 10.8 & 113.08 & 141.22 & 8.45 & 8.35 & 9.24 & 8.68 \\
\hline Fev & $\begin{array}{l}21.1 \\
37.7\end{array}$ & $\begin{array}{r}242.86 \\
452.112\end{array}$ & & $\begin{array}{l}25 \\
35\end{array}$ & & 250.38 & 247.89 & $\begin{array}{l}5.61 \\
6.03\end{array}$ & 5.89 & 6.23 & \\
\hline 14 & 52.7 & 641.02 & 43.4 & 523.84 & & 449.50 & 538.12 & 4.50 & 4.82 & 5.02 & \\
\hline & 59.9 & 731.74 & 58.3 & 711.58 & & 671.26 & 704.86 & 3.51 & 3.77 & & \\
\hline & 60.3 & 736.78 & 59.2 & 722.92 & 56.9 & 693.94 & 717.88 & 3.35 & 3.71 & 3.81 & 3.6 \\
\hline
\end{tabular}

Quaäro 4.5. Valores de $\mathrm{h}(\mathrm{cmHg}), \psi\left(\mathrm{cmH}_{2} \mathrm{O}\right)$, e $\theta(8)$ observados. Solo arenoso. Tensiómetro convencional, horário 9:00 hs.

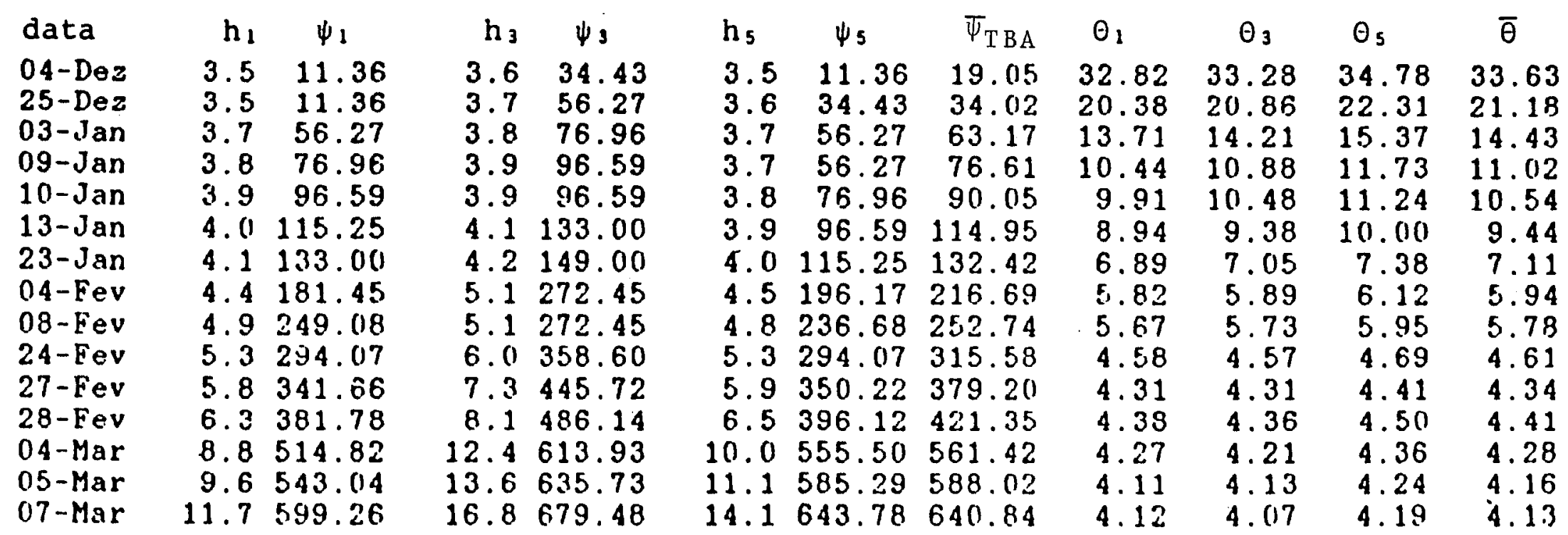

Quadro 4.6. Valores de $\mathrm{h}$ ( $\mathrm{cmHg}), \psi\left(\mathrm{cmH}_{2} \mathrm{O}\right)$ e $\theta(8)$ observados. Solo arenoso. 


\begin{tabular}{|c|c|c|c|c|c|c|c|c|c|c|c|}
\hline data & $\mathrm{h}_{8}$ & $\psi_{\text {a }}$ & $h_{10}$ & $\psi_{10}$ & $\mathrm{~h}_{12}$ & $\psi_{12}$ & $\bar{\psi}_{\mathrm{TC}}$ & $\theta_{8}$ & $\theta_{10}$ & $\Theta_{12}$ & $\bar{\theta}$ \\
\hline (11-Dec & 4.6 & 34.96 & 4.7 & 36.22 & 4.9 & 38.74 & 36.64 & 35.49 & 34.70 & 35.23 & 35. \\
\hline$-D \in C$ & 4.9 & 38.74 & 5.1 & 41.26 & & 40.00 & 40.00 & 32.27 & 31.46 & 32.04 & 31.5 \\
\hline $12-\mathrm{Dec}$ & 5.2 & 42.52 & 5.5 & 46.30 & & 45.04 & 44.62 & 28.26 & 27.50 & 28.12 & 27.8 \\
\hline $19-I \in C$ & 5.5 & 46.30 & 5.6 & 47.56 & & 48.82 & 47.56 & 24.99 & 24.33 & 24.98 & 24 \\
\hline 25-Iec & 5.9 & 51.34 & 6.2 & 55.12 & .2 & 55.12 & 53.86 & 20.66 & 20.05 & 20.90 & 20. \\
\hline $30-$ Dec & 6.3 & 56.38 & 6.7 & 61.42 & .7 & 61.42 & 59.74 & 16.81 & 16.22 & 17.25 & 1 \\
\hline Jan & 7.8 & 75.28 & 8.8 & 87.88 & .5 & 71.50 & 78.22 & 13.88 & 13.29 & 14.40 & \\
\hline Jan & 7.9 & 76.54 & 8.8 & 87.88 & 8.3 & 81.58 & 82.00 & 11.71 & 11.20 & 12.38 & 11.7 \\
\hline $11-$ & 10.8 & 113.08 & 12.0 & 128.20 & 9.6 & 97.96 & 113.08 & 9.63 & 9.35 & 10.44 & \\
\hline 31 & 20.8 & 239.08 & 21.0 & 241.60 & 19.4 & 221.44 & 234.04 & 5.59 & 5.89 & 6.21 & \\
\hline $01-$ & 28.7 & 338.62 & 26.0 & 304.60 & 22.5 & 260.50 & 301.24 & 5.52 & 5.84 & 6.14 & \\
\hline $05-$ & 35.6 & 425.56 & 28.2 & 332.32 & 24.2 & 281.92 & 346.60 & 5.24 & 5.56 & 5.81 & \\
\hline $12-$ & 50.1 & 608.26 & 40.3 & 484.78 & 34.7 & 414.22 & 502.42 & 4.76 & 5.12 & 5.31 & \\
\hline 21 & 56.4 & 687.64 & 48.7 & 590.62 & .6 & 501.16 & 593.14 & 4.08 & 4.44 & 4.58 & \\
\hline & & 726.70 & 57.7 & 704.02 & & 657.40 & 696.04 & 3.53 & 3.90 & 4.01 & \\
\hline $07-$ & 60.3 & 736.78 & 59.2 & 722.92 & & 687.64 & 715.78 & 3.45 & 3.78 & 3.93 & \\
\hline
\end{tabular}

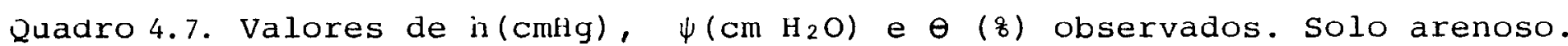
liensiônetro convencional, horário 16:00 hs.

\begin{tabular}{|c|c|c|c|c|c|c|c|c|c|c|c|}
\hline data & $\mathrm{h}_{1}$ & $\psi_{1}$ & $\mathrm{~h}_{3}$ & $\psi_{3}$ & $\mathrm{~h}_{5}$ & $\psi_{5}$ & $\bar{\psi}_{\mathrm{T} \mathrm{BA}}$ & $\theta_{1}$ & $\Theta_{3}$ & $\theta_{5}$ & $\bar{\theta}$ \\
\hline $07-$ Ie & 3.5 & $11.36^{\circ}$ & 3.7 & 56.27 & 3.6 & 34.43 & 34.02 & 30.66 & 31.16 & 32.82 & 31 \\
\hline 12 - Dez & 3.6 & 34.45 & 3.7 & 56.27 & 3.6 & 34.43 & 41.71 & 28.05 & 28.57 & 30.23 & \\
\hline - Dez & 3.6 & 34.43 & 3.7 & 56.27 & 3.7 & 56.27 & 43.99 & 24.71 & 25.19 & 26.74 & \\
\hline $25-D=2$ & 3.6 & 34.43 & 3.8 & 76.96 & 3.7 & 56.27 & 55.89 & 20.35 & 20.73 & 22.26 & 1 \\
\hline $07-J a n$ & 3.7 & 56.27 & 3.7 & 76.96 & 3.8 & 76.96 & 70.016 & 11.41 & 11.92 & 12.93 & \\
\hline $10-J a n$ & 3.9 & 96.59 & 3.9 & 96.59 & 4.0 & 115.05 & 102.74 & 9.83 & 10.87 & 11.16 & \\
\hline $16-\mathrm{Jan}$ & 4.1 & 133.00 & 4.2 & 149.91 & 4.0 & 115.25 & 132.72 & 7.644 & 8.87 & 9.49 & \\
\hline $08-$ Eev & 4.9 & 249.08 & & 272.45 & & 236.68 & 252.74 & E. 74 & 77 & 6.02 & \\
\hline $10-F \in V$ & 5.4 & 304.29 & E. 4 & 3014.29 & 5.3 & 294.07 & 300.88 & 5.55 & 62 & 5.83 & \\
\hline 28-Fev & 6.2 & 374.26 & 8.1 & 485.69 & 6.4 & 389.06 & 416.34 & 4.39 & 4.37 & 4.50 & \\
\hline & 8.9 & 518.62 & 12.6 & 617.84 & 10.2 & 561.38 & 565.05 & 4.27 & 4.22 & 4.36 & \\
\hline $05-$ Mar & 9.9 & 552.48 & 13.9 & 640.63 & 11.4 & 592.45 & 595.19 & 4.18 & 4.13 & 4.27 & \\
\hline
\end{tabular}

Quadro 4.8. Valores de $\mathrm{h}(\mathrm{cmHg}), \psi\left(\mathrm{cm} \mathrm{H}{ }_{2} \mathrm{O}\right)$ e $\theta\left(\frac{q}{8}\right)$ observados. Solo arenoso. 
Os resultados abtidos forma os seguintes:

4. 3.1. Leituras das 9:00

$$
\begin{gathered}
\psi_{\text {TC }}=11211,27-654,69 \theta+9,63 \theta^{2} \\
r^{2}=0,991 \\
\psi_{\text {TBA }}=9006,33-457,339+0,54 \theta^{2} \\
r^{2}=0,998
\end{gathered}
$$

4. 3.2. Leituras das 16:00

$$
\begin{gathered}
\psi_{\mathrm{TC}}=9406,72-854,08 \theta+7,96 \theta^{2} \\
r^{2}=0,985 \\
\psi_{\mathrm{TBA}}=10902,80-635,47 \theta+9,35 \theta^{2} \\
r^{2}=0,998
\end{gathered}
$$

Nas equacôes acima, os termos significam:

$\psi_{\text {TC }}=$ potencial matricial médio $\mathrm{Ccm} \mathrm{H}_{2}$ ol estimado polo tensiómetro conventional;

$\theta \quad=$ umi dade média do solo en \%;

$\psi_{\text {TBA }}=$ potencial matricial médio $\operatorname{com} \mathrm{H}_{2} O \mathrm{O}$ estimado pelo tensiometro de bol ha de ar.

Os ajustes $\psi \times \Leftrightarrow$ descriminados nas equacóos 4.1, 4.2, 4.3 4.4, foram necessários pelos seguintes moti vos: 
a) Devido a metodologia utilizada é impossivel fazer estimativas de $\psi$ para valores pré-determinados de $\theta$;

b) A variabilidade das medidas devido aos erros decorrentes exige que se determine uma funçăo representativa de $\psi \times \Leftrightarrow$

Nas Figuras 4.2 e 4.3 săo demonstradas graficamente as dependencias $\psi \times \theta$ nos diferentes horários de leitura para os valores médi os observados dos dois conjuntos tensiométricos mostrando que a parabola expressa razoavelmente a ligacăo $¥{ }^{\prime}$ e. Nota-se que este confronto foi realizado para valores de $\psi$ superiores a $100 \mathrm{~cm}$ de $\mathrm{H}_{2} \mathrm{O}$. Este fato se prende aos erros devido a diferencas de temperatura na hora do fechamento Ccargas e da leitura, cuja ordem de grandeza pode ser elevada para valores baixos de $\psi$, como demonstraremos posteriormente.

\section{4. Comparaçóes $\psi_{\text {TC }} \times \psi_{\text {TBA }}$ (Solo Argiloso)}

Através das equacões $4.1,4.2,4.3 \ominus 4.4$, foi nos possivel realizar as comparacäes entre $\psi_{\text {rc }}$ Cestimativas do potencial matricial através do tensiometro convencional - $\psi_{\text {TBA }}$ Cestimativas do potencial matricial realizadas pelo tensiômetro de bolha de arl, para valores simultâneos de $\theta$. Nas Figuras 4.4 (A E B) demonstra-se que o alinhamento de $\psi_{\text {TBA }} e \psi_{\text {ra }}$ é representado pelas equacõos de regressão lvide Quadro A-5 do Apêndices. 


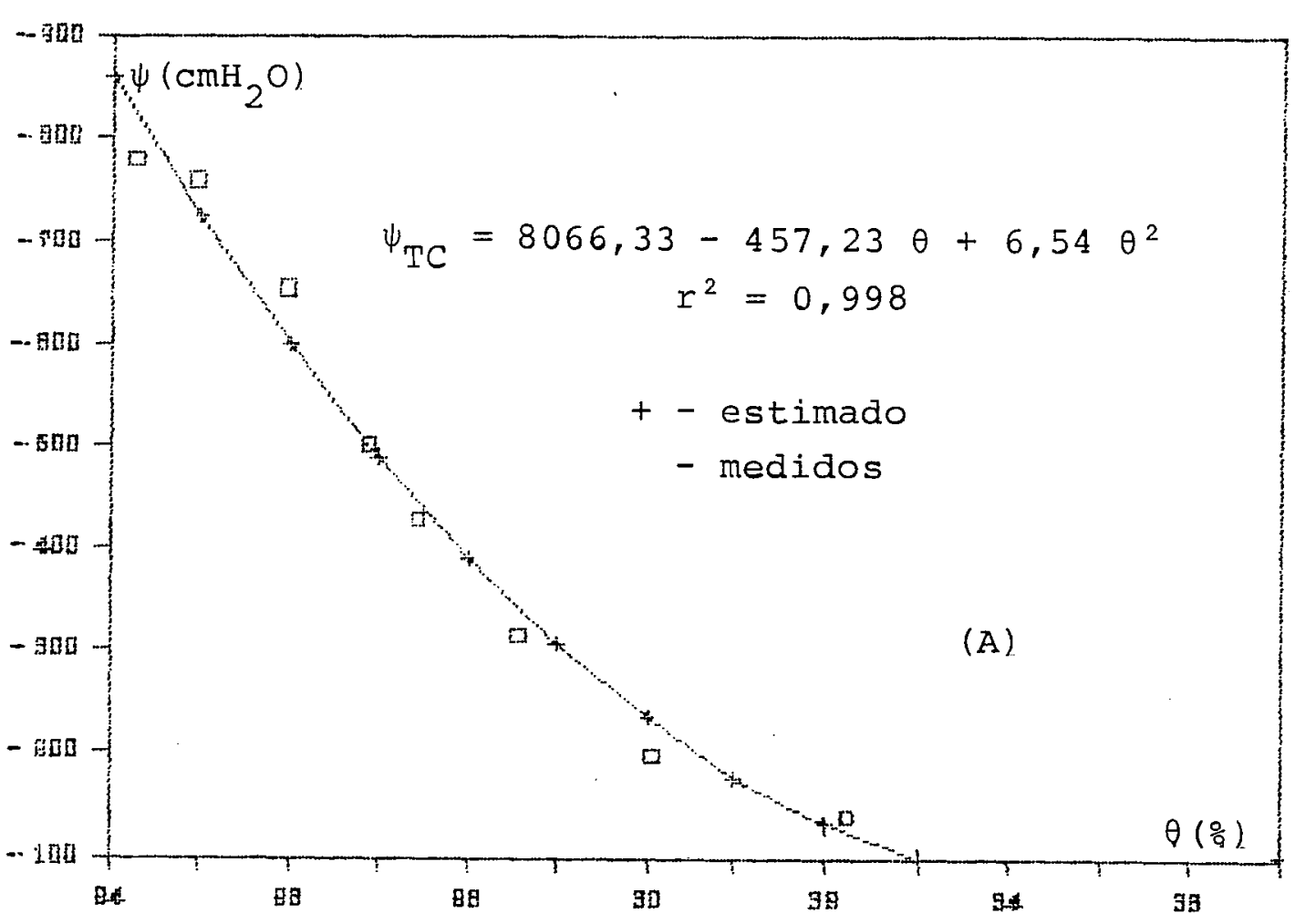

38.

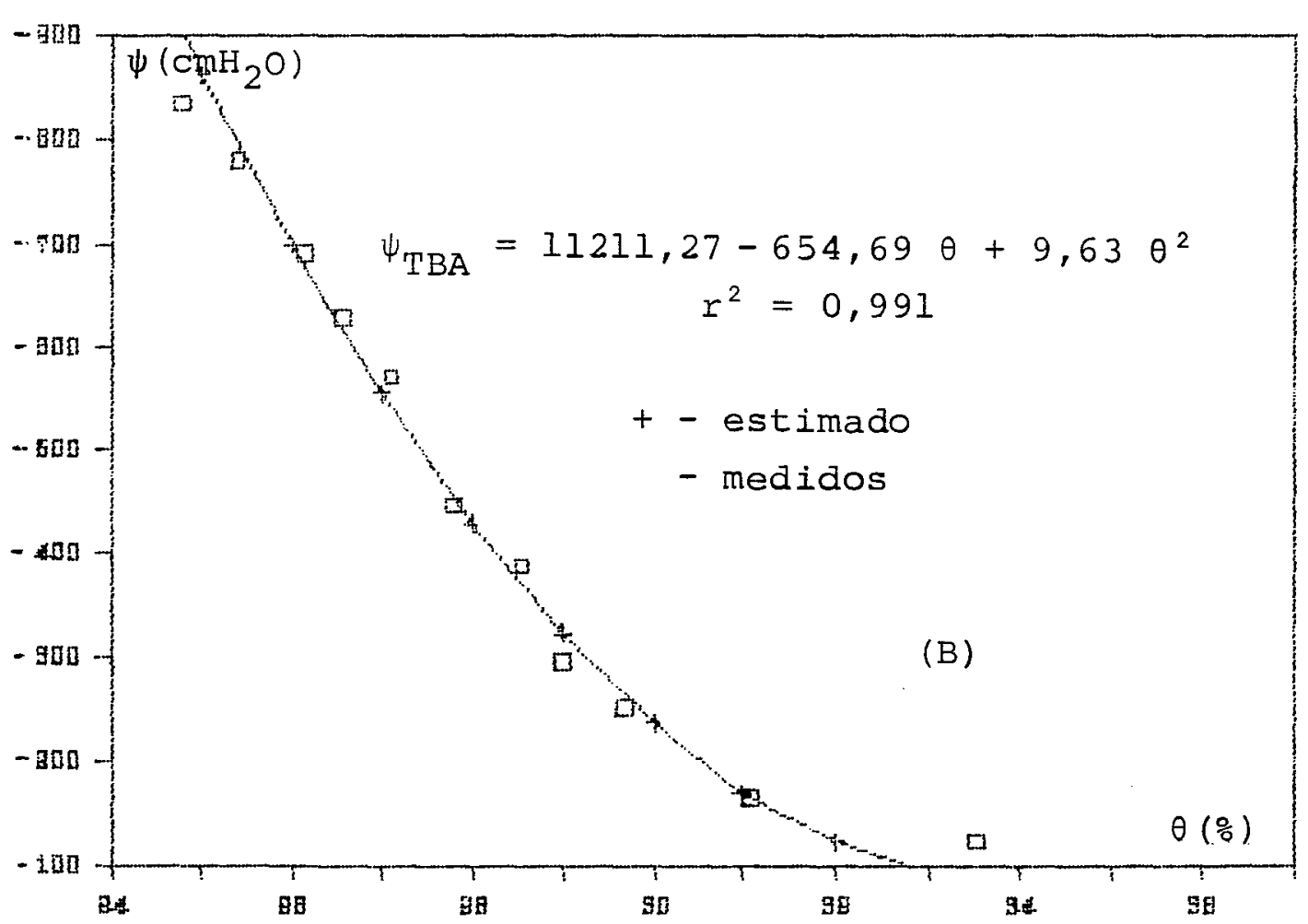

Fig. 4.2. Valores estimados e medidos de $\psi \mathrm{x} \theta$ Leitura das 9:00 hs (solo argiloso) A - Tens. convencional ( $\left.\psi_{\mathrm{TC}}\right)$ B - Tens. bolha de ar ( $\left.\psi_{\text {TBA }}\right)$ 


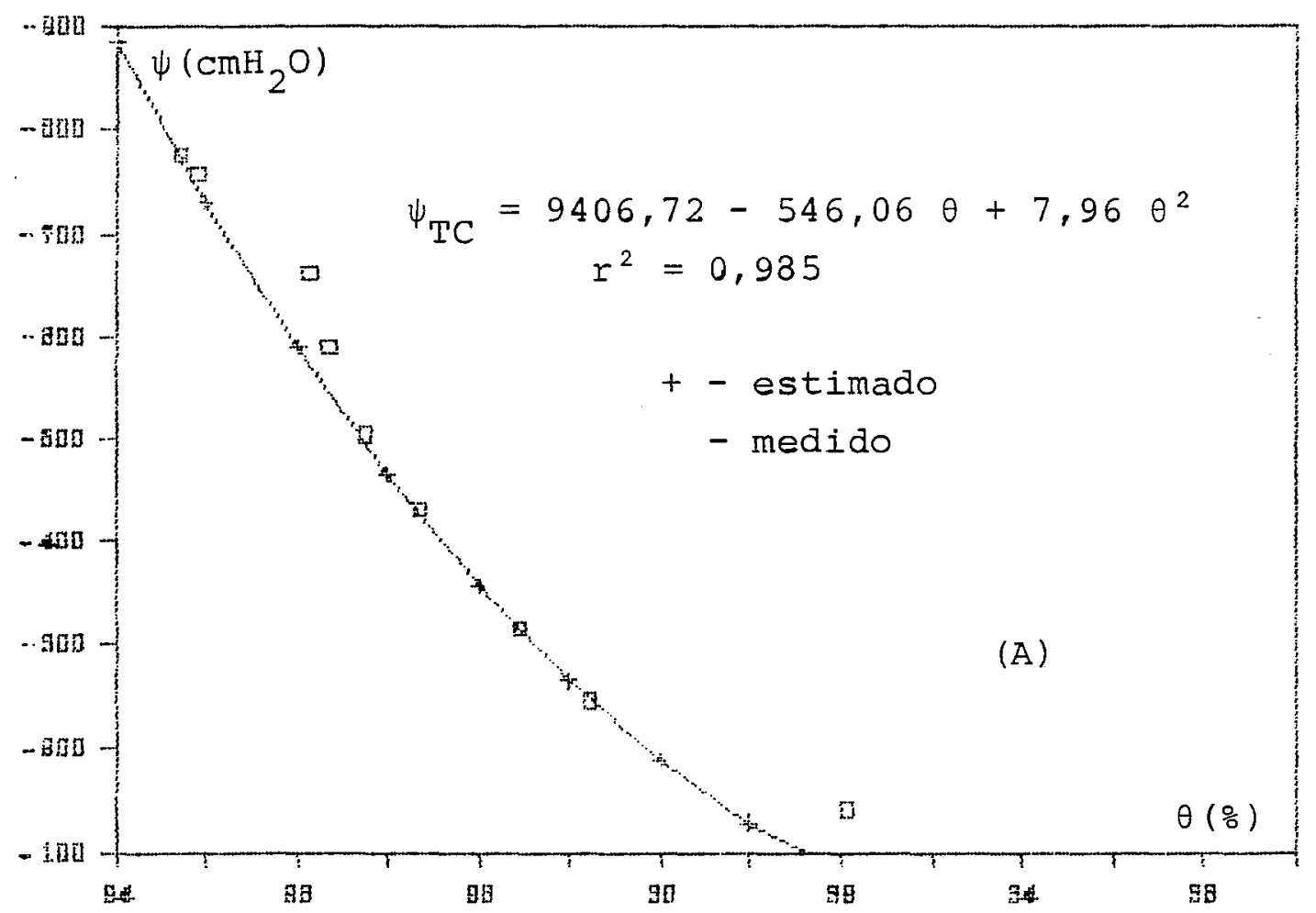

39.

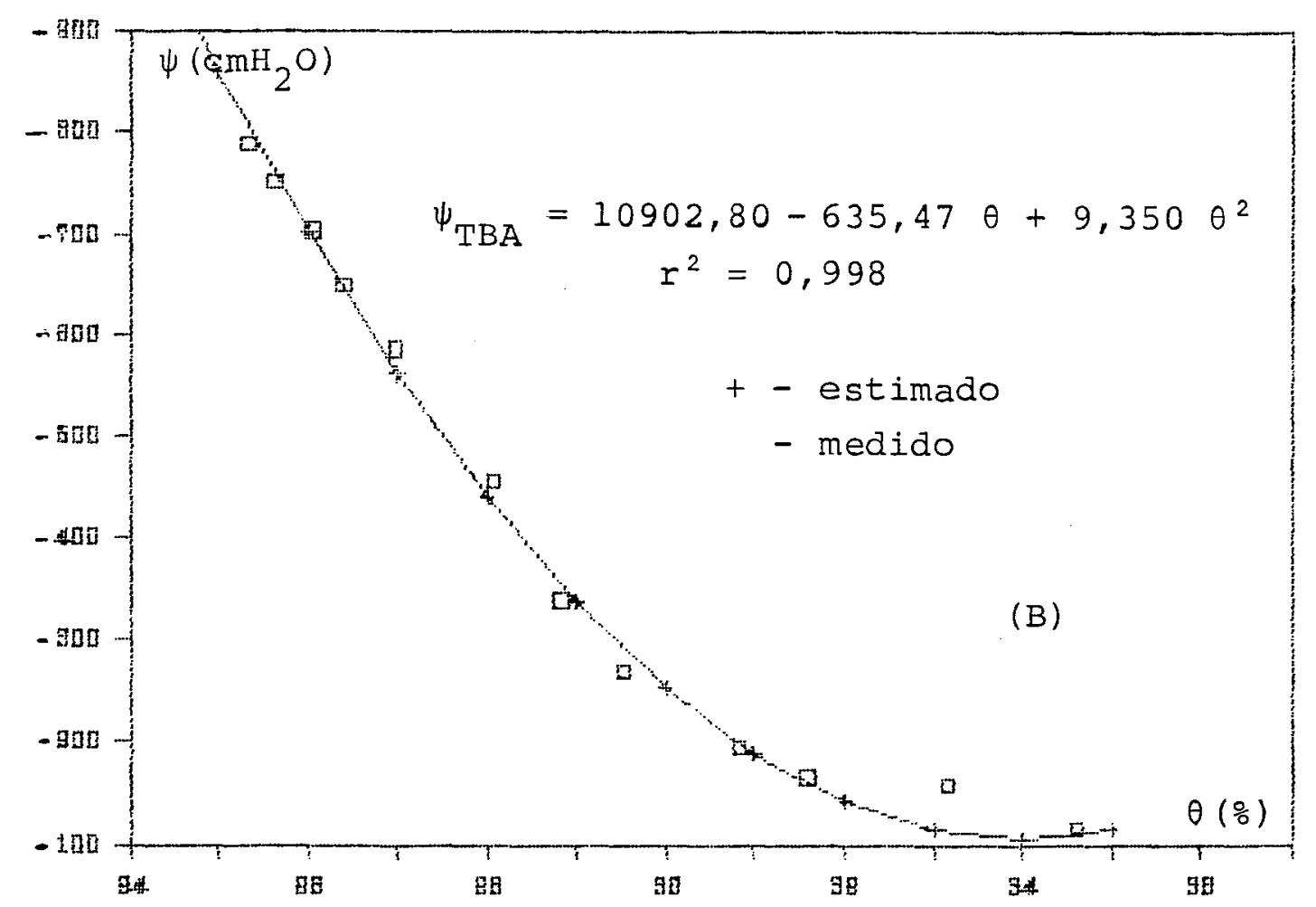

Fig. 4.3. Valores estimados e medidos de $\psi \mathrm{x} \theta$ Leitura das 16:00 hs (solo argiloso)

A - Tens. :onvencional ( $\left.\psi_{\mathrm{TC}}\right)$

B - Tens. bolha de ar ( $\psi_{\mathrm{TBA}}$ 
40.
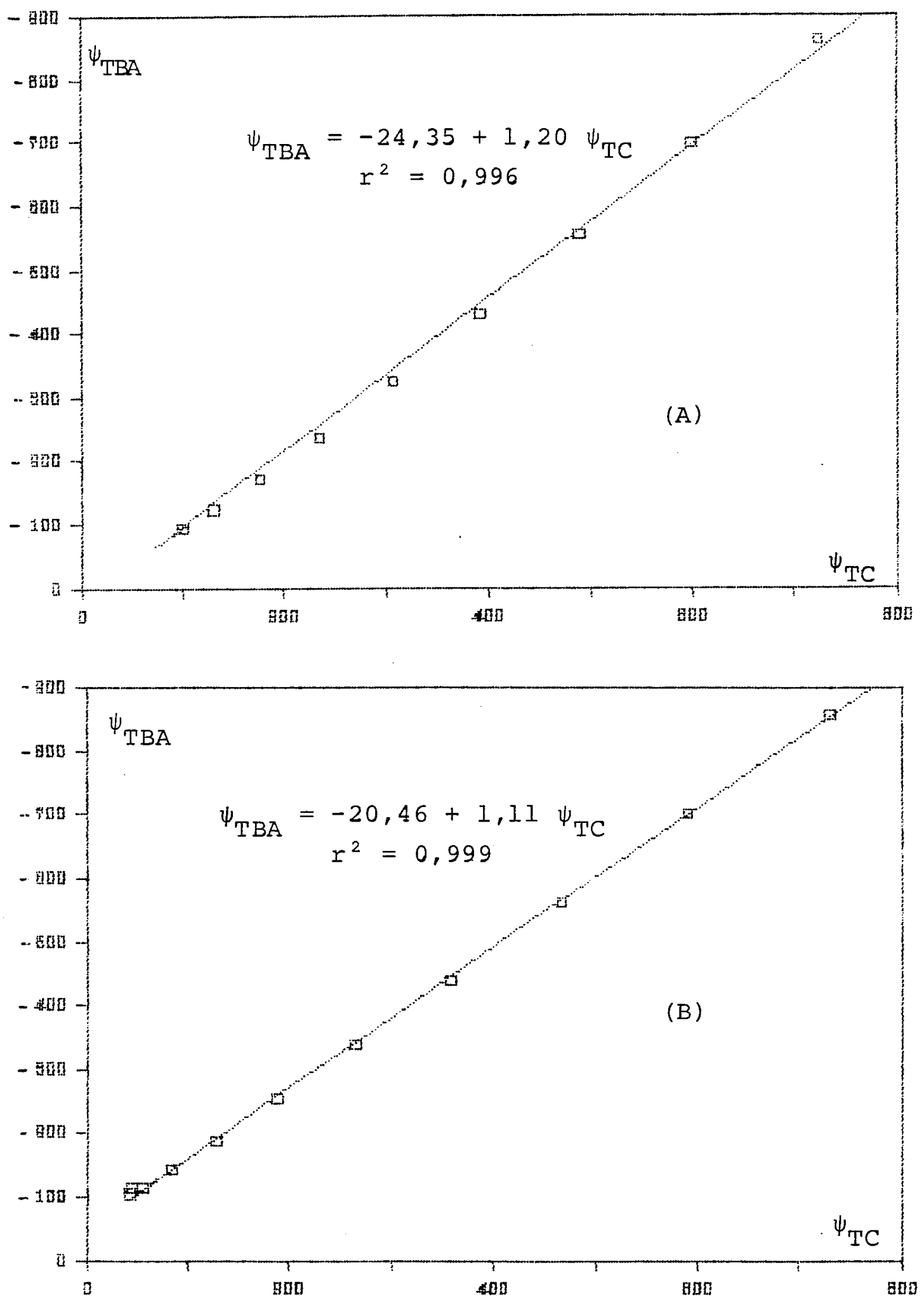

Fig. 4.4. Correção entre as estimativas ( $\left.\psi_{\mathrm{TBA}} \times \psi_{\mathrm{TC}}\right)$ A - Leituras das 9:00 hs (solo argiloso) B - Leituras das 16:00 hs 
a) horário das 9:00

$$
\begin{gathered}
\psi_{T B A}=-24,35+1,20 \psi_{T C} \\
r^{2}=0,996
\end{gathered}
$$

b) horário das 16:00

$$
\begin{gathered}
\psi_{\text {TBA }}=20,4 \theta+1,11 \psi_{\text {TC }} \\
r^{2}=0,999
\end{gathered}
$$

Os altos coeficientes de determinacão encontrados demonstram que existe uma boa associacão entre $\psi_{\text {TBA }}$ e $\psi_{\text {Tc }}$ No entanto os coeficientes $a e b$, diferentes da unidade indicam que para mesmos valores de $\Theta, \psi_{\text {TBA }}$ difere de $\psi_{\text {TC }}$ de uma fraç̃o significativa. Estas diferencas podem ser vistas na Figura 4.5, onde se representou as curvas de $\psi_{\text {TC }}$ e $\psi_{\text {TBA }}$ para valores simultâneos de $\Leftrightarrow$ Cequarónes de 4.1 a 4.4 . Para - mesmo valor de $\theta, \psi_{\text {TBA }}$ é sempre maior do que $\psi_{\text {TC' }}$ sugerindo que este comportamento é devido a existencia de um tempo de resposta diferenciado entre os dois tensiómetros. 


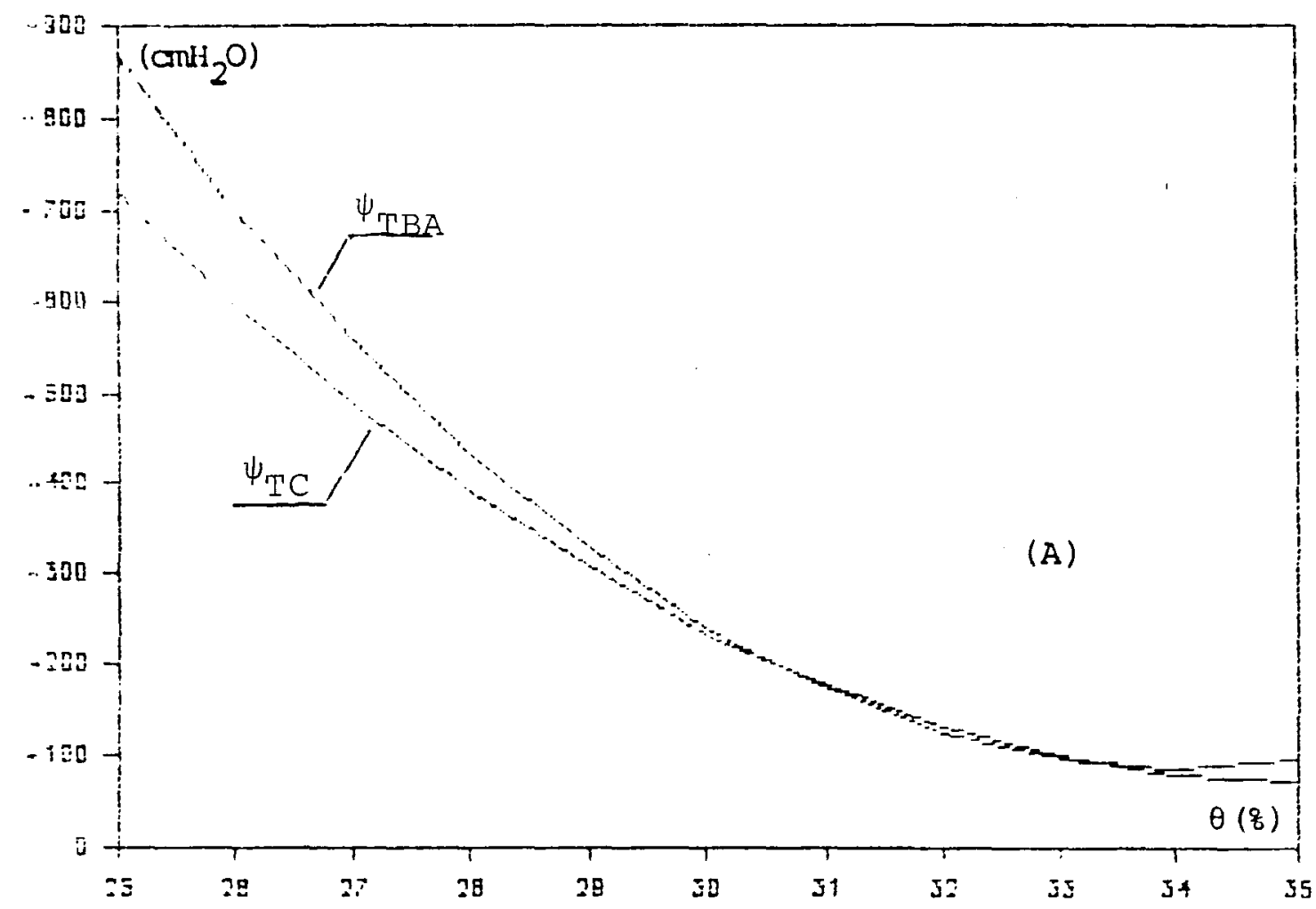

42.

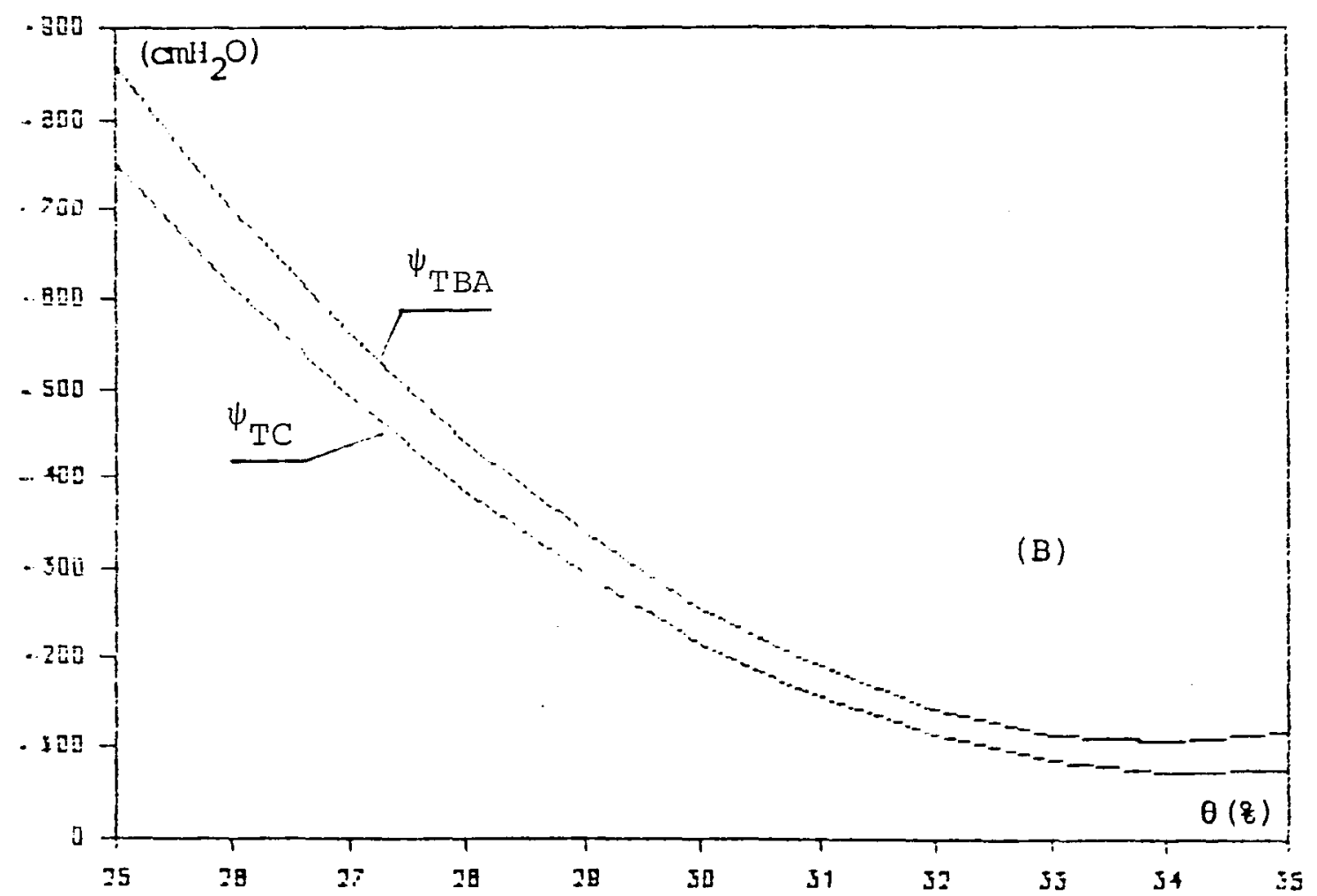

Fig. 4.5- Confronto gráfico entre as estimativas de $\psi_{\text {TBA }}$ e $\psi_{\text {TC }}$ (Solo argiloso)
A - Leituras das 9:00
B - Leituras das 16:00 
43.

\subsection{Erro Estimado no Tensiometro de Bolha de Ar Devido}

\section{a Diferencas de Temperatura}

A equação (4.6) estimava $\psi_{\text {BA }}$, se levarmos em conta as passiveis diferencas de temperatura do ar dentro da camara vazia do tensiometro, na hora do fechamento CD e na hora da leitura (T'):

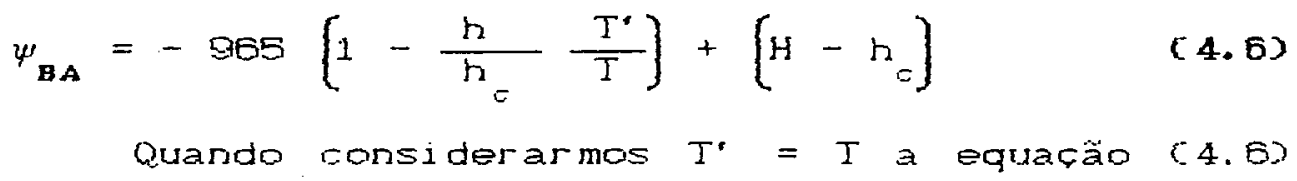

tornar-se-á:

$$
\begin{aligned}
& w_{B A}=-\operatorname{seg}\left[1-\frac{h}{h_{C}}\right]+\left[H-h_{C}\right] \\
& \begin{array}{l}
\text { Definindo-se un fator de correcăo cf } 2 \text { como, } \\
-\operatorname{seg}\left[1-\frac{h}{h_{c}} \frac{T^{\prime}}{T}\right]+\left[H-h_{c}\right]
\end{array} \\
& f_{C}=\frac{\psi_{T}}{\psi_{T}^{\prime}}=\frac{-\operatorname{ges}\left[1-\frac{h}{h_{C}} \frac{T^{\prime}}{T}\right]+\left[H-h_{C}\right]}{-\operatorname{ges}\left[1-\frac{h}{h_{C}}\right]+\left[H-h_{C}\right]}
\end{aligned}
$$

vemos que o mesmo depende do valor de $\psi$ Cexpresso for $h_{c}$ 'e do valor do quociente $T^{\prime} / T$. No Quadro 4.5 são demonstrados os valores de $f_{c}$ decorrentes para diferentes valores de $T^{\prime} / T$ - he, de acordo com a equacão (4.7). Assim por exemplo se fechassemos o tensiometro a temperatura $I=293^{\circ} \mathrm{K} 620^{\circ} \mathrm{C} \theta$ na hora da leitura a temperatura fosse $\mathrm{T}^{\prime}=304,7 \mathrm{Z}^{\circ} \mathrm{K}$ $631,72^{\circ} \circ$ p valor verdadeiro cvalor corrigidos, para $h_{e}=4$, seria:

$$
\psi_{\mathbf{T}}=f_{C} \times \psi_{T}=0,748 \times 115,25=86,3 \mathrm{~cm} \mathrm{H} \mathrm{O}
$$

ou seja, $74,8 \%$ do valor observado, assumindo-se $T, T$, ou seja considerando a forma da equacão $(4.7)$. 


\begin{tabular}{|c|c|c|c|c|c|c|}
\hline $\begin{array}{c}h \\
(\mathrm{~cm})\end{array}$ & $\mathrm{T} \cdot / \mathrm{T}$ & $\begin{array}{l}t^{\prime} \\
\left({ }^{O} C\right)\end{array}$ & $\left.{ }^{\mathrm{T}}{ }^{\mathrm{O}} \mathrm{C}\right)^{-\mathrm{T}}$ & $\begin{array}{c}\psi \mathrm{T}^{\prime} \\
\left(\mathrm{cmH}_{2} \mathrm{O}\right)\end{array}$ & $\begin{array}{l}\psi \mathrm{T}^{\prime}-\psi \mathrm{T} \\
\left(\mathrm{cmH}_{2} \mathrm{O}\right)\end{array}$ & $f_{C}=\frac{\psi T^{\prime}}{\psi T^{\prime}}$ \\
\hline $\begin{array}{l}3.8 \\
3.8 \\
3.8 \\
3.8 \\
3.8 \\
3.8\end{array}$ & $\begin{array}{l}1.00 \\
1.02 \\
1.04 \\
1.06 \\
1.08 \\
1.10\end{array}$ & $\begin{array}{l}20.00 \\
25.86 \\
31.72 \\
37.58 \\
43.44 \\
49.30\end{array}$ & $\begin{array}{r}0.00 \\
5.86 \\
11.72 \\
17.58 \\
23.44 \\
29.30\end{array}$ & $\begin{array}{l}-76.90 \\
-61.70 \\
-46.50 \\
-31.20 \\
-16.00 \\
-0.77\end{array}$ & $\begin{array}{r}0.00 \\
15.20 \\
30.40 \\
45.60 \\
66.20 \\
76.10\end{array}$ & $\begin{array}{l}1.000 \\
0.802 \\
0.605 \\
0.405 \\
0.208 \\
0.010\end{array}$ \\
\hline $\begin{array}{l}4.0 \\
4.0 \\
4.0 \\
4.0 \\
4.0 \\
4.0\end{array}$ & $\begin{array}{l}1.00 \\
1.02 \\
1.04 \\
1.06 \\
1.08 \\
1.10\end{array}$ & $\begin{array}{l}20.00 \\
25.86 \\
31.72 \\
37.58 \\
43.44 \\
49.30\end{array}$ & $\begin{array}{r}0.00 \\
5.86 \\
11.72 \\
17.58 \\
23.44 \\
29.30\end{array}$ & $\begin{array}{r}-115.30 \\
-100.80 \\
-86.30 \\
-71.80 \\
-57.40 \\
-42.90\end{array}$ & $\begin{array}{r}0.00 \\
14.50 \\
29.00 \\
43.50 \\
57.90 \\
72.40\end{array}$ & $\begin{array}{l}1.000 \\
0.874 \\
0.748 \\
0.622 \\
0.497 \\
0.372\end{array}$ \\
\hline $\begin{array}{l}5.0 \\
5.0 \\
5.0 \\
5.0 \\
5.0 \\
5.0\end{array}$ & $\begin{array}{l}1.00 \\
1.02 \\
1.04 \\
1.06 \\
1.08 \\
1.10\end{array}$ & $\begin{array}{l}20.00 \\
25.86 \\
31.72 \\
37.58 \\
43.44 \\
49.30\end{array}$ & $\begin{array}{r}0.00 \\
5.86 \\
11.72 \\
17.58 \\
23.44 \\
29.30\end{array}$ & $\begin{array}{l}-261.00 \\
-249.40 \\
-237.80 \\
-226.30 \\
-214.70 \\
-203.10\end{array}$ & $\begin{array}{r}0.00 \\
11.60 \\
23.20 \\
34.70 \\
46.30 \\
57.90\end{array}$ & $\begin{array}{l}1.000 \\
0.955 \\
0.911 \\
0.867 \\
0.822 \\
0.778\end{array}$ \\
\hline $\begin{array}{l}6.0 \\
6.0 \\
6.0 \\
6.0 \\
6.0 \\
6.0\end{array}$ & $\begin{array}{l}1.00 \\
1.02 \\
1.04 \\
1.06 \\
1.08 \\
1.10\end{array}$ & $\begin{array}{l}20.00 \\
25.86 \\
31.72 \\
37.58 \\
43.44 \\
49.30\end{array}$ & $\begin{array}{r}0.00 \\
5.86 \\
11.72 \\
17.58 \\
23.44 \\
29.30\end{array}$ & $\begin{array}{l}-358.50 \\
-348.80 \\
-339.20 \\
-329.50 \\
-319.90 \\
-310.20\end{array}$ & $\begin{array}{r}0.00 \\
9.70 \\
19.30 \\
29.00 \\
38.60 \\
48.30\end{array}$ & $\begin{array}{l}1.000 \\
0.973 \\
0.946 \\
0.919 \\
0.917 \\
0.865\end{array}$ \\
\hline $\begin{array}{l}7.0 \\
7.0 \\
7.0 \\
7.0 \\
7.0 \\
7.0\end{array}$ & $\begin{array}{l}1.00 \\
1.02 \\
1.04 \\
1.06 \\
1.08 \\
1.10\end{array}$ & $\begin{array}{l}20.00 \\
25.86 \\
31.72 \\
37.58 \\
43.44 \\
49.30\end{array}$ & $\begin{array}{r}0.00 \\
5.86 \\
11.72 \\
17.58 \\
23.44 \\
29.30\end{array}$ & $\begin{array}{l}-428.40 \\
-420.60 \\
-411.90 \\
-403.60 \\
-395.30 \\
-387.10\end{array}$ & $\begin{array}{r}0.00 \\
7.80 \\
16.50 \\
24.80 \\
33.10 \\
41.30\end{array}$ & $\begin{array}{l}1.000 \\
0.982 \\
0.961 \\
0.942 \\
0.922 \\
0.903\end{array}$ \\
\hline $\begin{array}{l}8.0 \\
8.0 \\
8.0 \\
8.0 \\
8.0 \\
8.0\end{array}$ & $\begin{array}{l}1.00 \\
1.02 \\
1.04 \\
1.06 \\
1.08 \\
1.10\end{array}$ & $\begin{array}{l}20.00 \\
25.86 \\
31.72 \\
37.58 \\
43.44 \\
49.30\end{array}$ & $\begin{array}{r}0.00 \\
5.86 \\
11.72 \\
17.58 \\
23.44 \\
29.30\end{array}$ & $\begin{array}{l}-481.10 \\
-473.90 \\
-466.70 \\
-459.40 \\
-452.20 \\
-444.90\end{array}$ & $\begin{array}{r}0.00 \\
7.20 \\
14.40 \\
21.70 \\
28.90 \\
36.20\end{array}$ & $\begin{array}{l}1.000 \\
0.985 \\
0.970 \\
0.954 \\
0.939 \\
0.925\end{array}$ \\
\hline
\end{tabular}

Quadro 4.5 - Fatores de correção (fa) devido a diferenças de temperatura no fechamento (T) e na hora da leitura $\left(T^{\prime}\right),\left(T^{\prime} / T \neq I\right)$ e $\left(T=293^{\circ} \mathrm{K}, \mathrm{h}=3,0 \mathrm{~cm}\right)$. 
Na Figura 4.6 são demonstrados graficamente os dados do Quadro 4.5 que mostram claramente que a bai xas 1 eituras de $\psi$ (pequenos valores de $h_{c}$ o erro cometido nas leituras do tensiometro de bolna de ar pode ser muito grande. Em funcăo disto neste trabalho nas comparacöes praticamente eliminamos as leituras de potencial menor que $100 \mathrm{~cm}$ $\mathrm{H}_{2}$. Pela Figura 4.6 nota-se ainda que para valores de potencial de $385,5 \mathrm{~cm} \mathrm{H}_{2}$ o estes erros são já bastante minimizados Cfator de correcão > 0,9〉. Estas verificacões são importantes, pois a possivel insercano de termómetros no forpo dos tensiómetros causariam a perda de rusticidade desejada na sua canstrucăo. Isto mastra também que o corpo do tensiömetro năo deve ficar diretamente exposto ao sol caso em que as temperaturas da camara poderiam atingir até $40^{\circ} \mathrm{C}$ ou mais ocasionando erros de montas. Todavia para minimizar estes erros recomenda-se estimar as temperaturas do ar a sombra na hora da leitura para se obter a razão $T^{\prime} / T$, que nos permitirá calcular o fator de correcăo fic.

\subsection{Relações de Dependência Entre $\psi$ e $\theta$ (Solo Arenoso)}

Da mesma maneira que para o solo argiloso, e pelos mesmos motivos procurou-se para o solo arenoso a funrão que melhor se ajustasse aos dados simul tâneos de $\bar{\psi}_{\mathbf{T}} \times \bar{\theta}$ $\ominus \bar{\psi}_{\mathbf{T B A}} \times \bar{\Theta}$

os resultados obtidos foram os seguintes: Cvide Quadros $A-10, A-11, A-12$ e $A-13$ do Apéndice. 
46.

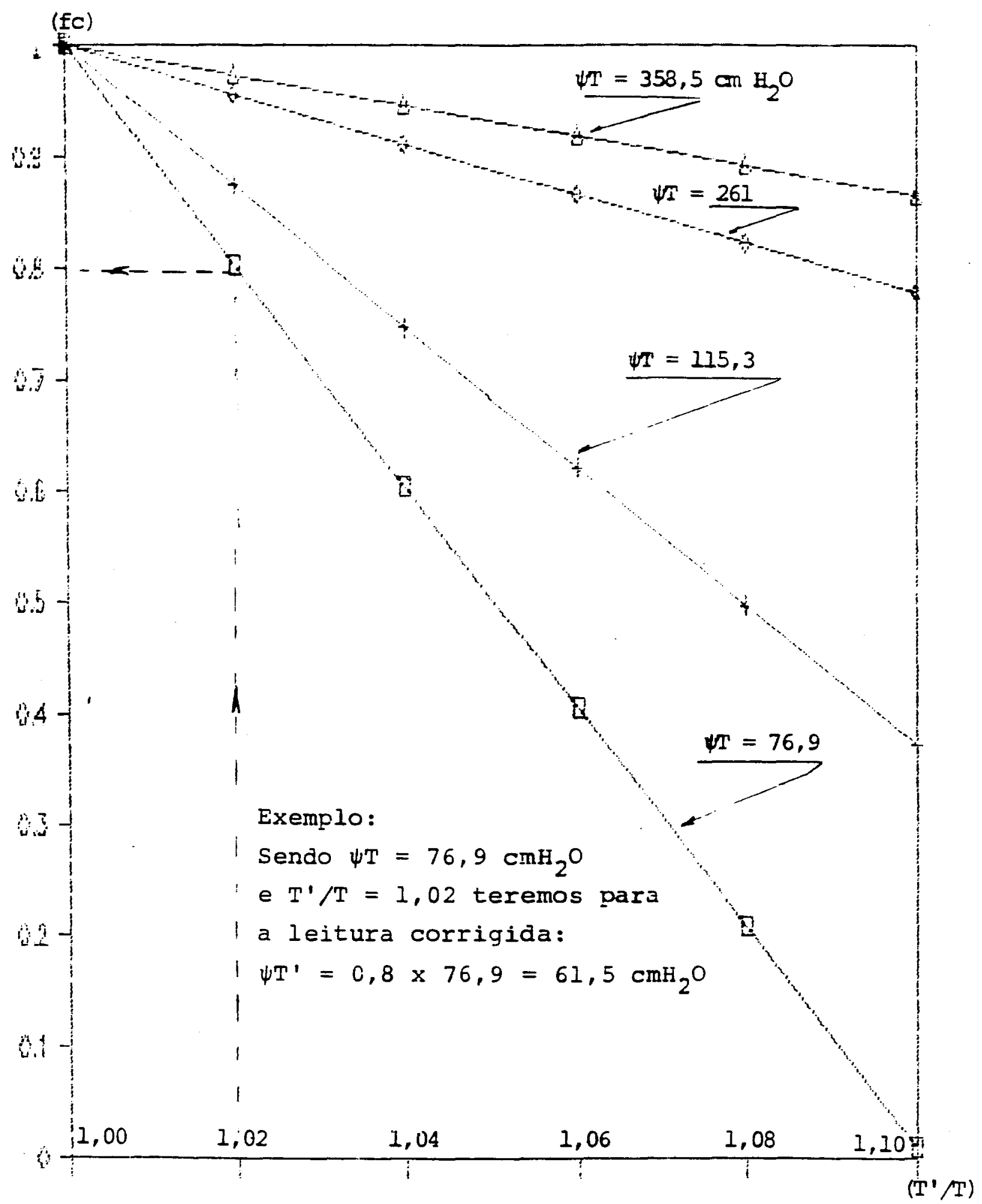

Fig. 4.6 - Fatores de correção da leitura $\psi_{\perp}^{\pi}$ devido a diferenças de temperatura na hora do fechamento (T) e na hora da leitura ( $T^{\prime}$ ) $\left(T^{\prime} / T \neq 1\right)$. 


\subsubsection{Leituras das 9:00}

$$
\begin{gathered}
\psi_{\text {TC }}=-8363,64 \theta^{-1,87} \\
r^{2}=0,983 \\
\psi_{\text {TBA }}=-7939,78 e^{-1,95} \\
r^{2}=0,928
\end{gathered}
$$

4.6.2. Leituras das 16:00

$$
\begin{gathered}
\psi_{\mathrm{TC}}=-9668,16 e^{-1,95} \\
\Gamma^{2}=0,975 \\
\psi_{\mathbf{T A A}}=-7859,16 \theta^{-1,88} \\
r^{2}=0,984
\end{gathered}
$$

Embora possamos considerar razoável o ajuste destas equacões, pela disfersão dos pontos demonstradas nas Figuras 4.7 e 4.8 as resultados foram inferiores ao do solo argiloso. Atribui-se este fato ao elevado teor da fracão areia, combinado com a pouca profundidade de instalação da cápsula. A exagerada macroporosidade parece, principalmente nos baixos teores de umidade, ter permitido que as variaçóes de umidade relativa do ar interteressem no ar do solo, causando esta variabilidade. 
48.
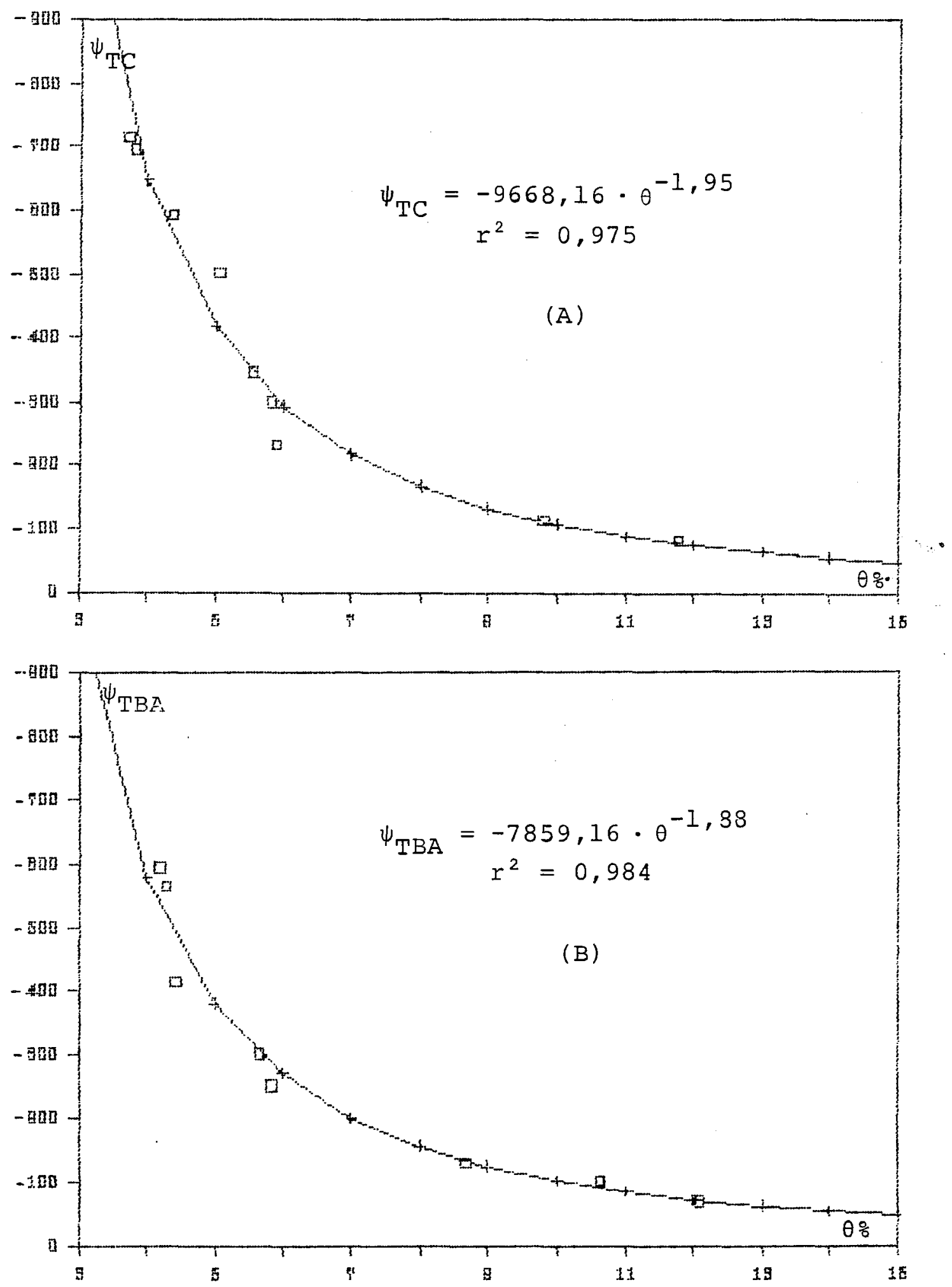

Fig. 4.7. Valores estimados e medidos de $\psi \times x$ Leitura das 16:00 horas (solo arenoso)

A - Tensiômetro convencional ( $\left.\psi_{\mathrm{TC}}\right)$ B - Tensiômetro de bolha de ar ( $\psi_{\mathrm{TBA}}$ ) 


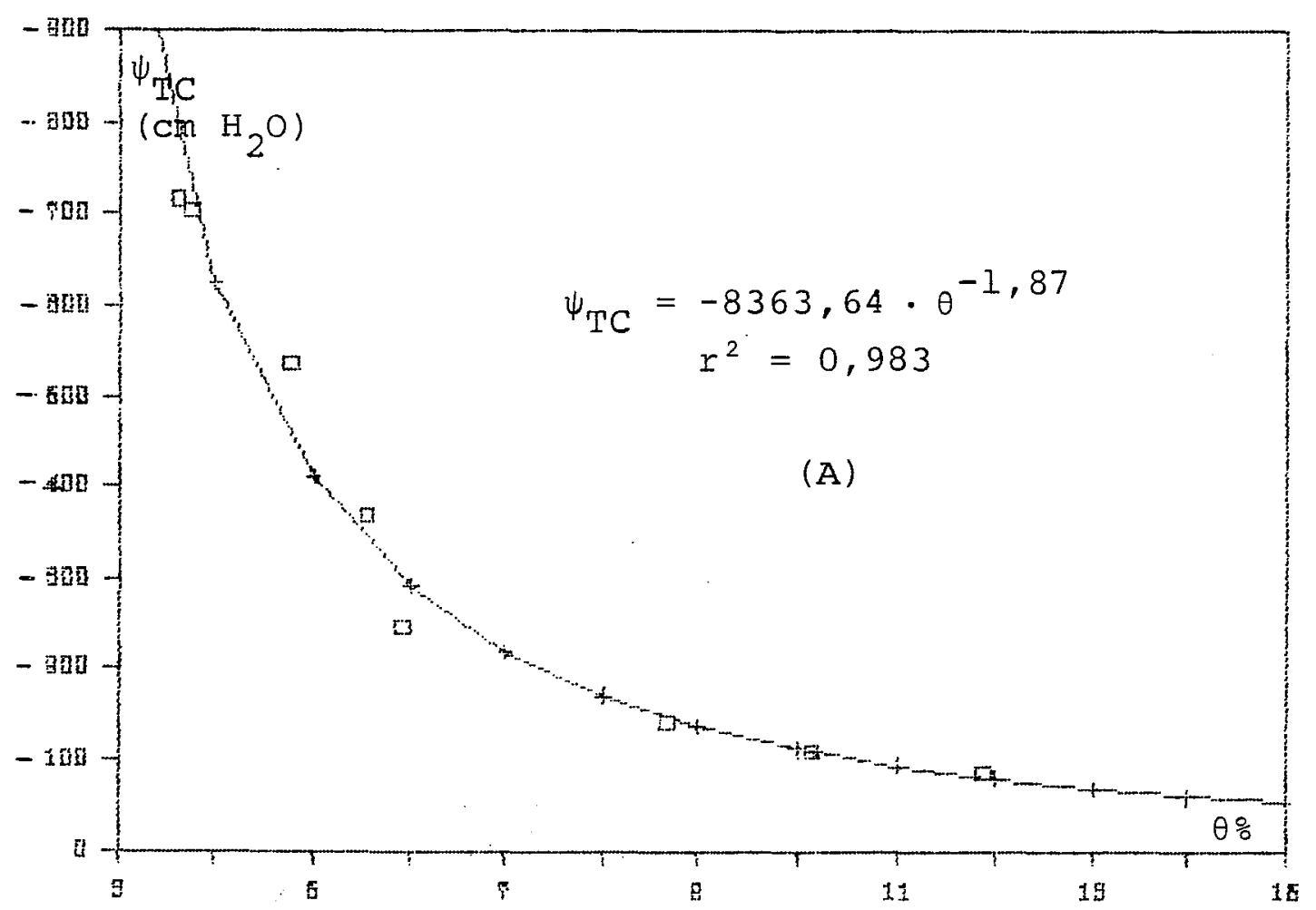

49.

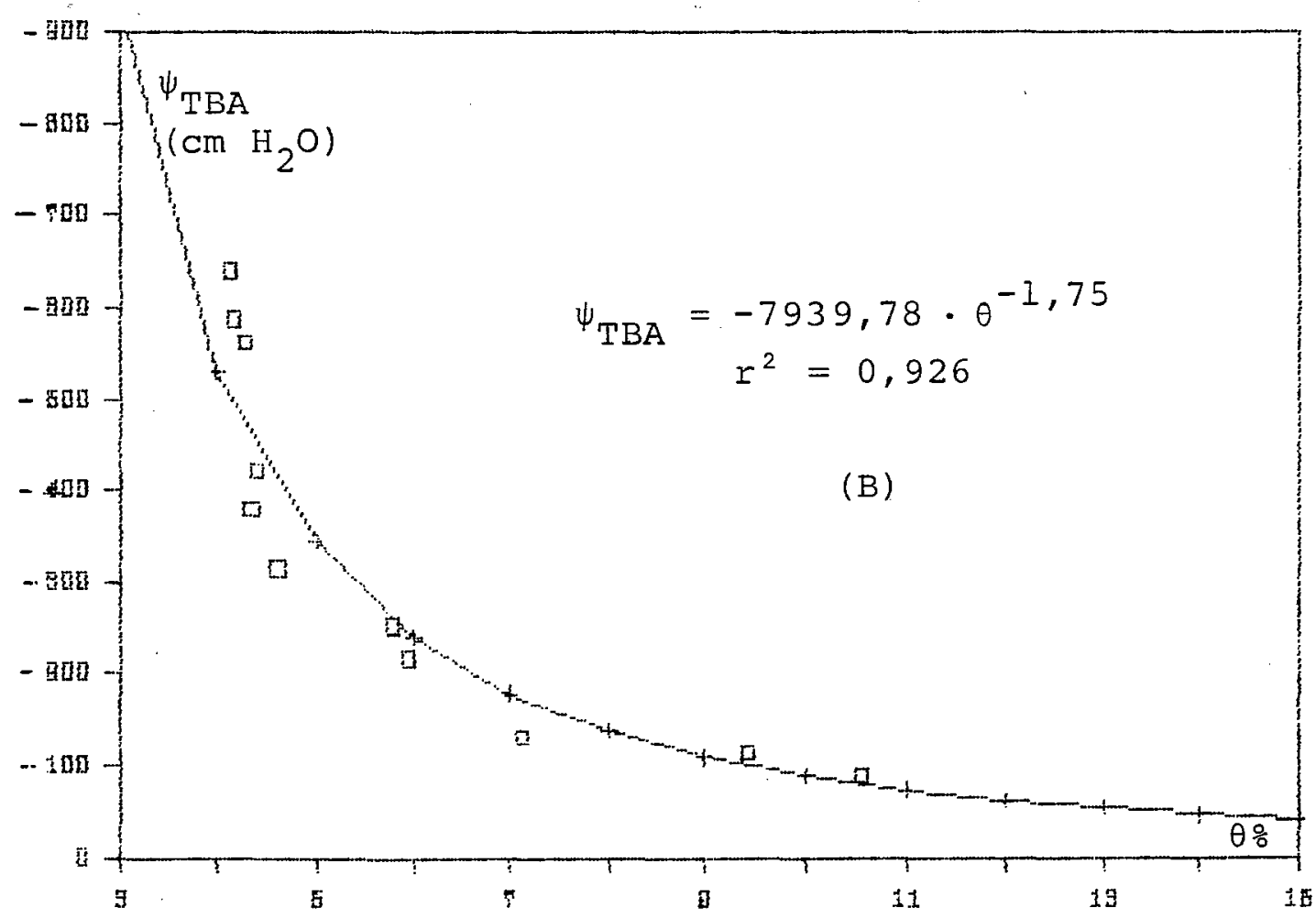

Fig. 4.8. Valores estimados (+) e medidos ( ) de $\psi \mathrm{x} \theta$ Leitura das 9:00 horas (solo arenoso)
A - Tensiômetro convencional ( $\psi_{\mathrm{TC}}$ )
B - Tensiōmetro de bolha de ar $\left(\psi_{\mathrm{TBA}}\right)$ 


\subsection{Comparacốes $\psi_{\text {THA }} \times \psi_{\text {TC }}$ (Solo Arenoso)}

Através das equacóes (4.8), (4.9), (4.10)

(4.11) foi nos possivel de maneira similar ao solo argiloso realizar as comparacốes e $\psi_{\text {TBA }} \odot \psi_{\text {TC }}$ para valores simultâneos de $\theta$. Na Figura 4.9 demonstram-se as equacốes de regressão Cride Quadros A-14 e A-15 do Apendice e o alinhamento dos pontos $\psi_{\text {TBa }} \times \psi_{\text {TC }}$ para os dois horários de leitura 6:00 $016: 00)$

os coeficientes de determinacão encontrados demonstram como no solo argiloso uma boa correlarăo entre as duas estimativas. As diferencas detectadas principalmente em valores mais elevados podem ser ao tempo de resposta diferenciado, cuja causa provável identificada de maneira analoga ao solo argiloso quando se comparam $\psi_{\text {TBA }}$ e $\psi_{\text {TC }}$ contra valores simultâneos de $\theta$ como é demonstrado na figura 4.10 .

\section{8. Tempo de Resposta}

De acordo com as comparacóos de $\psi_{\mathbf{T B A}} \in \psi_{\text {TC }}$ fara valores simultâneos de $\Theta(v i d e$ Figura 4.5 ) observamos que para um mesmo valor de $\theta$, o valor de $\psi_{\text {TBA }}$ é sempre maior, esta diferenca sendo mínima para altos valores de $\Theta$, aumentando a medida que $\theta$ diminui (potenciais mais elevados. Tais diferencas, poderiam ter a seguinte origem:

a) Erros de leitura devido a situacão na qual $T^{*} T \neq 1$. Tal hipótese não é viável, posto que estes erros se 
51.

minimizam a valores altos de potencial (vide Quadro 4.1), situacão na qual as diferencas de tempo de resposta se maximizam.

b) Erros devido a tempo diferenciado de resposta, hipótese que nos parece viável. Nas figuras 4.11 e 4.12 são demonstradas as curvas representativas da variacão de $\psi_{L D} e \psi_{C}$ em funcão do tempo de secamento. As equacães que estimam $\psi=f(t)$ (vide análise estatistica Quadros de A-B a A-9 do Apendices nos mostram que as diferencas são diretamente proporcionais aos valores de $t$ cou inversamente aos de $\theta$. Uma explicacão plausivel deste comportamento seria a da formação de um bulbo úmido permanente em volta da cápsula do TBA, fato que não ocorre no TC. Este bulbo devido ao maior volume de água que o IBA tem que liberar para entrar em equilibrio, materia melhor a "ligacão" cápsula água do solo, fato que răo ocorreria ná cápsula do IC que debita baixissimos volumes para modificar seu equilibrio de pressöes. O bulbo úmido não teria importância em situacăo de alta umidade do solo, mas ao longo do tempo de secagem estas diferencas tenderiam a aumentar, devido a manutencăo do bulbo úmido no TBA.

Embora possa se reconhecer que mais repeticões identificaram melhor o problema note-se que as Figuras 4.11 - 4.12 mostram a tendencia sistemática dos valores de $\psi_{\mathbf{B A}}$ serem sempre maiores que os de $\psi_{\mathrm{C}}$. 


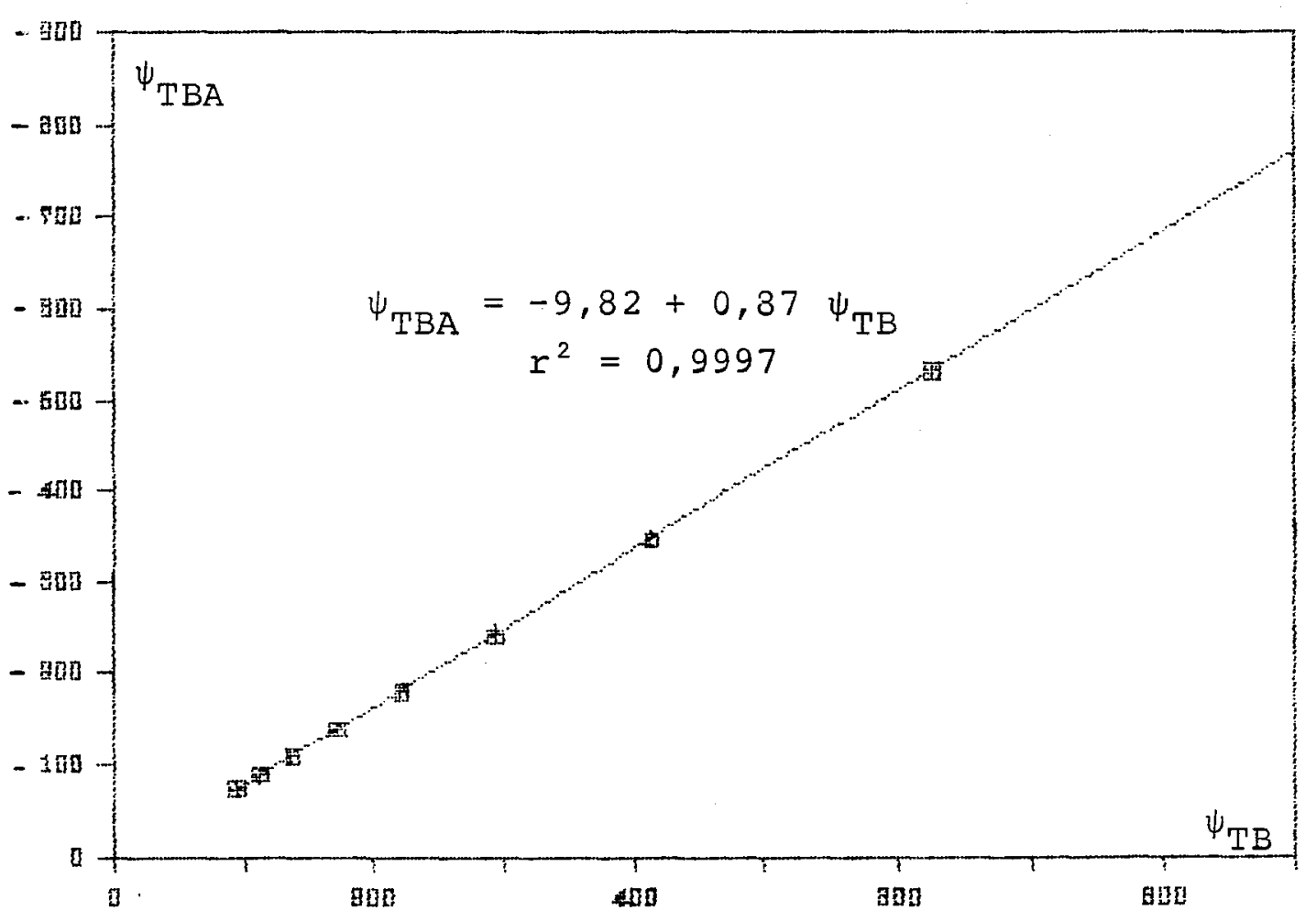

52.

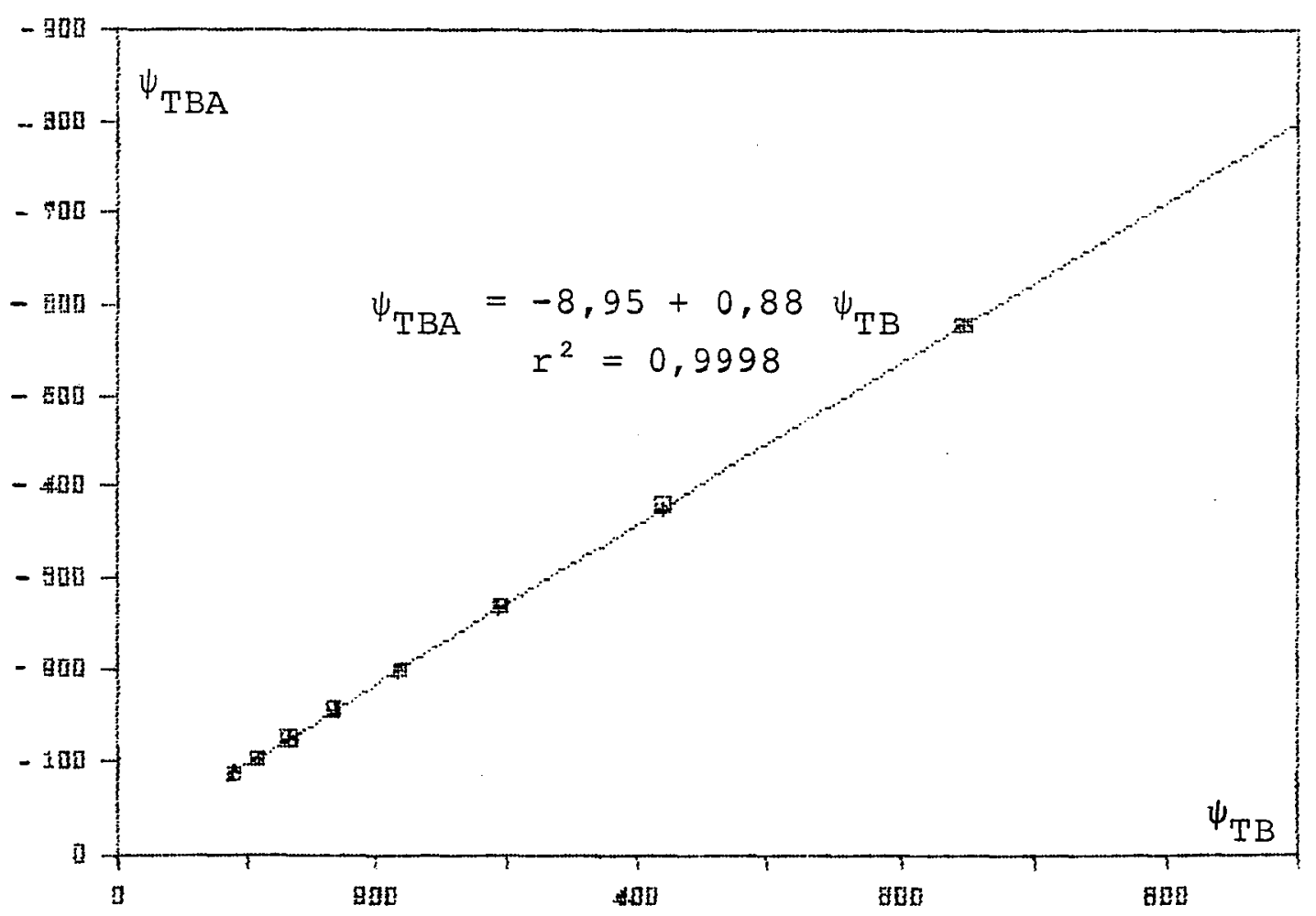

Fig. 4.9. Correlação entre as estimativas ( $\psi_{\mathrm{TBA}} \times \psi_{\mathrm{TC}}$ ) (solo arenoso)
A - Leitura das 9:00 horas
B - Leitura das 16:00 horas 
53.

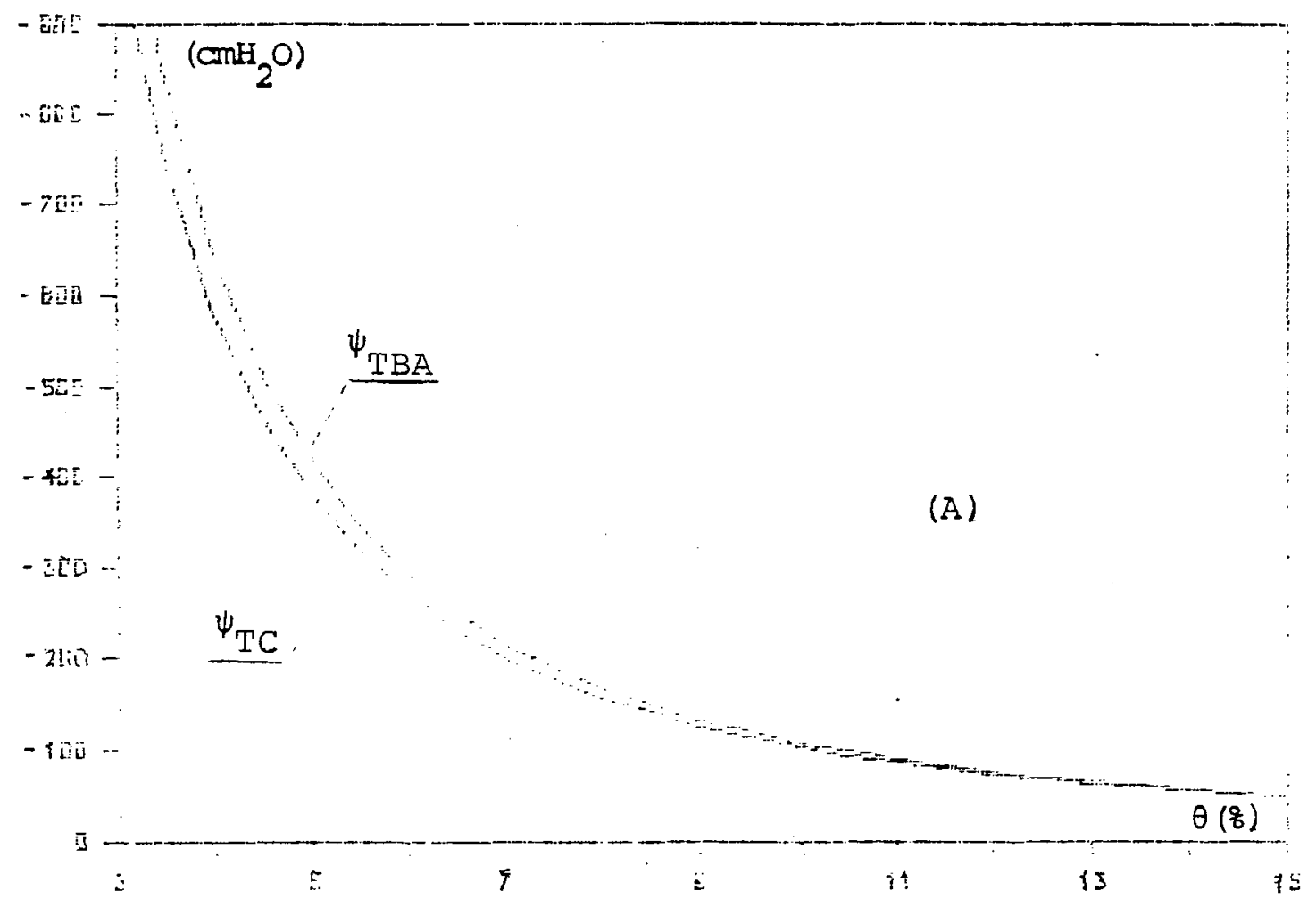

Fig. 4.10. Confronto gräfico entre as estimativas de $\psi_{\mathrm{T} B A}$ e $\psi_{\mathrm{T} C}$ (solo arenoso)

A - leitura das 9:00

B - leitura das $16: 00$

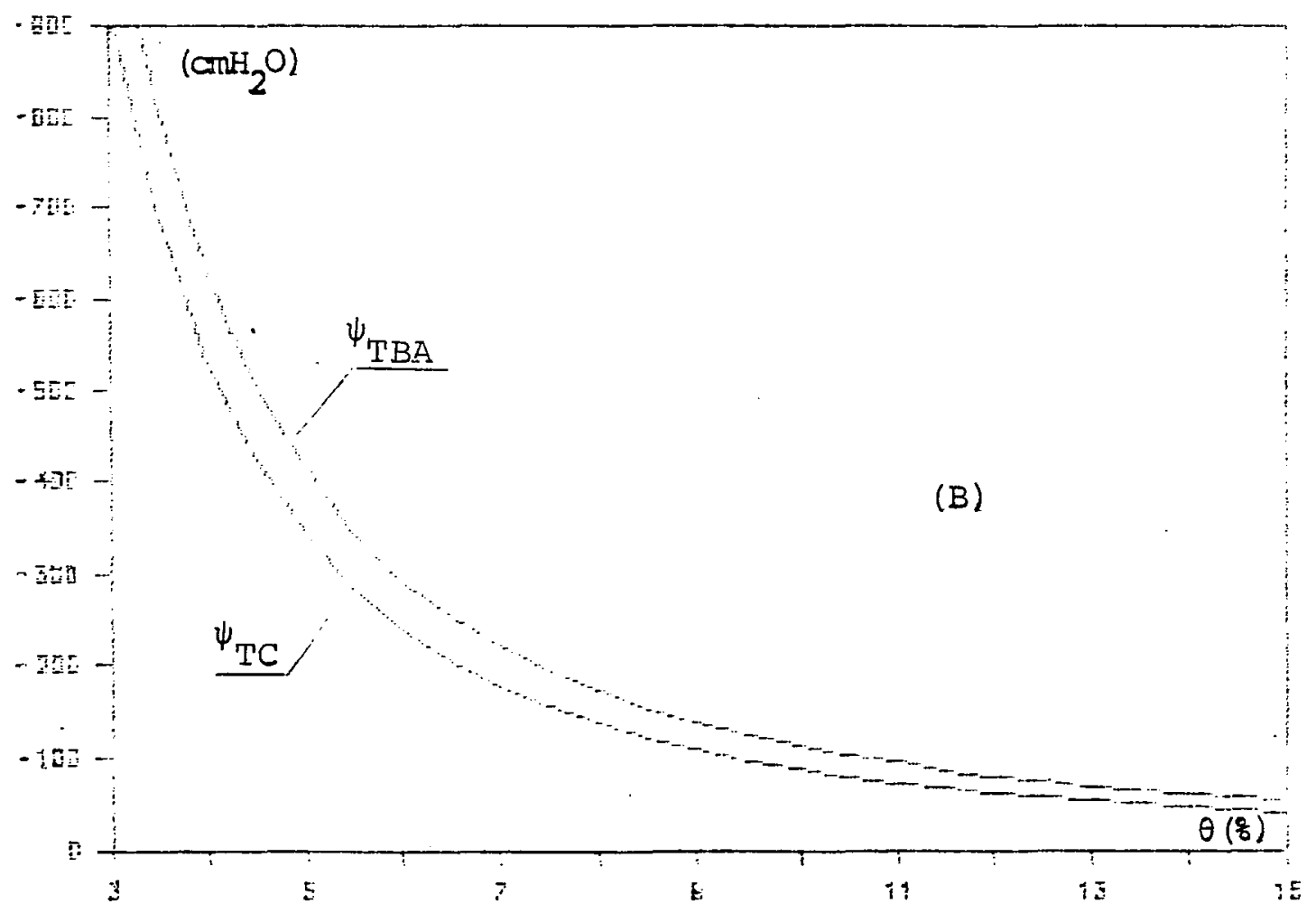


54.

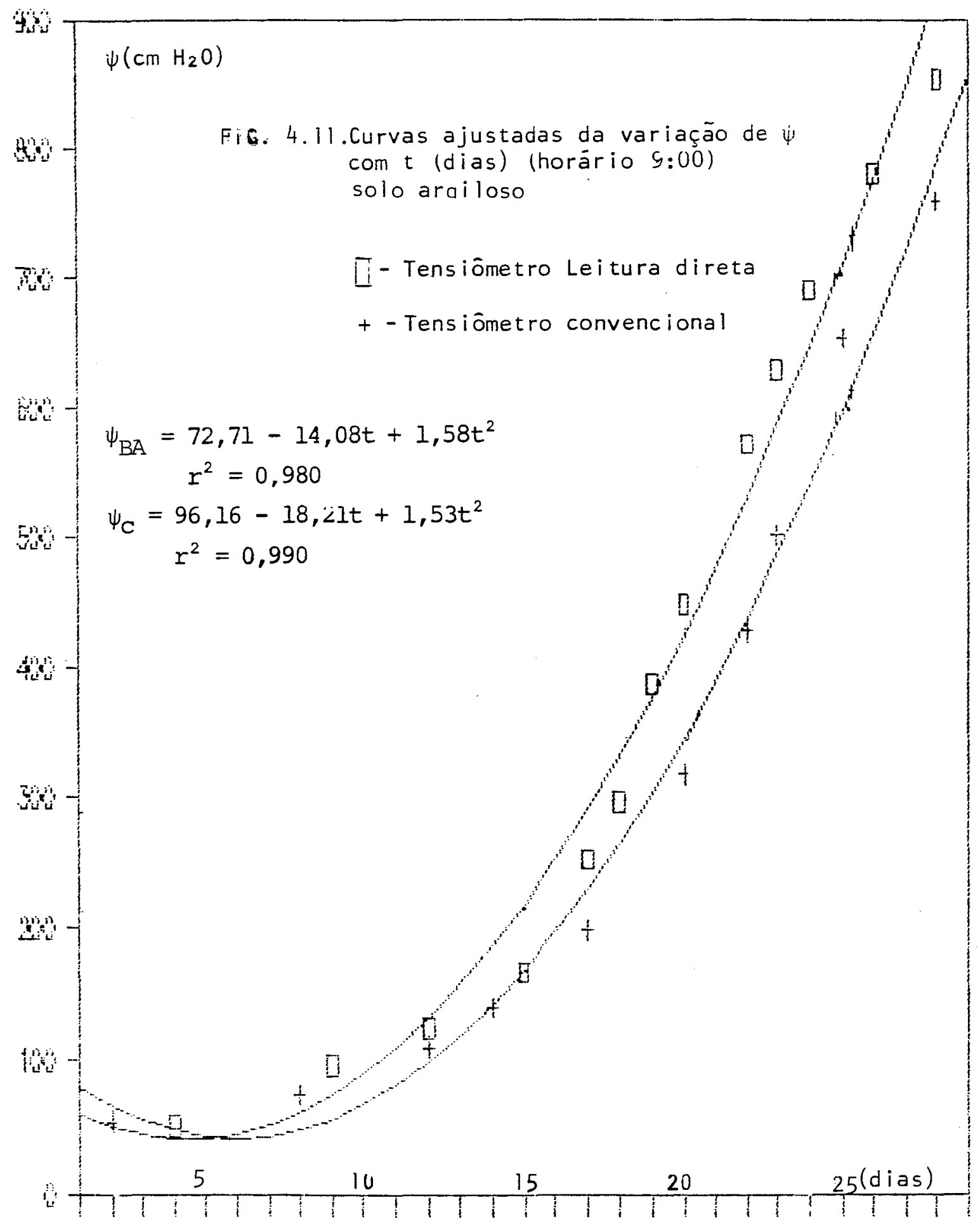

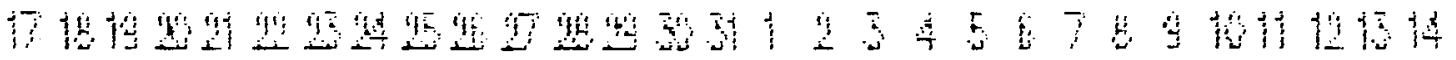


55.

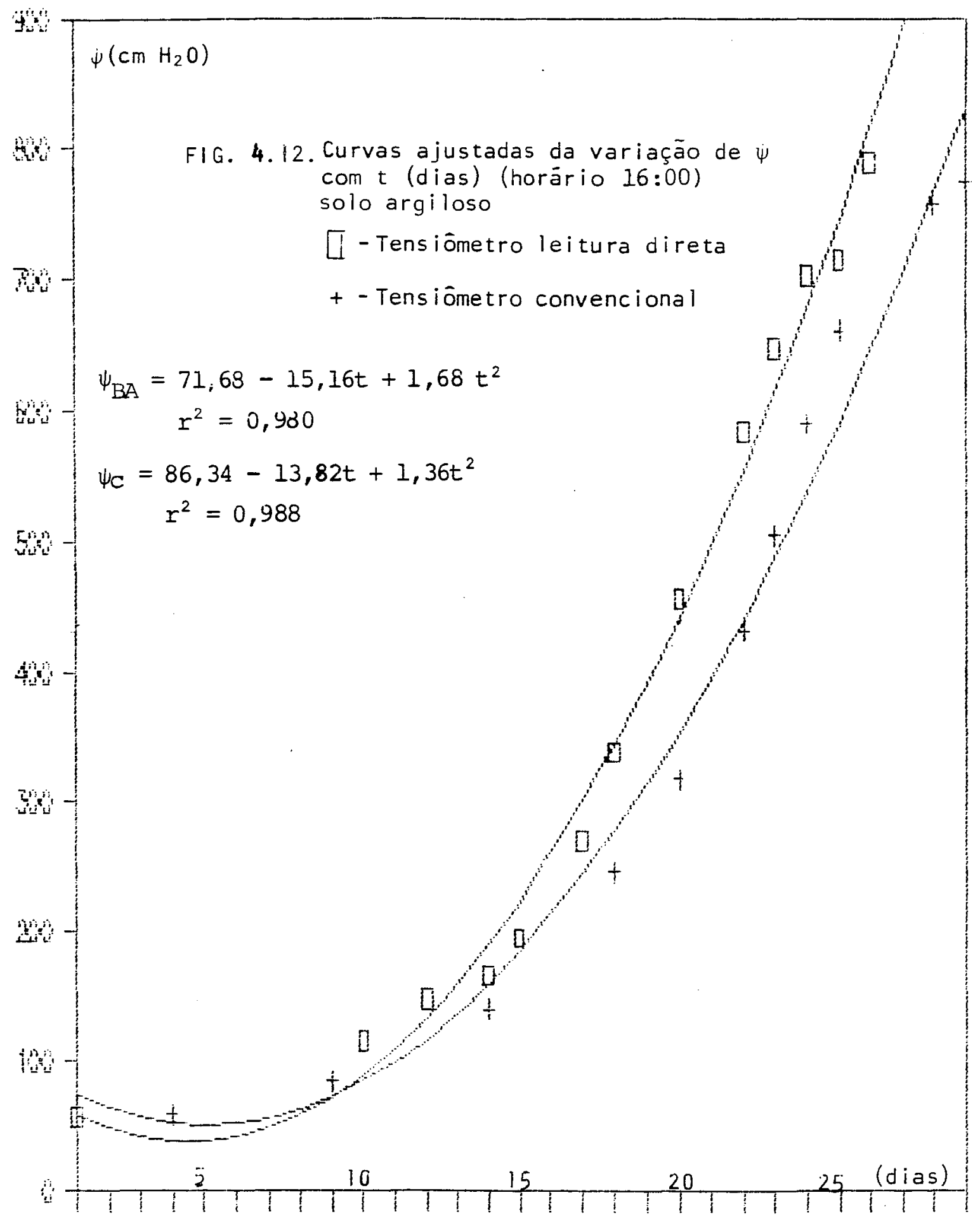

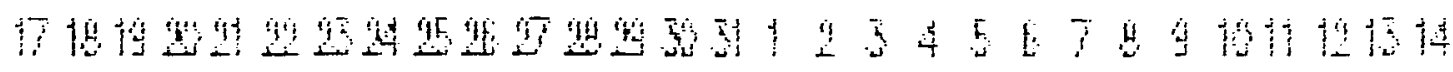


56.

Dispensado-se cálculos araliticos, vê-se pelas

Figuras 4.11 e 4.12 , que a diferenca entre os tempos de resposta variou entre zero e 1,8 dias. Se confirmada esta ordem de grandeza, com experimentacão posterior, deveriamos rever - processo de monitoracão de irrigacão via tensiómetro convencional que se pratica ra atualidade.

\subsection{Generalidades}

o presente trabal ho de comparação entre o tensiometro convencional e o de bolha de ar foi iniciado instalando-se o conjunto de tensiometros em um container de $2,5 \times$ $1,0 \times 1,0 \mathrm{~m}$ de prof undidade. O sistema não se mostrou viável devido aos seguintes problemas.

a) Redistribui cão irregular da umidade ao longo do solo;

b) Excessivas amostras que deformavam o perfil de solo;

c) Impossibilidade de definir para o perfil uma umidade média consistente.

Em face a estas dificuldades optou-se pelo sistema de vasos individuais, que permitiram a avaliarão da umidade com razoável precisão através de simples pesagens. Optou-se pela condicão de laboratório porque a maior veloci- 
57.

dade de secamento que se teria ao ar livre, não melhoraria as comparações.

Numa segunda fase deste trabalho pretende-se fazer as comparaç̆es em condicões de campo. 
58.

\section{CONCLUSÖES}

Em face aos resultados obtidos, para as condiCões do experimento pode-se afirmar que:

O tensiometro de bolha de ar, na geometria de construcão projetada, mostrou-se viável praticamente pelos seguintes aspectos.

a) É de construcão bem simples e de custo mais baixo que o convencional e é não polvente.

b) Fornece medidas do potencial matricial da água do so10 que apresentam correlacões significativas com aquelas realizadas pelo tensiómetro convencional para o intervalo de 100 a $800 \mathrm{~cm} . c . a$.

c) Não necessita de calibraçóes descle que se observem as condições locais de pressão atmosférica.

d) Possui um tempo de resposta mais rápido que o tensiómetro convencional para tensões compreendidas entre 300 e $900 \mathrm{~cm}$. c.a. e que é a faixa de maior interesse agronômico, principalmente em solos argilosos. 
59.

e) Não deve ser utilizado para medida acima de -200 cm.c.a. a não ser que se facam correcöes de temperatura. Para potenciais ahaixo de $-400 \mathrm{~cm} . c . a$. o fator de correcão é negligivel e pode ser minimizado por estimativas das diferencas de temperatura da câmara, entre a condicão inicial e a da hora de leitura.

f) Comportou-se comparativamente melhor em condicôes de solo argiloso do que arenoso, talvez devido a variacöes mais bruscas de umidade no solo arenoso que no argiloso devido às condicóes de irstalacăo das cápsulas a pouca prof undidade. 


\section{B. REFERËNCI AS BI BLI OGRÁFICAS}

ABELE, G.; MCKIM, H.L.; BROCKETIE, B. Mass water halance during spray irrigation with waste at Deer Greek Lake and treatment site. Rep. 79-29, U.S. Army Corps of Eng., Hannover, N.H., 1979.

GARDNER, w.; ISRAELSEN, O.W.; EDLEFSEN, N.E.; CONRAD, H. The Cappilary potential function and its relation to irrigation practice. Phys. Rev., Ser. 2, 20, $196,1922$.

HILLEL, D. Soil and water: physical principles and processes. Academic Press, New York, p. 73-77, 1971.

KLUTE, A. \& GARDNER, W.R. Tensiometer response time. Soil Sci., 93: 204-207, 1962.

LIBARDI, P.L. Dinâmica da água no sistema solo-plantaatmosfera. Piracicaba, CENA USP, 1984. 232 p.

OLITIA, A.F.L. Construcão de tensiómetros para controle de irrigacão. IV Congresso de Engenharia Agricola, SBEA, Viçosa, MG, 1974 .

PAES DE CAMARGO, A.; GROHMANN, F.; PAES DE CAMARGO, M. B. Tensiometro simples de leitura direta. Pesq. agropec. bras., 17(12): 1763-1772, 1982 .

REICHARDT, $K$. Processos de transferência no sistema solo-planta-atmosfera. Campinas, Fundacão Cargil1, 1975. 286p. 
RICHARDS, L. A. Methods of measuring soil moisture tension. Sail Sci., 68: 95-112, 1949 .

RICHARDS, L.A. \& GARDNER, W. Tensiometers for measuring the capillary tension of soil water. J. Amer. Soc. Agron., 28: $352-358,1936$.

RICHARDS, L. A. \& ONEAL, R. Some field observations with tensiometeres. Proc. Soil Sci. Am., 1: 71-91, 1937.

ROSE, C. W. Agricultural physics. Oxford, Pergamon Press, 1966. $230 \mathrm{p}$.

SCHMUGGE, I.J.; JACKSON, T.J.; MCKIM, H.L. Survey of methods for soil moisture determination. Water Resour. Res., 16: $1961-979,1980$.

TAYLOR, S.A. \& ASHCROFT, G.L. Physical edaphology: the physics of irrigated and non-irrigated soils. W.H. Freeman \& Co., U.S.A., F. 2S6-26Z, 1972.

TOHER, G.D. Theary of time response of tensiomet.ers. J. Soil Sxi., 31: 807-621, 1980.

VILLA NOVA, N.A.; REICHARDT, K.; LIBARDI, P.L. B MORAES, S.O. Direct reading "airpocket tensiometer". Soil Techonology, Cremlingen, 2: 403-407, 1989. 
COEFICIENTES DA EQUACAO

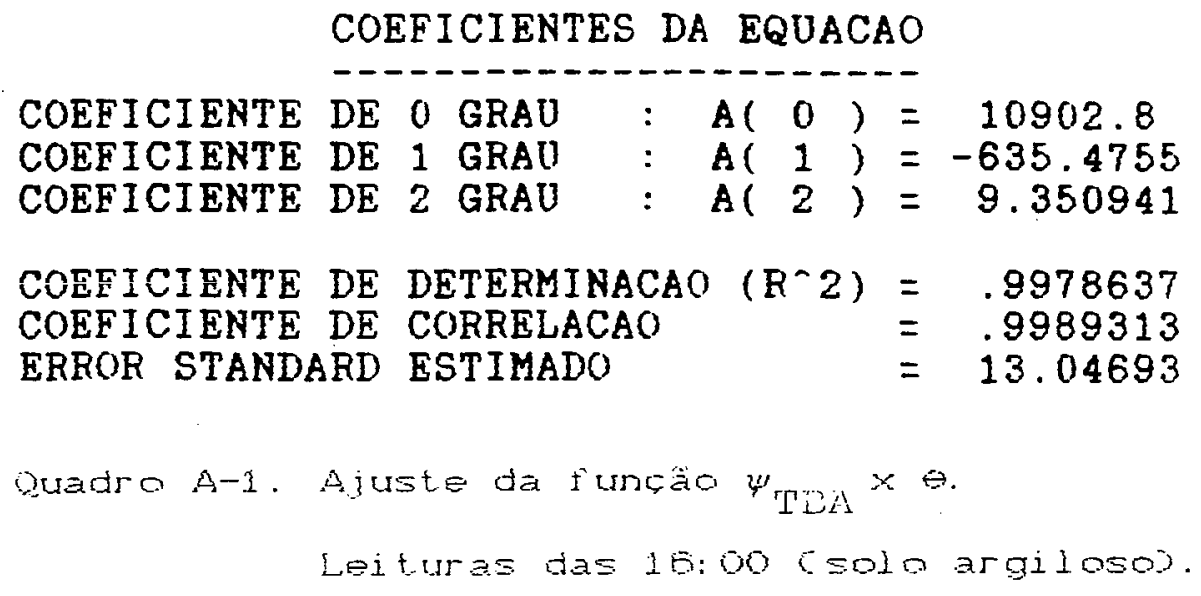

COEFICIENTES DA EQUACAO

COEEICIENTE DE O GRAU: $A(0)=9406.762$

COEFICIENTE DE 1 GRAU: $A(1)=-545.0579$ COEFICIENTE DE 2 GRAU : $A(2)=7.956856$

COEFICIENTE DE DETERMINACAO $\left(R^{\wedge} 2\right)=.9852268$ COEFICIENTE DE CORRELACAO $=.9925859$ ERROR STANDARD ESTIMADO $=34.30587$

Quadro A-Z. Ajuste da funcăo $\psi_{\text {TC }} \times \theta$.

Leituras das 1b:00 (solo argiloso). 
63.

COEFICIENTES DA EQUACAO

\begin{tabular}{|c|c|c|c|c|c|c|}
\hline $\begin{array}{l}\text { COEEICIENTE } \\
\text { COEEICIENTE } \\
\text { COEEICIENTE }\end{array}$ & $\begin{array}{l}\mathrm{DE} \\
\mathrm{DE} \\
\mathrm{DE}\end{array}$ & $\begin{array}{ll}0 & \text { GRAU } \\
1 & \text { GRAU } \\
2 & \text { GRAU }\end{array}$ & $\begin{array}{l}: \\
: \\
:\end{array}$ & 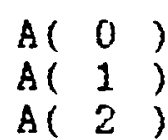 & $\begin{array}{l}= \\
= \\
=\end{array}$ & $\begin{array}{r}8066.329 \\
-457.2322 \\
6.539218\end{array}$ \\
\hline $\begin{array}{l}\text { COEEICIENT } \\
\text { COEEICIENT } \\
\text { ERROR STAN }\end{array}$ & $A B D$ & $\begin{array}{l}\text { CORREL } \\
\text { ESTIMA }\end{array}$ & & $0\left(R^{-} 2\right)$ & $\begin{array}{l}= \\
=\end{array}$ & $\begin{array}{l}.9878068 \\
.9938847 \\
33.75119\end{array}$ \\
\hline
\end{tabular}

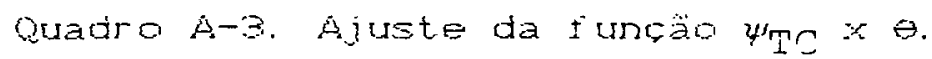

Leituras das 9:00 csolo argiloso.

COEFICIENTES DA EQUACAO

COEFICIENTE DE O GRAU : A( 0$)=11211.27$

COEFICIENTE DE 1 GRAU : A( 1$)=-654.6963$

COEFICIENTE DE 2 GRAU : A( 2$)=9.633385$

COEFICIENTE DE DETERMINACAO $\left(R^{\wedge} 2\right)=.9907757$

COEEICIENTE DE CORRELACAO $=.9953772$

ERROR STANDARD ESTIMADO $=25.64603$

Quadro A-4. Ajuste da funcão $\psi_{\text {TEA }} x \theta$.

Leituras das 9:00 Csoio argilosol. 


\begin{tabular}{lr}
\multicolumn{2}{c}{ Regression Output: } \\
Constant & -24.3574 \\
Std Err of Y Est & 17.88480 \\
R Squared & 0.996039 \\
No. of Observations & 11 \\
Degrees of Ereedom & 9
\end{tabular}

$X$ Coefficient( $\varepsilon$ ) 1.203512

Std Err of Coef. 0.025296

(A)

Std Err of Coef. 0.025286

\section{1}

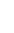

Constant

17.88480

$R$ Squared 


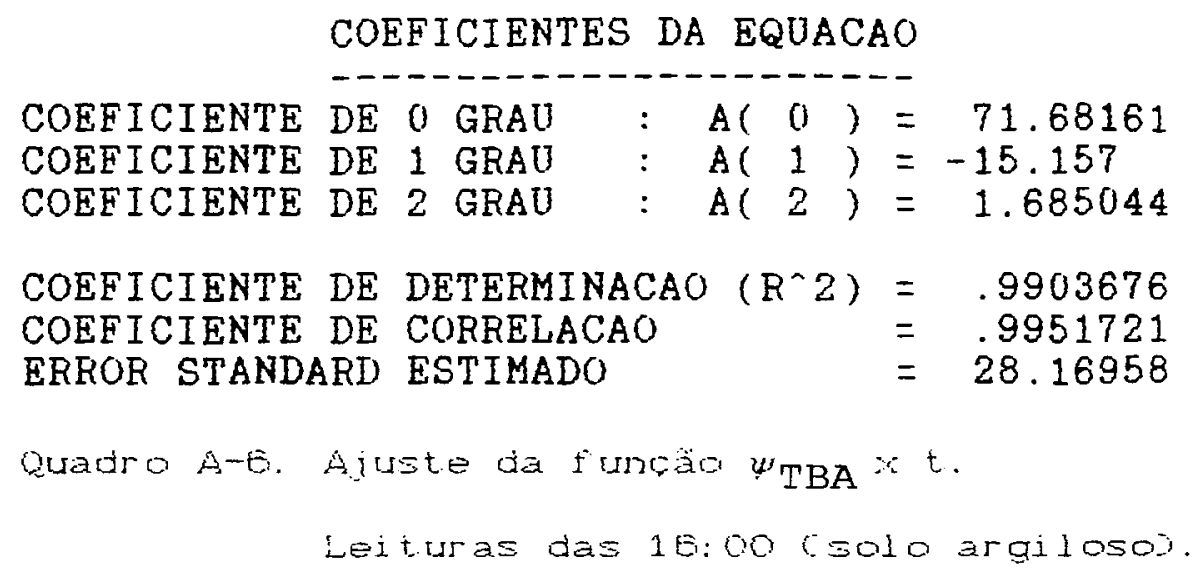

COEFICIENTES DA EQUACAO

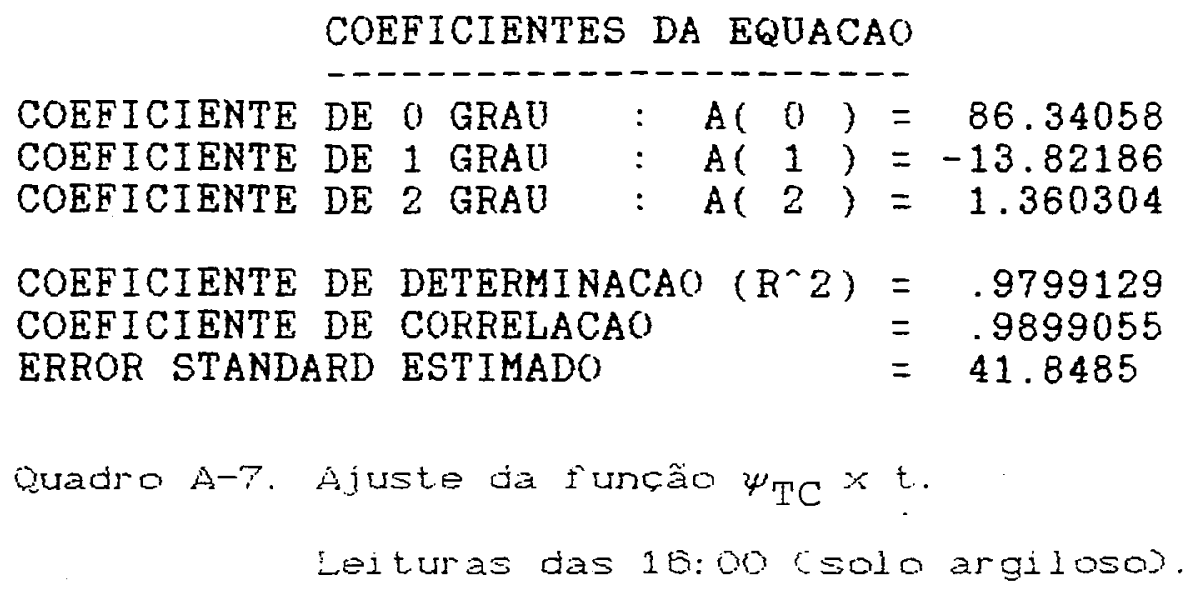


66.

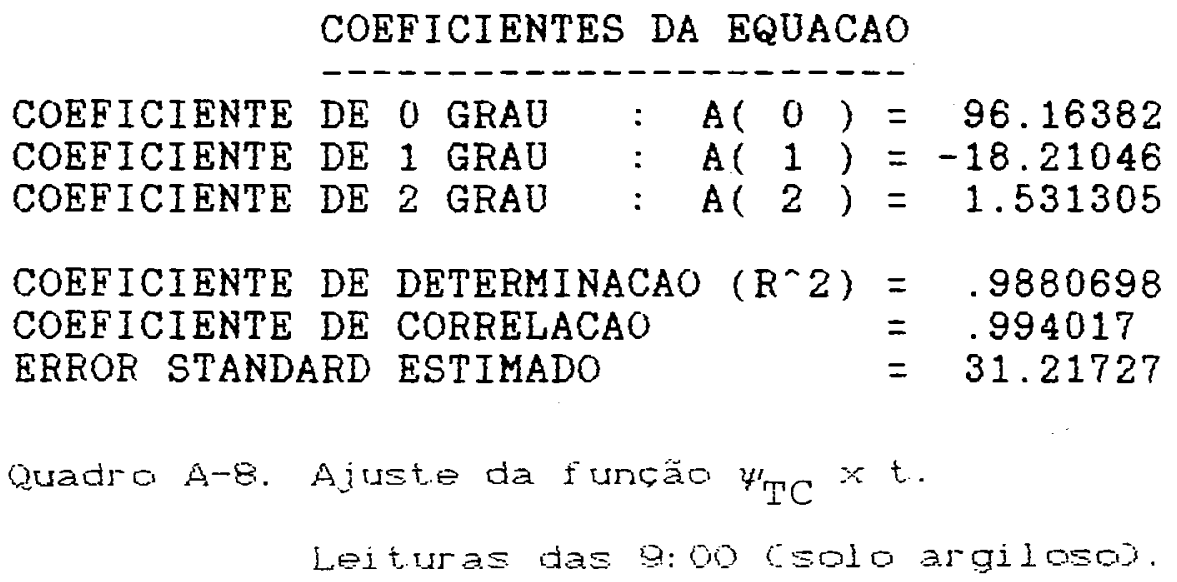

COEFICIENTES DA EQUACAO

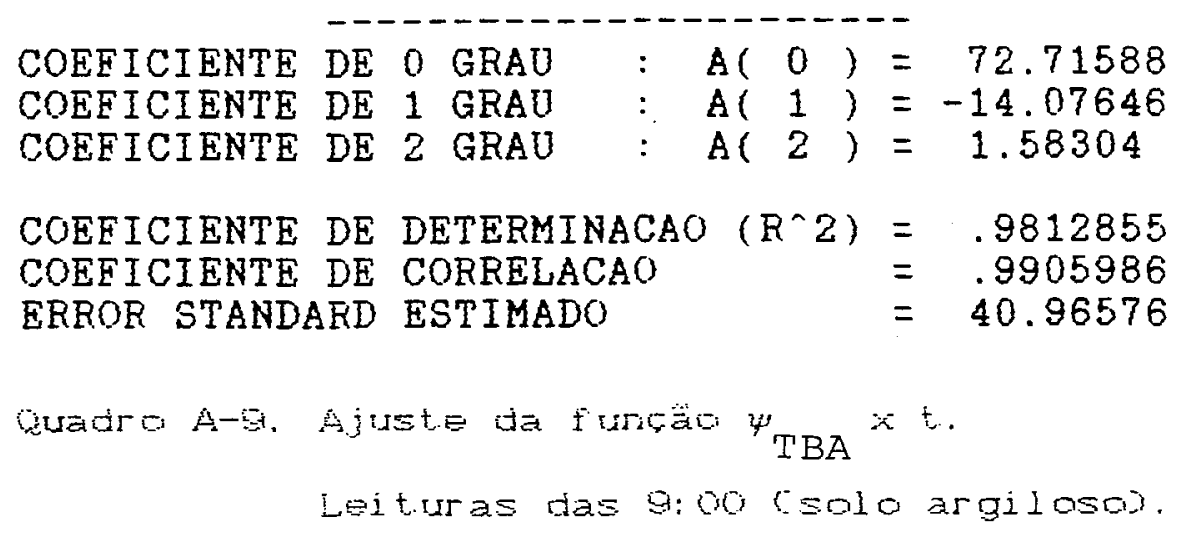


67.

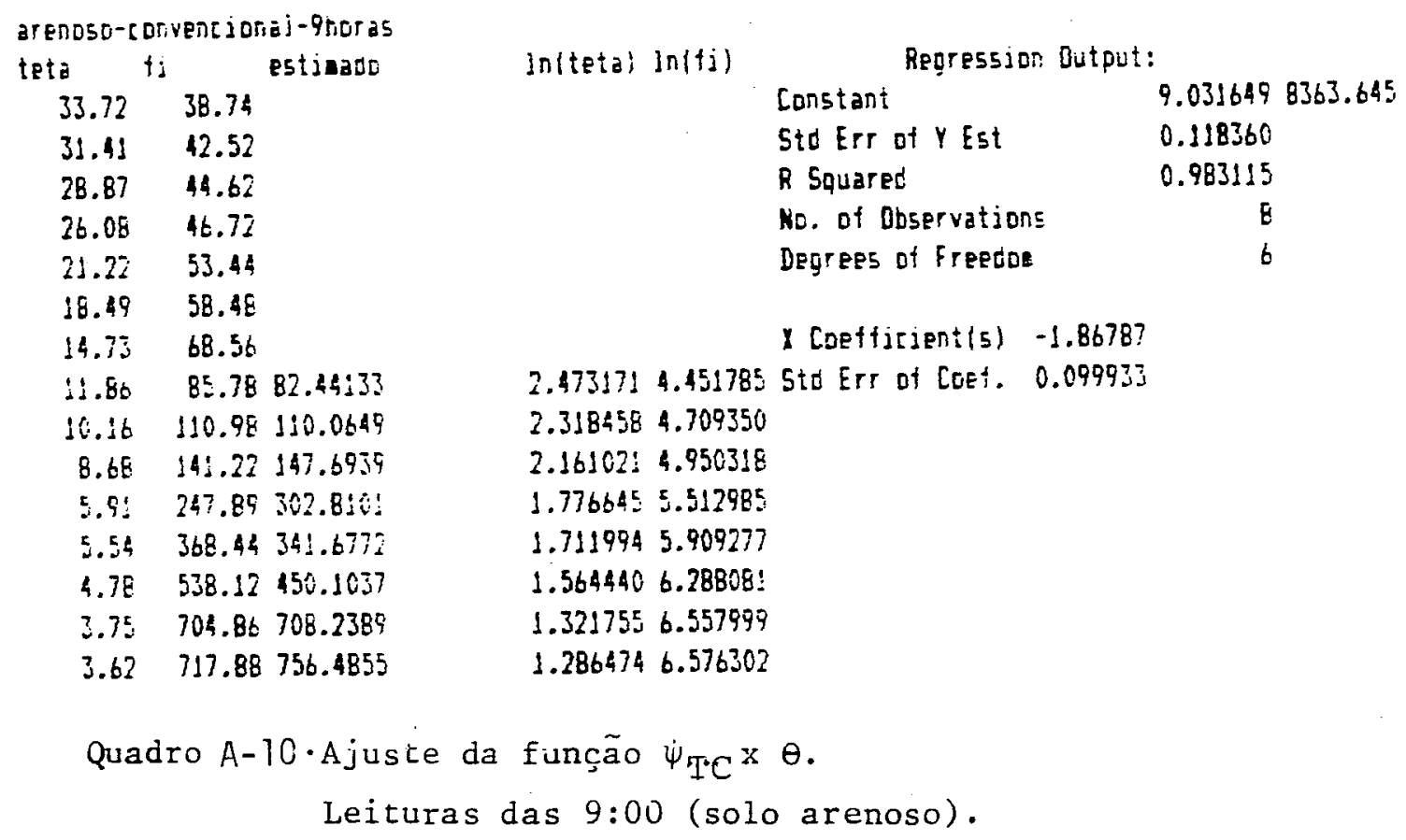

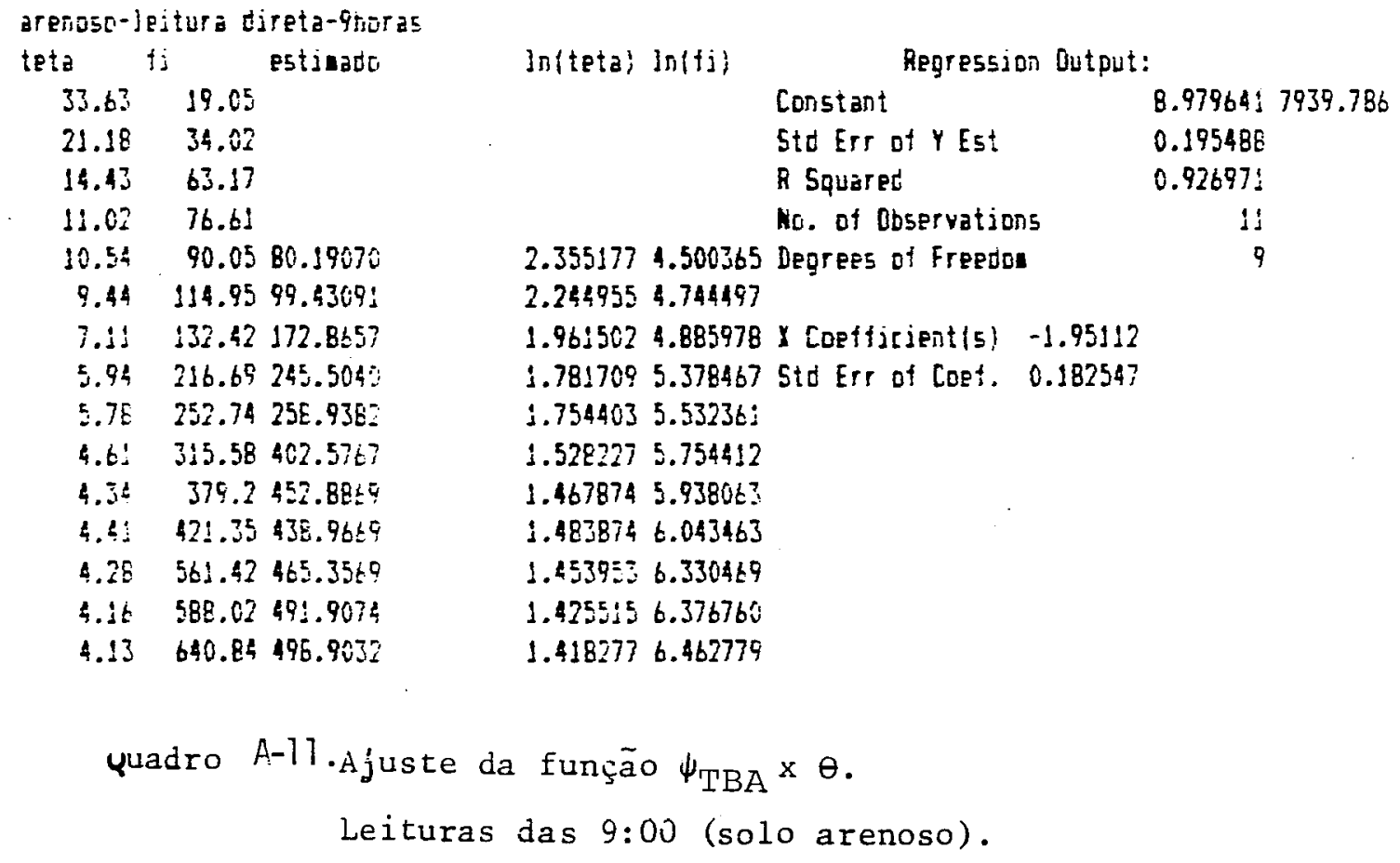


68.

\begin{tabular}{|c|c|c|c|c|}
\hline $\begin{array}{l}\text { IEta } \\
35.14\end{array}$ & ${ }^{3} 36.64^{\text {estieado }}$ & In(teta) $\ln (t j)$ & Regression Dutput: & \\
\hline 31.92 & 40 & & Constant & 9.1765939668 .165 \\
\hline 27.96 & 44.62 & & Std Err of Y Est & 0.131556 \\
\hline 24.77 & $4 i .56$ & & R Squared & 0.975174 \\
\hline 20.54 & 53.86 & & Ho. of 0esprvationis & 9 \\
\hline 16.76 & 59.74 & & Degreas of Freedoz & 7 \\
\hline 13.86 & 78.22 & & & \\
\hline 11.76 & 8278.88612 & 2.4647034 .406719 & $x$ Cuefficierit(s) -1.95098 & \\
\hline 9.81 & $\$ 13.08 \quad 112.3614$ & 2.2834024 .728095 & Std Err of coet. 0.11765b & \\
\hline 5.9 & 234.04302 .9891 & 1.7749525 .455492 & & \\
\hline 5.83 & $301.24310 .227 !$ & 1.7630175 .707907 & & \\
\hline 5.54 & 346.6343 .5872 & 1.7119945 .848171 & & \\
\hline 5.06 & 502.42408 .8465 & 1.6213666 .219436 & & \\
\hline 4.37 & 593.14544 .2236 & 5.4747636 .385430 & & \\
\hline 3.81 & 696.02711 .1658 & 1.3376296 .545407 & & \\
\hline 3.72 & 715.78745 .1196 & 1.3137236 .573372 & & \\
\hline
\end{tabular}

arenoso-jejtura sireta-16 horas

\begin{tabular}{|c|c|c|c|c|}
\hline tetó & fj estjuato & Initeta) $\ln \left(t_{j} j\right)$ & & \\
\hline 31.55 & 34.02 & & Regreessioñ Butput: & \\
\hline 28.95 & 41.71 & & Constant & 8.9694357859 .160 \\
\hline 25.55 & 48.99 & & Std Err of Y Est & 0.108642 \\
\hline $2 \mathrm{2} .1 \mathrm{H}$ & 55.89 & & R Squared & 0.984277 \\
\hline 12.09 & 70.0672 .52726 & 2.4923784 .249352 & No. of Doservations & 8 \\
\hline 10.62 & $102.7492 .5431 \mathrm{j}$ & $2.3627394 .63220:$ & Degrees of Freedat & b \\
\hline $8.6 i$ & $132.72 \quad 135.5112$ & 2.1598684 .888741 & & \\
\hline$\Xi .84$ & 252.74284 .8270 & $1.7647365 .53236:$ & $x$ Coetticient(s) -1.87992 & \\
\hline 5.67 & 300.88301 .0927 & 1.7351895.70671: & Sto Err of Coet. 0.097000 & \\
\hline 4.42 & 416.34480 .8768 & $1.4861396 .03150 ?$ & & \\
\hline 4.28 & 565.95510 .8723 & 1.4539536 .338505 & & \\
\hline 4.19 & 595.19531 .5961 & $1.432700 \quad 6.388880$ & & \\
\hline
\end{tabular}




\begin{tabular}{|c|c|c|}
\hline $\begin{array}{c}\text { Shorar } \\
\\
\text { Salda do }\end{array}$ & & $\begin{array}{r}85.9864 .52442 \\
110.9886 .36391\end{array}$ \\
\hline Coostante & $=9.81647$ & $141.22 \quad 112.5912$ \\
\hline Irro Padrde Is: I & 3.902192 & 217.89205 .0164 \\
\hline I a quacrads: & 0.999735 & 368.14309 .190 \\
\hline Mc. de Observacbee & 25 & $338.12 \quad 456.543$ \\
\hline Graus de liberdadt & 23 & $\begin{array}{l}901.86601 .019 \\
717.88612 .331\end{array}$ \\
\hline
\end{tabular}

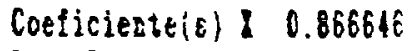

Irro Fadrdo Coefied oc298

$$
\begin{aligned}
& \text { Quadro A.r14. Correlação entre } \psi_{\text {TBA. }}{ }^{\text {e }} \psi_{\text {TC }} \\
& \text { Leituras das 9:00 (solo arenoso). }
\end{aligned}
$$

If horas - 2recoib 2 areldit

Salda da legressato.

\section{Coustant}

Irro Padrso Est?

I ac peadrads

Ro. de Observacdes

Graus de liberdade

Coeficiedte(e) \& 0.89850

Irto Fadrdo cotict.0023\%"
8280.98595

113.08108 .2837

$\begin{array}{ll}8.948955 & 234.01214 .5530 \\ 3.378211 & 301.21273 .588:\end{array}$

$\begin{array}{ll}8.948955 & 234.01214 .5530 \\ 3.378211 & 301.21273 .588:\end{array}$

$0.999810 \quad 346.6313 .4390$

28502.12450 .3218

23593.11530 .0224

698.01620 .1200

915.18637 .1616

$$
\begin{aligned}
& \text { üuadro A-15. Correlação entre } \psi_{\mathrm{TBA}} \text { e } \psi_{\mathrm{TC}} \\
& \text { Leituras das 16:00 (șolo arenoso). }
\end{aligned}
$$

